\title{
Investigating the Evolution and Formation of Coastlines and the Response to Sea-Level Rise
}

\author{
By \\ Alejandra C. Ortiz \\ B.A., Wellesley College, 2010 \\ Submitted in partial fulfillment of the requirements for the degree of \\ Doctor of Philosophy \\ at the

\section{MASSACHUSETTS INSTITUTE OF TECHNOLOGY \\ and the} \\ WOODS HOLE OCEANOGRAPHIC INSTITUTION \\ September 2015 \\ (C) 2015 Alejandra C. Ortiz \\ All rights reserved.
}

The author hereby grants to MIT and WHOI permission to reproduce and to distribute publicly paper and electronic copies of this thesis document in whole or in part in any medium now known or hereafter created.

Signature of Author

Joint Program in Oceanography/Applied Ocean Science and Engineering Massachusetts Institute of Technology and Woods Hole Oceanographic Institution

\section{Certified by}

August 20, 2015

Andrew D. Ashton

Associate Scientist Geology \& Geophysics

Accepted by

Thesis Supervisor

Tim Grove
Chair, Joint Committee for Marine Geology \& Geophysics
Massachusetts Institute of Technology
Woods Hole Oceanographic Institution


Investigating the Evolution and Formation of Coastlines and the Response to Sea-Level Rise

by

\title{
Alejandra C. Ortiz
}

Submitted to the Department of Civil and Environmental Engineering on August 20, 2015 in partial fulfillment of the requirements for the degree of Doctor of Philosophy in Marine Geology and Geophysics at the Massachusetts Institute of Technology and the Woods Hole Oceanographic Institution.

\begin{abstract}
To understand how waves and sea level shape sandy shoreline profiles, I use existing energetics-based equations of cross-shore sediment flux to describe shoreface evolution and equilibrium profiles, utilizing linear Airy wave theory instead of shallow-water wave assumptions. By calculating a depth-dependent characteristic diffusivity timescale, I develop a morphodynamic depth of shoreface closure for a given time envelope, with depth increasing as temporal scale increases. To assess which wave events are most important in shaping the shoreface in terms of occurrence and severity, I calculate the characteristic effective wave conditions for both cross-shore and alongshore shoreline evolution. Extreme events are formative in the cross-shore shoreface evolution, while alongshore shoreline evolution scales linearly with the mean wave climate. Bimodal distributions of weighted wave heights are indicative of a site impacted more frequently by tropical storms rather than extra-tropical storms.

To understand how offshore wave climate and underlying geometry of a carbonate reef platform shapes evolution of atolls, I simulate the hydrodynamics of a simplified reef flat, using XBeach, a two-dimensional model of infragravity wave propagation. The reef flat self-organizes to a specific width and water depth depending on the offshore wave climate and characteristics of the available sediment. Formation of a sub-aerial landmass, like a motu, can be initiated by a change in offshore wave climate (like a storm), which can create a nucleation site from mobilization and deposition of coarse sediment on the reef flat. Once a motu is present, the shoreline should prograde until reaching a critical reef-flat width. Our conceptual model of reefflat evolution and motu formation is governed by understanding the hydrodynamics of the system and subsequent response of sediment transport.
\end{abstract}

Thesis Supervisor: Andrew D. Ashton

Title: Associate Scientist Geology \& Geophysics 


\section{Acknowledgements}

Foremost, I want to thank my advisor Andrew Ashton for his advice and mentorship over the last five years. This thesis would not have been possible without Andrew's generous help and support. I want to thank Heidi Nepf for her help and advice from my first class at MIT to setting up a mock interview. I have been incredibly lucky to be a part of the Coastal Systems Group and work with so many wonderful people, particularly Stephanie Madsen, Richard Sullivan, Toomey, Jaap, and Jorge.

I would like to thank my friends and family. These last five years would not have been possible without the loving support of my wife, parents, and friends. In particular, I want to thank Lynn, Natasha, Helen, Elizabeth, Mara, Laura, Anna, and Melissa for all of their encouragement, help, and support. I would not be where I am today without the continued and unstinting encouragement, advice, and mentorship of Britt Argow and Zoe Hughes.

I also would like to thank my committee, Andrew Ashton, Jeff Donnelly, Rob Evans, Heidi Nepf, and Sergio Fagherazzi for their suggestions and guidance through my projects and research.

This research was supported by funding from Ocean Ventures Fellowship, Coastal Studies Institute, Geological Society of America Research Grant, DOD Strategic Environmental Research and Development Program Grant \#RC-1701 and \#RC-2336, National Science Foundation grant \#CNH-0815875. 


\section{Chapter 1 - Introduction}

Climate change has many diverse and severe impacts on our planet, including accelerated rates of sea-level rise. Over the past twentieth century, eustatic sea level rose around $1.5-2.0$ mm/yr (IPCC, 2013; Cazenave et al., 2014; Hay et al., 2015), and predicted rates of eustatic sealevel could far exceed $5 \mathrm{~mm} / \mathrm{yr}$ in by the end of coming century (IPCC, 2013; Horton et al., 2014; Kopp et al., 2014). Understanding the response of coastal systems to increased rates of sea-level rise is important; $10 \%$ of the world's population lives in the Low Elevation Coastal Zone (IPCC, 2014; Wong et al., 2014). My research has focused on understanding the processes that shape different coastal systems and how these systems evolve. I am interested in the response of coastal sandy and carbonate sedimentary systems to changes in sea level and predicting how future climate might impact coastal evolution.

Geomorphology is the study of landscape evolution through time: by understanding the processes that shape the landscape, it is possible to predict how a landscape may respond to changing forces. Changes in sediment flux can be a primary driver of coastal evolution, and understanding the movement of sediment in and out of a system is key to understanding how the coast evolves. As waves can be the primary driver of coastal sediment transport, my research has focused on investigating how waves transport sediment and how the long-term deposition and erosion of sediment shapes the coast. In particular, I have focused on two different coastal systems: sandy, wave-dominated coasts like the East and Gulf Coasts of the US and carbonate reef platforms like the atolls of French Polynesia and the Marshall Islands.

Main Objectives: To develop and apply theoretical and numerical models of the evolution of different coastal systems to address the following questions:

1. Which processes are the main drivers of sediment transport in these two varied systems?

2. If waves are the primary driver of sediment transport fluxes, can we understand the longterm effect of these fluxes?

3. How do these fluxes affect the geomorphic evolution of sandy, wave-dominated coasts and carbonate reef flats?

4. What are the timescales over which these processes operate in sandy, wave-dominated coasts?

5. How do these processes vary in the different coast systems? 
Chapter 2: Exploring shoreface dynamics and a mechanistic explanation for the morphodynamic depth of closure

Much controversy surrounds understanding how wave-driven sediment transport affects shoreface evolution in on sandy coasts. In Chapter 2, I develop a robust methodology for estimating the morphodynamic evolution of a cross-shore sandy coastal profile. The methodology is based on combining linear Airy wave theory and an energetics-based formulation of wave-driven sediment transport. I present a formulation that defines a dynamic equilibrium profile founded on three components of wave influence driving sediment onshore and offshore. A depth-dependent characteristic timescale of diffusion helps characterize a morphodynamic depth of closure for a given time envelope. In this chapter, I apply the methodology to six sites around the US coastline. Computed equilibrium profiles and depths of closure for these sites demonstrate reasonable similarities except where geologic control is strong.

Chapter 3: Understanding timescales of morphologic evolution for the cross-shore and alongshore for sandy, wave-dominated coasts

Debate exists about whether the background wave climate or extreme events most shape the coast. To address this question, I utilized magnitude and frequency analysis to investigate which wave parameters are most influential in shaping the coastline in both the alongshore and cross-shore direction. Using 43 different sites from around the US coastline in 3 different ocean basins, I find that the cross-shore is shaped primarily by extreme events like hurricanes or nor'easters. On the other hand, the alongshore evolution of the coast is controlled by the background wave climate that scales linearly with the mean wave climate. Thus I find that both the background waves and large but infrequent extreme events are important in shaping the coastline.

Chapter 4: Exploring carbonate reef flat hydrodynamics and formation mechanisms of sub-aerial land

Why are some atolls covered with motu, sub-aerial landmasses, on top of the carbonate reef-flat platform while other parts of the same atoll or other atolls may have very little sub-aerial 
landmasses? To understand this question, I use the model XBeach to investigate the hydrodynamics and response of varying geometry of carbonate reef-flats to the presence of subaerial landmasses. Existing theories for understanding how sub-aerial land forms on a reef flat rely on wave convergence zones or falling sea level. To understand other possible mechanisms for motu formation, I use XBeach to numerically model a simplified carbonate reef-flat. By varying the phase space such as the underlying geometry of the reef-flat or the offshore wave climate, I find that for given dominant sediment size and type, there is an equilibrium depth to the reef-flat. Moreover, over some distance landward over the reef flat, the potential for deposition of sediment increases towards the middle of the flat. Thus the mid-flat could operate as a nucleation site for increased sediment deposition leading to the formation of a sub-aerial landmass. Whether or not extreme events are required to create these motu is dependent on the sediment available in the system for land building. The larger or denser the sediment in the system, the more energetic the wave climate must be to mobilize the sediment. For certain reefflats, I predict that motu could form without the presence of extreme events. I also find that when a motu is present on the reef-flat, a positive feedback can result in shoreline progradation until a critical width is attained where negative feedbacks inhibit the continued growth of the motu. In essence, there is an equilibrium distance from the edge of the reef-flat the motu will grow based on the hydrodynamics. This is true for a range of external wave climate. Our conceptual model of reef-flat evolution and motu formation is governed by understanding the hydrodynamics of the system and subsequent response of sediment transport.

Chapter 5: Conclusions and Future Work

I discuss the final conclusions from my various projects and investigate future research paths and questions.

\section{References}

Cazenave, A., Dieng, H.-B., Meyssignac, B., von Schuckmann, K., Decharme, B., and Berthier, E., 2014, The rate of sea-level rise: Nature Climate Change, v. 4, no. 5, p. 358-361.

Hay, C.C., Morrow, E., Kopp, R.E., and Mitrovica, J.X., 2015, Probabilistic reanalysis of twentieth-century sea-level rise: Nature, v. 517, no. 7535, p. 481-484. 
Horton, B.P., Rahmstorf, S., Engelhart, S.E., and Kemp, A.C., 2014, Expert assessment of sealevel rise by AD 2100 and AD 2300: Quaternary Science Reviews, v. 84, p. 1-6, doi: 10.1016/j.quascirev.2013.11.002.

IPCC, 2014, Climate Change 2014: Impacts, Adaptation, and Vulnerability. Part A: Global and Sectoral Aspects. Contribution of Working Group II to the Fifth Assessment Report of the Intergovernmental Panel on Climate Change [Field, C.B., V.R. Barros, D.J. Dokken, K.J.: Cambridge University Press, Cambridge, United Kingdom and New York, NY, USA.

IPCC, 2013, IPCC, 2013: Summary for Policymakers. In: Climate Change 2013: The Physical Science Basis. Contribution of Working Group I to the Fifth Assessment Report of the Intergovernmental Panel on Climate Change: Cambridge University Press.

Kopp, R.E., Horton, R.M., Little, C.M., Mitrovica, J.X., Oppenheimer, M., Rasmussen, D.J., Strauss, B.H., and Tebaldi, C., 2014, Probabilistic 21st and 22nd century sea-level projections at a global network of tide-gauge sites: Earth's Future, v. 2, no. 8, p. 383-406, doi: 10.1002/2014EF000239.

Wong, P.P., Losada, I.J., Gattuso, J.-P., Hinkel, J., Khattabi, A., McInnes, K.L., Saito, Y., and Sallenger, A., 2014, Coastal systems and low-lying areas, in Field, C.B., Barros, V.R., Dokken, D.J., Mach, K.J., Mastrandrea, M.D., Bilir, T.E., Chatterjee, M., Ebi, K.L., Estrada, Y.O., Genova, R.C., Girma, B., Kissel, E.S., Levy, A.N., MacCracken, S., et al. eds., Climate Change 2014: Impacts, Adaptation, and Vulnerability. Part A: Global and Sectoral Aspects. Contribution of Working Group II to the Fifth Assessment Report of the Intergovernmental Panel of Climate Change, Cambridge University Press, Cambridge, United Kingdom and New York, NY, USA, p. 361-409. 


\title{
Chapter 2: Exploring Shoreface Dynamics and a Mechanistic Explanation for a Morphodynamic Depth of Closure
}

\begin{abstract}
Using energetics-based formulations for wave-driven sediment transport, we develop a robust methodology for estimating the morphodynamic evolution of a crossshore sandy coastal profile. Using an energetics approach, wave-driven cross-shore sediment flux depends on three components: two onshore-directed terms (wave asymmetry and wave streaming) and an offshore-directed slope term. In contrast with previous work, which applies shallow water-wave assumptions across the transitional zone of the lower shoreface, we use linear Airy wave theory. The cross-shore sediment transport formulation defines a dynamic equilibrium profile and, by perturbing about this steady-state profile, we present an advection-diffusion formula for profile evolution. Morphodynamic Péclet analysis suggests that the shoreface is diffusionally dominated. Using this depth-dependent characteristic diffusivity timescale, we distinguish a morphodynamic depth of closure for a given time envelope. Even though wave-driven sediment transport can (and will) occur at deeper depths, the rate of morphologic bed changes in response to shoreline change becomes increasingly slow below this morphodynamic closure depth. Linear wave theory suggests a shallower shoreface depth and much sharper break in processes across depth than shallow-water wave assumptions. Analyzing hindcasted wave data using a weighted frequency-magnitude approach, we determine representative wave heights and periods for selected sites along the US coastline. Computed equilibrium profiles and depths of closure demonstrate reasonable similarities, except where inheritance is strong. The methodology espoused in this paper can be used to better understand the morphodynamics at the lower shoreface transition with relative ease across a variety of sites and with varied sediment transport equations.
\end{abstract}




\section{Introduction}

The wave-affected shoreface represents a transitional zone between the shoreline and the continental shelf. The dynamics of the shoreface and the definition of the lower "shoreface toe" or "wave base" are relevant across a wide range of coastal sciences, spanning sedimentology, coastal geology, and coastal engineering. Delineation and estimation of the lower shoreface transition is typically explicit in many models of coastal evolution, from the simple Bruun rule (Bruun, 1962) to barrier island translation models (Cowell et al., 1995; Stolper et al., 2005; Moore et al., 2010; Lorenzo-Trueba and Ashton, 2014) and even in engineering estimations of beach nourishment design volumes (Dean, 2002). The mechanisms, rates, and depths of wave-driven sediment exchange are important across many coastal settings, including sandy coasts (Bruun, 1988; Ranasinghe et al., 2012), barrier islands (Moore et al., 2010; Lorenzo-Trueba and Ashton, 2014), waveinfluenced deltas (Swenson et al., 2005; Ashton and Giosan, 2011), and even cliffed coasts fronted by sandy beaches (Dickson et al., 2009; Limber et al., 2014; Bray and Hooke, 1997; Ashton et al., 2011).

With sea-level-rise rates becoming faster than they have been over the past several millennia (Vermeer and Rahmstorf, 2009), the dynamics of the shorefaces of wavedominated coasts needs to be better understood to enable predictions of future coastal evolution. Just as important as understanding the potential for on- or offshore sediment transport between the upper and lower shoreface (Aagaard, 2014) is an understanding of how changes in the upper shoreface are morphologically communicated offshore. The myriad processes that can change coastlines, from overwash (Donnelly et al., 2006; Sherwood et al., 2014) to alongshore sediment transport gradients (Ashton and Murray, 2006a) or even human activities such as beach nourishment (Jin et al., 2013), motivate a better understanding of how the shoreface behaves as a morphologic unit. The focus of this study is the development of a formulation for the long-term morphodynamic evolution of a sandy wave-dominated shoreface. Our goal is to present methodologies that can better explain and quantify long-term shoreface evolution, emphasizing the dynamics of the lower shoreface rather than the surf zone and upper shoreface, which have characteristic response times much more rapid than sea-level rise rates. 


\section{Background}

\subsection{Depth of Closure, Wave Base, and the Shoreface Toe}

The wave-dominated inner shelf has long been the subject of scientific investigation (Komar, 1991; Wright et al., 1991), and it has long been understood that shoreface slopes develop as a balance between onshore and offshore sediment transport processes (Fenneman, 1902). In this paper, we use the term shoreface to describe several subdivisions of the shoreface including the surf zone, upper shoreface, lower shoreface, inner shelf, and midshelf. The upper shoreface includes the region where the effects of wave energy dissipation dominates while the lower shoreface is dominated by bed interactions from shoaling waves (Stive and de Vriend, 1995). Perhaps one of the most debated subjects in coastal science is the concept of the depth of shoreface closure. Regardless of the specific definition, there is a general agreement that there exists an offshore transition whereby wave influence on bed stresses, and therefore sediment transport, becomes significantly smaller than within the surf zone or upper shoreface.

Sedimentologists and stratigraphers define the "wave base" as the depth to which waves interact with the bed (Nichols, 1999). This transition can be seen in sedimentary sequences, often accompanied by changes in sediment characteristics and preserved bedforms - the location of this transition may be called the shoreface toe (Dean and Maurmeyer, 1983). Swift (1985) defined the shoreface toe as a geometric slope break, reflecting an implied change in geologic processes. Observations of sediment texture along nourished beaches suggest an offshore limit to vigorous on- and offshore sediment exchange but one that is deeper than typically predicted by depth of closure arguments (Thieler et al., 1995). Sedimentological approaches also often distinguish the fair-weather wave base as the depth at which the background wave climate interacts with the bed. This transition is associated with a change in sedimentary structures and bedforms from wave ripples and dunes to hummocky cross-stratification (Dott, R. H. and Bourgeois, 1982; Duke, 1985; McCave, 1985). Likewise, the depth at which mean storm waves interact with the bed defines the storm wave base, and is also associated with a change in bed sedimentology and bedforms from hummocky cross-stratification to mostly muddy or silty sediments (Sageman, 1996). Often the end of upper shoreface and transition to the lower shoreface is defined as the depth of the fair weather wave base, while the transition between the lower 
shoreface and offshore is defined as the storm wave base (Nichols, 1999; Dean and Dalrymple, 1991). However, recently Peters and Loss (2012) suggested that, based upon wave height distributions, modern open ocean wave distributions may not clearly distinguish between fair-weather and storm conditions, questioning the fair versus storm wave distinction often applied to sedimentary records.

In engineering practice, the "depth of closure," or "closeout depth," (Birkemeier, $1985)$ is often used to define a short-term (1-10 year) limit of annual/interseasonal bed change. Hallermeier (1978) computed the depth of closure as the "maximum water depth for intense bed agitation," which he defines as the wave conditions that are exceeded 12 hours each year. Often closure depth is also inferred as the seaward limit of measurable shoreface depth change (Hallermeier, 1978; Birkemeier, 1985; Nicholls et al., 1996). Wright et al. (1991), however, argued that a measurable depth of closure should be on the order of magnitude of the rate of bed accumulation equal to local relative sea-level-rise rates-for most coasts this would require measurements with sub-cm accuracy to capture rates of $\mathrm{mm} / \mathrm{yr}$ (Kemp et al., 2011).

Closure depths computed following the approaches of Hallermeier (1978) and Birkemeier (1985) typically range from 5-10 m. These computed depths of closure are shallower than those inferred from geological evidence of the shoreface transition and active wave reworking and may only apply for annual to decadal scales (Thieler et al., 1995; Wallace et al., 2010). As discussed by Stive et al. (1991), the relevant depth of closure should increase with an increase in timescale considered. Additionally, the shoreface toe may not represent a true 'sediment fence', as some studies suggest long-term onshore transport across the shoreface toe (Aagaard, 2014; Stive and de Vriend, 1995).

\subsection{Shoreface Response to Sea-level Rise}

The Bruun Rule (Bruun, 1962), which quantifies and visualizes shoreline translation assuming geometric rules, offers perhaps the most straightforward conceptualization of shoreface response to sea-level rise. If a concave offshore profile retains its shape and there is a shoreface toe, the entire shoreface profile is assumed to respond as sea level rises and, due to mass conservation, the shoreline is expected to retreat along the shoreface slope. 
This relationship has been used extensively by both researchers and managers of beaches (Bruun, 1983; Bruun, 1988; Ranasinghe et al., 2012; Larson et al., 1995).

There remain criticisms on the applicability of the Bruun Rule, in some cases, through questioning of the underlying assumptions, for instance the assumption of a depth of closure or sediment fence (Pilkey et al., 2009; Cooper and Pilkey, 2004). For specific applications, alongshore sediment transport gradients can locally dominate shoreline change rates such that local application of the Bruun rule may be inappropriate, (e.g. List et al., (1997)), although Zhang et al. (2004) suggested the Bruun rule may be applicable away from inlets and other shoreline irregularities. Modifications of the Bruun rule to other settings such as barrier islands (Dean and Maurmeyer, 1983; Larson et al., 1995) suggest that the long-term trajectory of shoreline retreat follows the backshore slope (Wolinsky, 2009; Wolinsky and Murray, 2009), regardless of the shoreface slope. Such modified Bruun rule approaches have also been implemented in numerical models of coastal translation; these models presume a constant-shape shoreface (or relaxation about such a shape) and a fixed shoreface toe (Cowell et al., 2006b; Stolper et al., 2005; Moore et al., 2010).

\subsection{Dynamic Shoreface Evolution}

The Bruun rule presumes a steady shape shoreface slope; others have used dynamic approaches to better understand shoreface dynamics and a potential origin for a dynamic equilibrium. Dean (1991) proposed that the shoreface attains a shape whereby the rate of wave energy dissipation becomes constant, with increasing shoreface slope for coarser sediment. Similarly, Jenkins and Inman (2005) applied thermodynamic principals to calculate an equilibrium profile by treating the shoreface as an "isothermal shorezone system of constant volume that dissipates wave energy." Leont'yev (2012) similarly used a dissipation argument where accretion and erosion are balanced by wave energy flux gradients.

Other approaches examine shoreface equilibrium through a balance of sediment transport relationships. Several models apply the energetics-based sediment transport formulations developed by Bagnold (1963) and adapted by Bowen (1980) and Bailard and Inman (1981). Stive and de Vriend (1995) applied these energetics equations and shallowwater wave assumptions in a multi-panel model of lower shoreface evolution, and suggest 
that only on geological timescales (on the order of 1000 years or more) is the bottom slope effect on sediment transport important. Similarly, Swenson et al. (2005) used shallowwater wave assumptions and a breaking-wave closure model to investigate the basic controls on subaqueous delta progradation. Although their approach uses energetics formulations (as we do below), in this model river-supplied sediment is transported offshore by both a slope term and a presumed downwelling current with no onshoredirected fluxes. A possible concern with these previous methods is their reliance of shallow-water wave assumptions rather than linear Airy wave theory as the inner shoreface to the midshelf spans intermediate water depths. .

Dynamic shoreface evolution has also been studied using other sediment transport relationships such as using an empirical equations (Patterson, 2012). Recent work by Aagaard and Sorenson (2012), computing cross-shore sediment transport based on wave

orbital skewness and Longuet-Higgins' streaming velocity for the onshore components and undertow as the offshore component, argued for mainly onshore sediment transport during sea-level rise. This would appear to be in contrast with the Bruun Rule, which predicts a mass transport of sediment offshore with rising sea level with a translation of the shore landward.

\subsection{Outline}

Here we investigate shoreface dynamics through explorations of sediment transport relationships with the following goals:

1. Use relationships that can lead to a long-term steady-state shoreface shape.

2. Investigate the importance of linear versus shallow-water waves on estimates of shoreface dynamics

3. Quantify the order of magnitude of potential morphologic bed change as a function of depth.

From this last point, although long-term cross-shore sediment input/export to the shoreface is important for developing long-term sediment budgets (Cowell et al., 2006b; Cowell et al., 2006a), we specifically choose to pursue a definition of a morphodynamic depth of closure to describe a depth beyond which the bed shape changes slowly in response to external forcings, with a particular emphasis on changes to the shoreline. 
The paper is organized as follows: we present a theoretical approach to our formulation of shoreface evolution, including a comparison of shallow-water versus linear Airy wave values. These equations lead to a steady state or dynamic equilibrium shoreface profile, and, combined with the conservation of mass, lead to a formulation for shoreface evolution that takes the general form of an advection-diffusion equation describing bed evolution. Given dynamic equilibrium shoreface geometry, computation of a morphodynamic Péclet number allows us to determine the characteristic timescales of bed evolution as a function of depth, thus yielding a morphodynamic depth of shoreface closure. Finally, we compare our theoretical approach to sites estimating characteristic wave values for each site. We then discuss our findings, in particular we posit that the shoreface transition may not necessarily arise from a threshold in sediment transport, but rather because the timescales of morphologic evolution become excessively large compared to exogenous drivers, such as sea-level rise.

\section{Theory}

In this section, we present a theoretical approach to investigate long-term shoreface evolution using an energetics-based sediment transport formulation following the approach of Bowen (1980). First, we do not attempt to predict accurately sediment flux in the surf zone, which is characterized by the domination of non-linear interactions where linear Airy wave theory and Stokes wave theory break down very quickly and breaking waves and associated currents (such as the undertow) are present (Fredsoe and Deigaard, 1992; Madsen, 1991). Furthermore, we ignore bedload sediment transport because suspended sediment comprises the bulk of the sediment load transported at deeper depths (Swenson et al., 2005; Stive and de Vriend, 1995; Bailard and Inman, 1981), an assumption that we will justify at the end of this section. Offshore fining of sediment increases the importance of suspended load transport as the finer the sediment the more is transported as suspended load vs. bedload, all other things being held equal. Thus, we expect suspended load to dominate at deeper depths. 


\subsection{General Equation}

Derived from Bagnold's model (1963), Bowen (1980) developed a theoretical model for wave-driven sediment transport, balancing onshore-directed flows attributable to wave asymmetry and streaming with offshore-directed slope terms. We adopt Bowen's (1980) formulation for cross-shore width-averaged suspended sediment transport flux, $q_{s},\left(\mathrm{~m}^{2} / \mathrm{s}\right)$ :

$$
q_{s}(\mathrm{z})=\mathrm{K} \frac{u_{o}^{3}}{w_{s}}\left[-5 u_{1}-3 u_{2}+\frac{\beta(x)}{w_{s}} u_{o}^{2}\right]
$$

with the coefficient $K\left(\mathrm{~s}^{2} / \mathrm{m}\right)$ :

$$
\mathrm{K}=\frac{16 e_{s} C_{s} \rho}{15 \pi\left(\rho_{s}-\rho\right) g}
$$

where $e_{s}$ is the suspended sediment transport efficiency factor (0.01), $C_{s}$ is a bed friction factor (0.01), $\rho$ is the seawater density $\left(1.04 \mathrm{~g} / \mathrm{cm}^{3}\right), \rho_{s}$ is the sediment density (assumed to be quartz, $\left.2.65 \mathrm{~g} / \mathrm{cm}^{3}\right), g$ is acceleration by gravity $\left(9.81 \mathrm{~m} / \mathrm{s}^{2}\right), \beta$ is the local bed slope, and $w_{s}$ is the sediment fall velocity $(\mathrm{m} / \mathrm{s})$. Positive values are directed onshore and negative values are directed offshore. Finally, the wave velocity components are defined by $u_{i}(\mathrm{i}=0$, 1 , or 2) which represent the wave orbital velocity, Longuet-Higgins' streaming velocity, and wave asymmetry, respectively, as discussed below.

Note that equations are numbered systematically. The letter $a$ represents formulations for wave variables derived from linear Airy wave theory and $b$ represents formulations for wave parameters variables from shallow water wave assumptions. Bailard and Inman (1981) inserted an additional efficiency term $\left(\mathrm{e}_{s}\right)$ into the slope component (in addition to the constant K), which neither Stive and de Vriend (1995) nor we use due to the lack of a strong argument for its inclusion and deviation from the original derivation by Bagnold (1963). We also choose not to nondimensionalize our formulations (as done by Swenson et al. (2005)), which allows us to investigate them in terms of common characteristics (i.e. wave height spanning 1-5m and wave period spanning 6-14s). Fall 
velocity is the relevant dynamic property that varies with grain size (for the non-cohesive sand sized sediment), thus all references to grain size refer to variations in $w_{s}$.

\subsection{Components of $q_{s}$}

Here we describe the components of the sediment transport equation (1), utilizing Stokes $2^{\text {nd }}$ order approximations of the wave contributions to sediment transport. In previous energetics approaches, both Stive and de Vriend (1995) and Swenson et al. (2005) used shallow water wave assumptions to calculate wave velocity components, with Swenson et al. (2005) closing their equations using empirical breaking-wave relationships. In contrast, we calculate wave velocity components using linear theory (while offering a comparison to shallow-water-wave computations). Although linear theory and shallow water wave assumptions converge in shallow depths approaching the surf zone, the active shoreface spans the intermediate depths where neither shallow- nor deep-water wave assumptions are accurate. Note that basic equations for wave characteristics (wave height, wavelength, wave period) can be found in the Supporting Information.

\subsubsection{Wave Orbital Velocity: $u_{0}$}

The wave orbital velocity, $u_{o}$, here the maximum bed velocity of the wave motion, represents a "stirring" term, which determines sediment concentration that can be advected by the other currents $\left(u_{1}\right.$ and $\left.u_{2}\right)$ or moved downslope. The wave orbital velocity, $u_{o}(\mathrm{~m} / \mathrm{s})$, is:

$$
u_{0}(z)=\frac{\pi \mathrm{H}}{\mathrm{T} \sinh (\mathrm{kz})}
$$

for linear theory, and:

$$
u_{o}(z)=\frac{\operatorname{Hg}^{\frac{1}{2}}}{2 z^{\frac{1}{2}}}
$$


for shallow-water wave assumptions, where $H$ is the local wave height (m), $T$ is the wave period (s), $k$ is the wave number $\left(\mathrm{m}^{-1}\right)$, and $z$ is the local water depth $(\mathrm{m})$.

\subsubsection{Streaming Velocity: $u_{1}$}

The Longuet-Higgins' streaming velocity, $u_{1}$, is the mean drift approximation at the top of the boundary layer (Longuet-Higgins, 1957; Fredsoe and Deigaard, 1992). Using linear wave theory, the streaming velocity, $u_{1}(\mathrm{~m} / \mathrm{s})$, can be estimated as:

$$
u_{1}(z)=\frac{3 \pi^{2} \mathrm{H}^{2}}{4 \mathrm{TL} \sinh ^{2}(\mathrm{kz})},
$$

and, using shallow water wave assumptions:

$$
u_{1}(z)=\frac{3 H^{2} g^{\frac{1}{2}}}{16 z^{\frac{3}{2}}}
$$

where $L$ is the wavelength (m) (Longuet-Higgins, 1957).

Other non-wave-driven processes such as upwelling or downwelling (as investigated by Swenson et al. (2005)) could also be represented in the $u_{1}$ term. However, as our focus is on wave-driven transport across the shoreface, and in keeping with previous approaches, we include wave streaming as one of our onshore-directed terms.

\subsubsection{Wave Asymmetry: $u_{2}$}

Wave shoaling skews wave velocities, which can be estimated as:

$$
u_{2}(z)=\frac{3 \pi^{2} \mathrm{H}^{2}}{4 \mathrm{TLsinh}{ }^{4}(\mathrm{kz})}
$$

for linear theory and: 


$$
u_{2}(z)=\frac{3 H^{2} g^{\frac{3}{2}} T^{2}}{64 \pi^{2} z^{\frac{5}{2}}}
$$

using shallow water wave assumptions (Fredsoe and Deigaard, 1992; Holthuijsen, 2007). The ratio of $u_{1}$ to $u_{2}$ is $5 / 3 \sinh ^{2}(k z)$ and for typical values of wave height and wave period, sediment transport associated with the $u_{1}$ and $u_{2}$ terms tends to be of the same order of magnitude. As depth increases, wave streaming is greater than wave asymmetry and decreasing wave period increases the magnitude of wave streaming compared to wave asymmetry at depths greater than $5 \mathrm{~m}$.

\subsubsection{Sediment Transport}

Both the wave asymmetry and wave streaming terms direct sediment onshore, while the slope term directs sediment offshore, or downslope. Substituting the above definitions for the different order wave velocities, sediment transport for linear theory becomes:

$$
q_{s}(\mathrm{z})=\mathrm{K} \frac{\pi^{3} \mathrm{H}^{3}}{\mathrm{~T}^{3} \mathrm{Lsinh}^{3}(\mathrm{kz})}\left[-\frac{15 \pi^{2} \mathrm{H}^{2}}{4 \mathrm{TLsinh}{ }^{2}(\mathrm{kz})}-\frac{9 \pi^{2} \mathrm{H}^{2}}{4 \mathrm{TL} \sinh ^{4}(\mathrm{kz})}+\frac{\pi^{2} \mathrm{H}^{2} \beta(x)}{w_{s} \mathrm{~T}^{2} \sinh ^{2}(\mathrm{kz})}\right]
$$

and:

$$
q_{s}(\mathrm{z})=\mathrm{K} \frac{\mathrm{g}^{\frac{3}{2}} \mathrm{H}^{3}}{8 w_{s} \mathrm{z}^{\frac{3}{2}}}\left[-\frac{15 \mathrm{H}^{2} \mathrm{~g}^{\frac{1}{2}}}{16 \mathrm{z}^{\frac{3}{2}}}-\frac{9 \mathrm{H}^{2} \mathrm{~g}^{\frac{3}{2}} T^{2}}{64 \pi^{2} \mathrm{z}^{\frac{5}{2}}}+\frac{\mathrm{H}^{2} g \beta(x)}{4 w_{s} \mathrm{z}}\right]
$$

using shallow-water wave assumptions.

Sample computations show that increasing the initial deep-water wave height and wave period increases the magnitude of cross-shore sediment transport, $q_{s}$ (Figure 1). Importantly, comparing the shallow water and linear theory wave assumptions, the computed values of $q_{s}$ diverge increasingly with depth (Figure 1). At 50 meters (for $10 \mathrm{~s}$ waves), the calculated cross-shore sediment transport using the shallow water 
assumptions is more than an order of magnitude larger than predicted by the full linear wave theory. Even at $20 \mathrm{~m}$ depth, the shallow-water wave assumptions predict a crossshore sediment transport $\sim 3$ times less. The negative values of $q_{s}$ indicate onshore-directed sediment transport when the slope term is ignored.

\subsection{Equilibrium Profile}

Following the approach of Bowen (1980), we use the formulation for shoreface sediment transport to derive a steady-state, dynamic equilibrium profile by balancing the onshore-directed terms (streaming and asymmetry) with the offshore-directed slope term. For a long-term zero-flux condition, i.e. $q_{s}=0$, it is then possible to solve for an equilibrium slope and equilibrium profile such that:

$$
\beta_{0}(z)=\frac{w_{s}}{u_{0}^{2}}\left[5 u_{1}+3 u_{2}\right]
$$

Equilibrium slopes can be computed for linear wave theory:

$$
\beta_{0}(z)=\frac{3 w_{s} T}{4 L}\left[5+\frac{3}{\sinh ^{2}(\mathrm{kz})}\right]
$$

and shallow-water wave assumptions:

$$
\beta_{0}(z)=\frac{3 w_{s}}{4 z^{\frac{1}{2}} g^{\frac{1}{2}}}\left[5+\frac{3 g T^{2}}{4 \pi^{2} z}\right]
$$

Note that, in both cases, the dynamic equilibrium slope has no dependence on wave height and instead only depends on the wavelength, wave period, and sediment fall velocity.

Equations (7a) and (7b) are not conducive to analytical integration; however, equilibrium profiles can be numerically integrated from the shoreline. Using the first-order Eulerian integration starting from the shoreline, computed equilibrium profiles for typical wave conditions show little difference in shoreface shape for shallow-water wave 
assumptions and linear theory (Figure 2). Spanning fall velocities ranging from 0.008 to $0.16 \mathrm{~m} / \mathrm{s}$, corresponding to grain size ranging from very fine to coarse sand $(0.01-1 \mathrm{~mm})$, the strongest control on the profile slope is the grain size, sediment fall velocity (Fredsoe and Deigaard, 1992).

Below, we will make more explicit comparisons between measured and computed equilibrium profiles. However, the profile dimensions predicted by this approach (equation 7) generally match those of natural shorefaces. Bailard's (1981) formulation for suspended sediment transport multiplies the slope term again by the efficiency term, $\mathrm{e}_{\mathrm{s}}$. Inclusion of this additional efficiency parameter would predict equilibrium shoreface profiles over an order of magnitude ( 40 times) flatter. For this same reason, Stive and de Vriend (1995) argue against the inclusion of this term; accordingly, we also do not use the extra efficiency factor introduced by Bailard (1981), instead we follow Bagnold's (1963) original derivation.

\subsection{Exner Equation}

A shoreface bed evolution formulation can be derived by combing equation (1) with the conservation of sediment mass through the application of the Exner equation relating bed evolution to the divergence of sediment flux, similar to Swenson et al. (2005). Combining equation (1) for cross-shore sediment flux with the Exner equation:

$$
\frac{\partial \mathrm{z}}{\partial \mathrm{t}}=\frac{1}{\varepsilon_{\mathrm{o}}} \frac{\partial \mathrm{q}_{\mathrm{s}}}{\partial \mathrm{x}}
$$

where $\varepsilon_{o}$ is one minus the porosity and using the chain rule:

$$
\frac{\partial \mathrm{q}_{\mathrm{s}}}{\partial \mathrm{x}}=\frac{\partial q}{\partial \mathrm{z}} \cdot \frac{\partial \mathrm{z}}{\partial \mathrm{x}}
$$

yields: 


$$
\frac{\partial z}{\partial t}=\mathrm{K} \frac{u_{o}^{2}}{\varepsilon_{0} w_{s}}\left[\left(-5 u_{1}^{\prime} u_{0}-15 u_{o}^{\prime} u_{1}-3 u_{2}^{\prime} u_{0}-9 u_{0}^{\prime} u_{2}+\frac{5 \beta_{0}}{w_{s}} u_{0}^{\prime} u_{0}^{2}\right) \frac{\partial z}{\partial x}+\left(\frac{u_{0}^{3}}{w_{s}}\right) \frac{\partial^{2} z}{\partial x^{2}}\right]
$$

The single prime above the wave velocity components represents the derivative relative to $z$ (the values of these derivatives can be found in the Supporting Information).

The general form of equation (10) is an advection-diffusion equation of the form:

$$
\frac{\partial z}{\partial t}=\left[(V) \frac{\partial z}{\partial x}+(D) \frac{\partial^{2} z}{\partial x^{2}}\right]
$$

The advection term, $V(\mathrm{~m} / \mathrm{s})$, represents the kinematic celerity for bed evolution $(\mathrm{m} / \mathrm{s})$ :

$$
V(z)=\mathrm{K} \frac{u_{o}^{2}}{\varepsilon_{0} w_{s}} V_{c}
$$

with the advection coefficient, $V_{c},\left(\mathrm{~m} / \mathrm{s}^{2}\right)$ :

$$
V_{c}(z)=-5 u_{1}^{\prime} u_{0}-15 u_{o}^{\prime} u_{1}-3 u_{2}^{\prime} u_{0}-9 u_{0}^{\prime} u_{2}+\frac{5 \beta_{0}}{w_{s}} u_{0}^{\prime} u_{0}^{2}
$$

The diffusivity $\left(\mathrm{m}^{2} / \mathrm{s}\right)$ is:

$$
D(z)=\mathrm{K} \frac{u_{o}^{2}}{\varepsilon_{\mathrm{o}} w_{s}} D_{c}
$$

with the diffusivity coefficient, $D_{c},\left(\mathrm{~m}^{2} / \mathrm{s}^{2}\right)$ :

$$
D_{c}(z)=\frac{u_{o}^{3}}{w_{s}}
$$

Using linear wave theory, the diffusivity equals: 


$$
D(z)=K \frac{\pi^{5} H^{5}}{\varepsilon_{\mathrm{o}} w_{s}^{2} T^{5} \sinh ^{5}(k z)} .
$$

\subsection{Morphodynamic Péclet Number}

Advection-diffusion equations can be characterized using the non-dimensional Péclet number, commonly applied to fluid flows, which quantifies the relative influence of advection versus diffusion in transport phenomena for a given system. Estimation of morphodynamic Péclet numbers has seen recent interest in terrestrial geomorphology (Perron et al., 2008; Pritchard et al., 2009; Pelletier and Perron, 2012). We adapt the concept of a morphodynamic Péclet number to describe coastal profile evolution.

The Péclet number is defined as:

$$
P e=\frac{V l}{D}
$$

where $P e>1$ characterizes an advection-dominated system and $P e<1$ characterizes a diffusion-dominated system. Dominance in this case refers to the faster process that controls system evolution. To compute a Péclet number for our problem, we require a characteristic length scale $(I)$, and we choose the steady-state profile distance to the coast, $x_{e q}$. We select this distance as it scales how the bed may respond to a change of the shoreline. Using the kinematic celerity, $V$ (equation 12), and the diffusivity, $D$ (equation 14), the morphodynamic, depth-dependent Péclet number (equation 16) for an equilibrium shoreface then becomes:

$$
P e(z)=\frac{V_{c} x_{e q} w_{s}}{u_{0}^{3}}
$$

Both the shallow water and linear theory computations of the Péclet number predict a diffusively dominated system (Figure 3). As the morphodynamic Péclet number is a ratio of the advection coefficient ( $V_{c}$, equation 13 ) and the stirring term, $u_{0}$, we see that this 
advection coefficient reduces more rapidly with depth than the stirring term thus decreasing the Péclet number at deeper depths.

Numerically computed morphodynamic Péclet numbers show only a dependence on wave period and not wave height or settling velocity. While there may be an expected dependence on grain size, the equilibrium cross-shore distance, $x_{e q}$, integrates the equilibrium slope, $\beta_{0}$ (equation 7), which has in inverse dependence on grain size, $w_{s}{ }^{-1}$. Therefore the computed morphodynamic Péclet number is unaffected by grain size. On the other hand, increasing the wave period increases the importance of the wave asymmetry in the advection term.

\subsection{Characteristic Timescales of Shoreface Evolution}

By demonstrating that slope-based diffusivity dominates profile evolution, the morphodynamic Péclet analysis allows us to calculate a depth-dependent characteristic timescale of shoreface evolution. Dimensionally, this timescale can be defined as:

$$
T_{\text {diff }}=\frac{l^{2}}{D}
$$

where $l$ is a characteristic length scale (again taken to be the distance to the steadystate shoreline, $x_{e q}$ ) and $D$ is the diffusivity (equation 14). The morphodynamic Péclet analysis is essentially a ratio of the characteristic timescales of advections versus diffusion, with the faster process setting the timescale needed for the system to trend towards a near steady state.

The diffusional timescale for shoreface evolution then becomes:

$$
T_{\text {diff }}(z)=\frac{x_{e q}^{2} w_{s}^{2}}{K \varepsilon_{0} u_{0}^{5}}
$$

Substituting in the terms from linear theory yields: 


$$
T_{\text {diff }}(z)=\frac{x_{e q}^{2} w_{s}^{2} \mathrm{~T}^{5} \sinh ^{5}(k z)}{\mathrm{K} \varepsilon_{0} \pi^{5} \mathrm{H}^{5}}
$$

Although these equations also appear to have a strong dependence on grain size, this dependence again becomes negligible as $x_{e q}$ has an inverse dependence on $w_{s}$ (equation 7) - the top two terms cancel out. Accordingly, the depth-dependent characteristic diffusive timescale varies primarily with deep-water wave height and wave period (Figure 4) and, at equilibrium configurations, perhaps surprisingly, does not depend on grain size.

For typical values of deep-water wave height and wave period, shoreface response timescales become significantly large (>1,000 years) at depths between 10 and 30 meters, suggesting a type of morphodynamic "depth of closure" (MDOC). In other words, profile evolution and, in particular, sediment transport may continue beyond this depth, but evolution of the shoreface shape in response to the shoreline becomes geologically slow and the bed shape response to environmental changes becomes virtually non-existent.

Note that shallow-water wave assumptions predict far more active shorefaces than those predicted by linear waves, particularly for larger wave heights (Figure $4 \mathrm{~b}$ and $4 \mathrm{~d}$ ), suggesting a deeper morphodynamic depth of closure than linear wave theory. Furthermore, linear Airy wave theory predicts a more tightly constrained shoreface transition than shallow-water wave theory-a strongly defined effective "wave base" across only a few meters of depth change. As such, linear wave theory suggests only a few meters difference in depth of the MDOC for the 100 and 1,000 year timescales, which suggests that, geologically, there a rather tightly constrained MDOC.

The computed morphodynamic depth of closure increases with increasing wave height and increasing wave period (Figure 5). Increasing wave height increases orbital velocities and increasing wave period deepens bed interaction (as expected from previous equations). Sediment grain size should not affect the response time or closure depth, only the equilibrium shoreface shape itself. In general, increasing response time by an order of magnitude (from 10 to 100 years) tends to increase the closure depth predicted by linear Airy wave theory by approximately $5 \mathrm{~m}$. 


\subsection{Discussion of the Theoretical Approach}

Here we discuss some of the assumptions and implications of the theoretical model of shoreface evolution. First we address the assumption that bedload transport dominates on the shoreface and then discuss the influence of offshore decreases in grain size. We then discuss the mechanistic response of an equilibrium shoreface to sea-level rise.

\subsubsection{Bedload Transport}

Our analysis assumes that suspended sediment transport dominates transport on the middle and lower shoreface, an assumption that need to be justified as bedload transport occurs throughout the shoreface (Kleinhans, 2002). Bowen (1980) and Stive and de Vriend (1995) demonstrate that the ratio between suspended sediment load and bedload transport for energetics approaches can be approximated as $\sim 1 / 15 u_{0} / w_{s}$. For values of this ratio greater than unity, suspended sediment transport dominates bedload sediment transport. This suspended versus bedload transport ratio varies with grain size (sediment fall velocity), such that the smaller the grain size, the more likely it is carried in suspension.

For small wave heights (e.g. $H_{0}=1 \mathrm{~m}$ ), bedload does indeed tend to dominate transport across the shoreface. However, as we present in the next section and also demonstrated by Stive and de Vriend (1995), effective wave heights for shoreface evolution tend to be much larger due to the weighting of sediment transport by $\mathrm{H}_{0}{ }^{5}$. Sample computations for a characteristic morphologic wave height $\left(H_{0}=5 \mathrm{~m}\right)$ and wave period $(T$ $=10 \mathrm{~s}$ ) similar to those computed for our representative coastal locations, show that suspended sediment transport dominates over shallow depths $(<10 \mathrm{~m})$ for coarse sand and over the entire shoreface for finer-grained sediment (Figure 6). During morphologically important conditions, the entire shelf is mobilized as suspended sediment. Given the general trend of fining of sediments with increasing offshore distance (Zenkovitch, 1946), suspended sediment transport should be the most effective long-term process across the entire shoreface in contrast to previous assumptions (Kleinhans, 2002). 


\subsubsection{Offshore Fining}

In general, the computed equilibrium profiles and analysis above assume a constant sediment size across the profile. Again, this is typically not the case for natural shorefaces where sediment tends to fine moving offshore. However, offshore fining is not incongruous with our approach for the following two reasons. First, our approach defines an equilibrium slope as a function of depth (equation 7). If shorefaces fine with depth, this would suggest "compound" shoreface slopes with local slopes defined by the local sediment characteristics (with local sediment distributions affected by both transport processes and, more importantly, local sediment availability). Second, as we discuss above, grain size effects cancel out when computing characteristic timescales, such that grain size only affects profile shape and profile diffusivity.

\subsubsection{Sea-level Rise Response of Equilibrium Profiles}

The analysis provided here potentially reconciles several apparent paradoxes regarding shoreface response to sea-level rise. For our formulation, if sea level rises instantaneously, both the onshore- and offshore-directed terms will be reduced. However, the reduction in the onshore terms is greater than the reduction in the offshore term-the shoreface is over-steepened and sediment would consequently be transferred offshore in the manner suggested by the Bruun Rule (Figure 7). Note that the magnitude of wave asymmetry $\left(u_{2}\right)$ is decreased more than wave streaming $\left(u_{1}\right)$ for driving sediment onshore with the instantaneous increase of sea level (Figure 7b).

On the other hand, if sediment is removed from the shoreface, perhaps by onshoredirected fluxes such as overwash (Ashton and Ortiz, 2011; Lorenzo-Trueba and Ashton, 2014) or aeolian processes (Davidson-Arnott, 2005), this will result in an overall flattening of the profile, reducing the offshore-directed slope-driven sediment transport, resulting in net onshore sediment transport. Likewise, aggradation of sediment in the upper shoreface, perhaps due to positive alongshore sediment transport gradients, would oversteepen the shoreface profile, leading to offshore transport within the active morphological shoreface. Short-term changes of the profile merely redistribute the mass across the profile, rather than changing the total shoreface volume. 
Our approach can also provide insight into the findings from other process-based investigations of shoreface evolution. Recently, Aagaard and Sorenson (2012), used a model of shoreface sediment transport including two onshore-directed terms based upon streaming and asymmetry (skewness), similar to those used in our analysis ( $\mathrm{u}_{1}$ and $\mathrm{u}_{2}$, respectively). Applying their model to a synthetic Dean-type profile, they concluded that sea-level rise should drive sediment flux onshore. However, close inspection of their results ((Aagaard et al., 2012) in Figures 6 and 7) suggests that their synthetic profile is not in equilibrium with an unperturbed sea level. Similar to our results, their model also suggests that a raised sea level reduces the onshore component of sediment transport offshore of the surf zone (Figure 7). If a dynamic equilibrium existed for Aagaard and Sorenson's (2012) synthetic shoreface shape, a reduction in onshore sediment transport should result in offshore-directed flux. Therefore, their model results appear to be congruent with our results and the concepts underlying the Bruun Rule which suggest that sea-level rise, by reducing onshore transport, oversteepens shoreface profiles, driving a net seaward flux; their interpretation of onshore-directed flux appears to conflict with their results.

As we state above, Swenson et al. (2005) (and also Hutton et al. (2008)) applied a similar energetics model to clinoform development, using only offshore-directed terms: a slope-based term and a downwelling velocity. As their model contains no onshore-directed components of flux, true dynamic profile equilibrium cannot exist in their model. Although this application may be appropriate for actively prograding deltas, this model cannot develop an equilibrium profile, a necessary requirement for coastal features, such as barrier islands, to survive on a passive coast.

\section{Application}

Although the formulations above use a single set of wave characteristics (height and period), at any given location these driving forces are constantly changing- fluctuating between calm and storm conditions. For a given location and associated wave climate, what are the characteristic wave conditions affecting profile evolution? Are they the wave heights and periods that occur most frequently (the mean wave climate), or are they storm waves (the extreme events)? Should conditions be selected based upon a set return interval or in some way weighted by sediment transport processes? We approach this problem by 
utilizing the classic geomorphic approach of Wolman and Miller (1960), which weights an event's frequency by the amount of potential morphologic change. Adopting this frequencymagnitude approach (Brunsden and Thornes, 1979; Sullivan and Lucas, 2007; Wolman and Gerson, 1978; Wolman and Miller, 1960) to address shoreface evolution, we weight wave conditions based upon the capacity for sediment transport (instead of wave energy density, i.e. $\mathrm{H}^{2}$, alone as used by Jimenez and Sanchez-Arcilla (2004) and Peters and Loss (2012)). We apply our theoretical formulation of shoreface evolution to six sites by calculating average profiles for each location and comparing these to estimated equilibrium profiles while also predicting a characteristic diffusive timescale across each profile.

\subsection{Analysis Sites and Data}

We select six sites along the US coast that span a range of oceanographic and geologic conditions to compare with our model: Eel River, CA, Martha's Vineyard, MA, Fire Island, NY, Santa Rosa Island, FL, Duck Pier, NC, Onslow Bay, NC (Figure 8). We chose sites from both active margin (Eel River, CA) and passive margins (Martha's Vineyard, MA, Fire Island, NY, Duck Pier, NC, and Onslow Bay, NC). In addition, we choose sites from different ocean basins (Atlantic Ocean, Pacific Ocean, and the Gulf of Mexico) to explore a variety of wave climates.

For each site, we use the Wave Information Studies (WIS) array of virtual buoys representing a dataset of long-term (20 year) hindcasted wave data (Jensen, 2010) every 3 hours from 1980-1999 (Figure 8). Additionally, we compute an average profile for each coast by averaging cross-shore profiles from GeoMapApp ${ }^{\text {TM }}$ bathymetric data (Haxby, 2012) and the NASA Aster-USGS basemap (METI and NASA, 2011), where offshore distance was calculated relative to the location of zero elevation. The profiles are binned along the crossshore distance to create a smooth profile; binned profiles are then averaged to create a mean profile.

\subsubsection{Wave Data Analysis}

For each site, virtual WIS buoy data are analyzed and weighted to calculate a representative wave height and wave period. The virtual WIS buoy locations are typically deeper than $20 \mathrm{~m}$, but to ensure consistency among all the sites, waves from the WIS buoys 
are back-shoaled to deep water $\left(z / L_{0}>0.5\right)$ values. Computed deep-water values are within $10 \%$ of the non-back-shoaled values.

For both linear Airy wave theory (equation 6a) and shallow-water assumptions (equation $6 b$ ), the cross-shore sediment flux is weighted by wave height to the fifth power $\left(q_{s} \propto H^{5}\right)$ (equation 1). Similarly, the magnitude of the diffusivity term (equation 14 ), describing bed evolution, is also dependent on wave height to the fifth power. The potential contributions to sediment transport for given wave conditions should be weighted accordingly (Figure 9); the means of these weighted distributions therefore represent the morphodynamically average wave conditions. The representative wave period is calculated based on the mean wave period associated with the calculated representative wave height.

Using these wave height and period calculations, we are able to estimate the characteristic morphodynamic wave conditions for each site (Figure 9). Weighting wave influence by potential contributions to cross-shore sediment transport $\left(q_{s} \propto H^{5}\right)$ emphasizes the importance of extreme wave events, the tail of the distribution (Figure 9). Thus, using the unweighted, or mean wave conditions as representative of the sediment transport mechanisms would systematically underestimate the characteristic morphodynamic wave conditions. This strong influence of large wave events on shoreface evolution also suggests that the omission of threshold sediment entrainment in our formulations does not have a morphological significance.

\subsection{Profile Comparisons}

Using the morphodynamically representative wave characteristics (wave period and wave height), we can compute estimated morphodynamic depths of closure for measured profiles (Figure 10) by calculating the timescale of diffusion (Figure 11). Our first comparison is for the Eel River, CA, which has been previously studied by Friedrichs and Wright (2004) to test their model of wave-suspended cross-shelf gravity flows. While their model performs well in predicting the convexity of the deeper shelf from 40-130 m, the fit and trend do not match for shallower depths where the shoreface becomes concave (Figure 3 (Friedrichs and Wright, 2004)). Predicted equilibrium slopes and morphodynamic closure depths from our model provide a better match to slopes and trends across inner to mid-shelf depths (5-40 m) (Figure 12). As our model nears predicted shoreface closure 
depths, concavity dovetails into the convex slopes predicted by their model, suggesting a transition in process across depth. Our model bridges the gap between their model and shallower depths (Figure 12).

Comparisons of predicted closure depths for passive margins present more of a mixed bag (Figure 11). In some cases, the calculated morphodynamic depth of closure at 100 or 1,000 years visually coincides with the offshore break in slope from the steeper shoreface to the shelf. In other cases, the fit is not strong, and the Onslow Bay, NC, site stands out as a poor fit. For Onslow Bay, this likely demonstrates a strong geologic control of the shoreface morphology; such control has been suggested previously by field work at nearby Wrightsville Beach, NC (Thieler et al., 1995; Thieler et al., 2001).

As a further comparison, we compute theoretical steady-state slopes (equation 7) using the representative wave height and wave period at each site for different grain sizes (from coarse to very fine-grained sand) and corresponding depths of closure (Figure 11). Computed equilibrium slopes for weighted wave conditions reasonably match the measured slopes above the computed closure depths. Slopes at shallow depths $(<5 \mathrm{~m})$ are in poor agreement. This is expected as surf-zone processes are expected to dominate at these depths (also the bathymetric data is less accurate close to shore) and our model is not intended to be used in the surf zone.

At all sites, the general trend is a flattening of the shoreface slope with increasing depth with the exception of the active margin location, the mouth of the Eel River, where the slope eventually begins to steepens with depth as discussed above. A reduction in slope for the smoothed profiles typically is apparent around 20-25 $\mathrm{m}$ depth (Figure 11). This depth tends to correspond with the predicted morphodynamic depth of closure from 100year or 1000-year timescales of diffusivity (within 5 meters). Even within the active shoreface region, the predicted equilibrium slopes tend to be steeper than smoothed actual slopes for all sites except the Eel River, CA (Figure 11). Actual profiles also decrease in slope faster than profiles computed for single grain sizes; offshore sediment fining typical of most shoreface could be responsible for this rapid slope decrease. Martha's Vineyard, MA, and Fire Island, NY, which share similar wave climates and geologic settings, also have similar profile shapes and are among the better matches to our model predictions. 
We then compare our approach to traditional methods for computing closure depth using the Hallermeier (1978) and Birkemeier (1985) equations. Utilizing the WIS virtual buoys for each site, we calculate the closure depth using these methods for each year of data using the 12-hour exceedence. Averaging these values at each site, we interpret these as 1-year closure depths. We also estimate a 20 year closure depth from the 12 hour exceedence from the entire data series (all 20 years). These computed closure depths are all shallower than the morphodynamic closure depths estimated using our method (which are continuous functions of time interval) (Figure 13) (Nicholls et al., 1996; Hallermeier, 1978; Nicholls et al., 1998). However, the disagreement between the methods interpreting the Hallermeier and Birkemeier methods as 1-year closure depths is not as large as would be presumed if comparing our 100- or 1,000-year closure depths to the engineering methods (Stive et al., 1991). This comparison emphasizes that closure predicted for shortterm engineering projects should be shallower than those applicable for decadal to geologic coastal change.

\subsection{Discussion of Application}

Each site we analyzed had multiple profiles that, across 10's of km of coastline, share similar slopes, particularly over the first $20 \mathrm{~m}$ and often extending to $40 \mathrm{~m}$ or more (Figure 10). This local similarity of shoreface geometry, both in elevation and slope suggests some form of active process control or underlying relict processes. At greater depths, transition to a flatter shelf slope is visually apparent at all of the passive coasts; the gross morphology at these depths is likely little affected by shoreline processes, and is perhaps influenced by geologic constraints and sea-level-rise history. Most shelf features are below our calculated morphodynamic depth of closure and morphologic evolution of the bed by processes included in our model would be geologically slow, even if wave-driven sediment transport occurs. Other processes, such as geostrophic flows (Niedoroda and Swift, 1991) or wavesupported gravity flows (Friedrichs and Wright, 2004) characteristic of active margins such as the Eel River, could control morphologic evolution.

Calculated values of representative wave heights range significantly across the different sites, and even sites with similar mean wave climates can have different effective wave heights depending on the influence of storm waves. In all cases, the calculated 
morphodynamic depths of closure are deeper then those computed using engineering formulae of Hallermeier (1978) or Birkemeier (1985) (Figure 13). However, the visual coincidence of computed closure depth with the offshore break in slope suggests that the active shoreface is deeper than often considered by engineering practice.

\section{Summary and Conclusions}

We investigated an energetics-based formula for wave-driven cross-shore sediment flux and shoreface evolution using both shallow wave assumptions (as has been done previously) and linear Airy wave theory (a new approach). Although similar equilibrium profiles are computed when using linear or shallow water wave assumptions, estimations of sediment flux with increasing depth diverge significantly. At a depth of only 20 meters, there is approximately a factor of two difference in the estimation of sediment flux between shallow water and linear wave theory. Both methods, using linear Airy wave theory or shallow water wave assumptions, predict diffusive profile evolution through morphodynamic Péclet number analysis. We estimate a morphodynamic depth of closure, beyond which evolution of the shoreface is geologically slow. Although grain size affects the equilibrium slope, the computed morphodynamic depths of closure depend only on wave height and wave period; there is no dependence on grain size.

Our general approach is to understand the order of magnitude of wave-driven sediment transport processes to characterize the potential envelope of the time and depth dependence of shoreface evolution. Our method provides a novel means to estimate a depth of closure. In our definition, the depth of closure does not depend on cessation of sediment transport, but rather attempts to quantify a depth beyond which the evolution of the shoreface in response to the shoreline becomes geologically slow.

The calculation of a characteristic morphodynamic wave values from a large dataset of hourly hindcasted wave heights (from WIS virtual buoys) also represents a useful tool for both regulators and scientists-it enables the parameterization of data for model inputs looking at the shoreface response to sea-level rise. The magnitude-frequency analysis highlights the importance of large, infrequent wave conditions on shoreface profile evolution. The comparison of our formulation and approach to sites highlights that, overall, there is reasonable agreement between our calculations of equilibrium profiles, actual 
profiles, and our calculated morphodynamic depth of closure, with improved fits for active coasts, suggesting that inheritance may play a significant role in the shape of shorefaces on passive margin shelves.

Following previous examples, we used an energetics approach here, but there are other approaches to compute sediment transport, for example those based on bed shear stress (Madsen, 1991). Although the energetics formulations for sediment transport do not encompass all processes occurring within the wave boundary layer, they are useful for our objective, which is to present gross quantification of the shoreface transition based upon the magnitude of wave-driven sediment transport by studying perturbations around a steady state. The main phenomena leading to our suggested morphologic depth of closure are the decay of wave influence with depth and a characteristic scale set by profile geometries. The robust nature of our general methodology suggests that different equations of sediment transport could be substituted in similar calculations, allowing for repeatability.

\section{Acknowledgments}

Data supporting Figures 8-14 is available from the Wave Information Studies at http://wis.usace.army.mil/and from the Marine Geoscience Data System within the GeoMapApp (http://www.geomapapp.org/). The MatLab code for the theoretical approach is available via email to the corresponding author.

This research has been supported by the National Science Foundation grant \#CNH0815875, the Strategic Environment Research and Development Program, and the Coastal Ocean Institute of the Woods Hole Oceanographic Institution. We thank Jorge LorenzoTrueba, Jeff Donnelly, and Rob Evans for fruitful discussions.

\section{Notation List}

\footnotetext{
$\beta \quad$ slope, $\mathrm{m} / \mathrm{m}$

$\rho \quad$ fluid density, $\mathrm{g} / \mathrm{cm}^{3}$

$\rho_{s} \quad$ sediment density, $\mathrm{g} / \mathrm{cm}^{3}$
} 


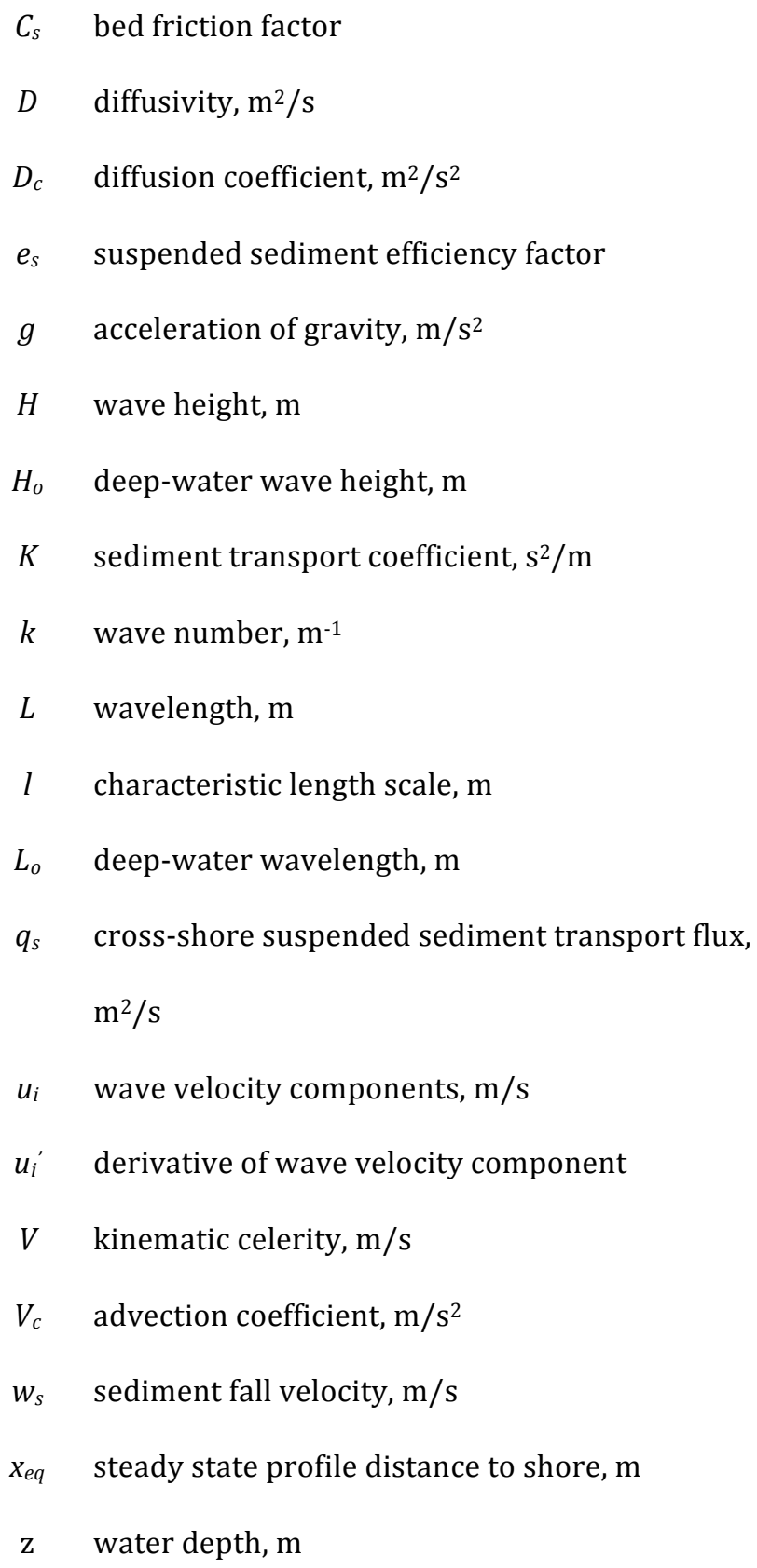




\section{$8 \quad$ Figures}
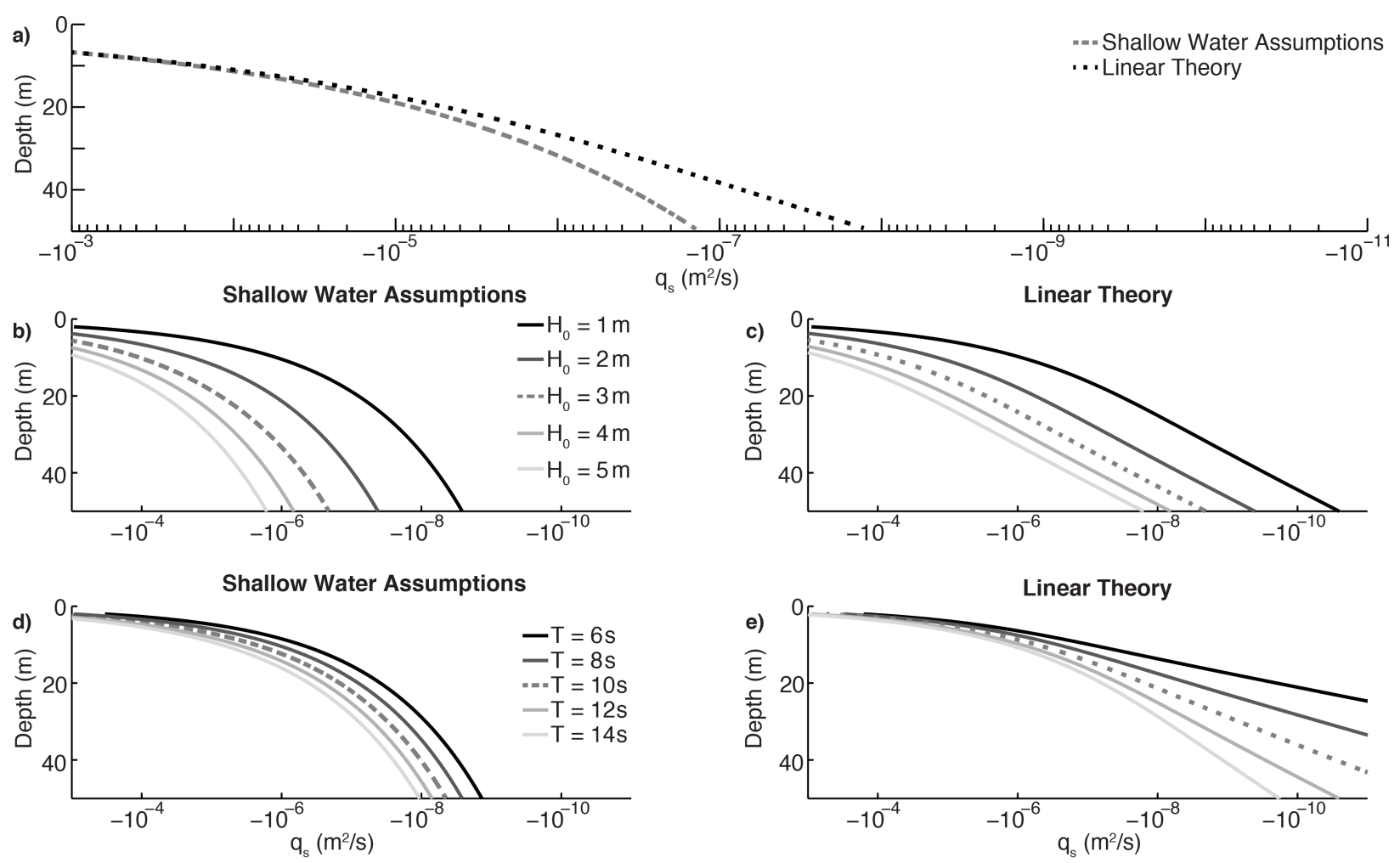

Figure 1. Plots of $q_{s}$ associated with the $u_{1}$ and $u_{2}$ terms (without the slope term) over depth comparing shallow-water and linear wave theory showing (a) comparison of approaches for $H_{0}=3 \mathrm{~m}$ and $T=10 \mathrm{~s}$ and values for varying (b \& c) deep-water wave heights and ( $\mathrm{d} \&$ e) period with negative values indicating onshore-directed sediment transport. 


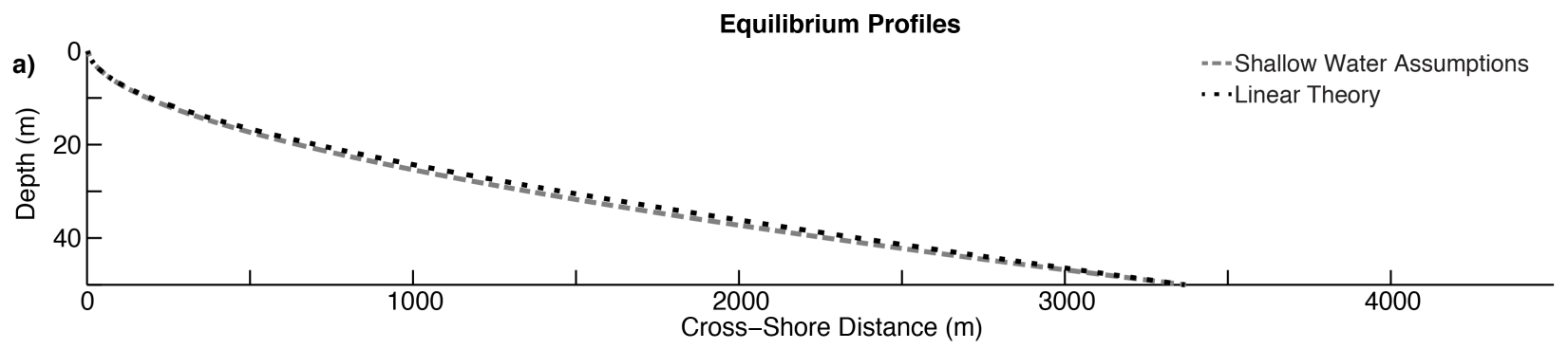

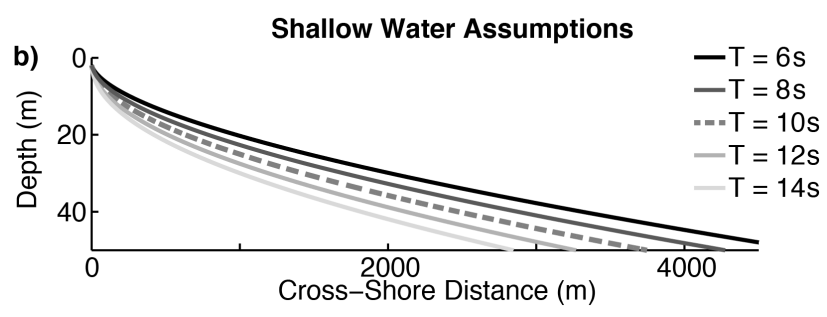

Shallow Water Assumptions

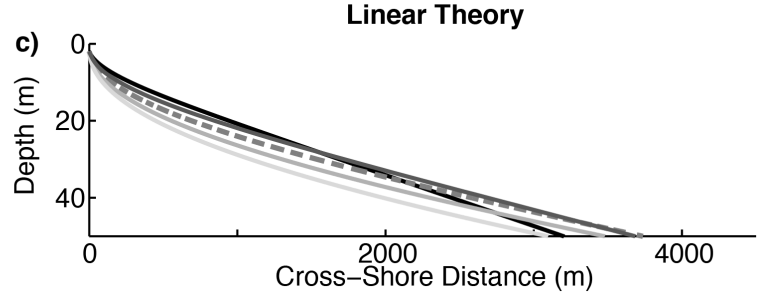

Linear Theory
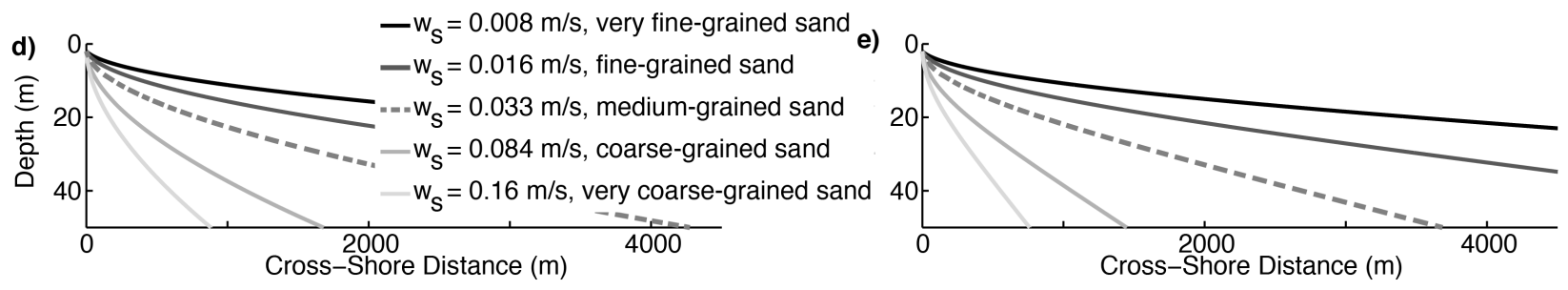

Figure 2. Computed equilibrium profiles (a) comparing shallow water and linear wave theory for $T=10 \mathrm{~s}$ and $w_{s}=0.033 \mathrm{~m} / \mathrm{s}$ for varying (b \& c) wave period and (d \& e) fall velocity. 

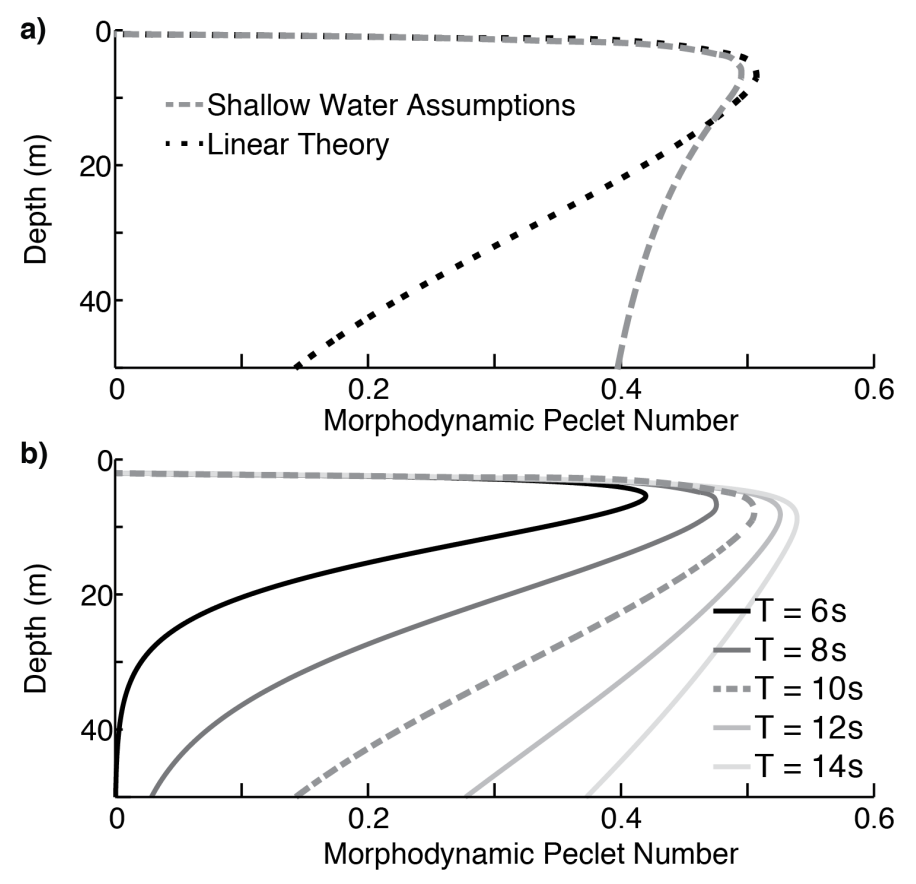

Figure 3. Morphodynamic Péclet number of an equilibrium shoreface over depth (a) comparing linear theory and shallow water wave assumptions for $H_{0}=3 \mathrm{~m}$ and $T=10 \mathrm{~s}$. (b) Péclet number for varying wave period over depth using linear wave theory for $H_{0}=3 \mathrm{~m}$. 

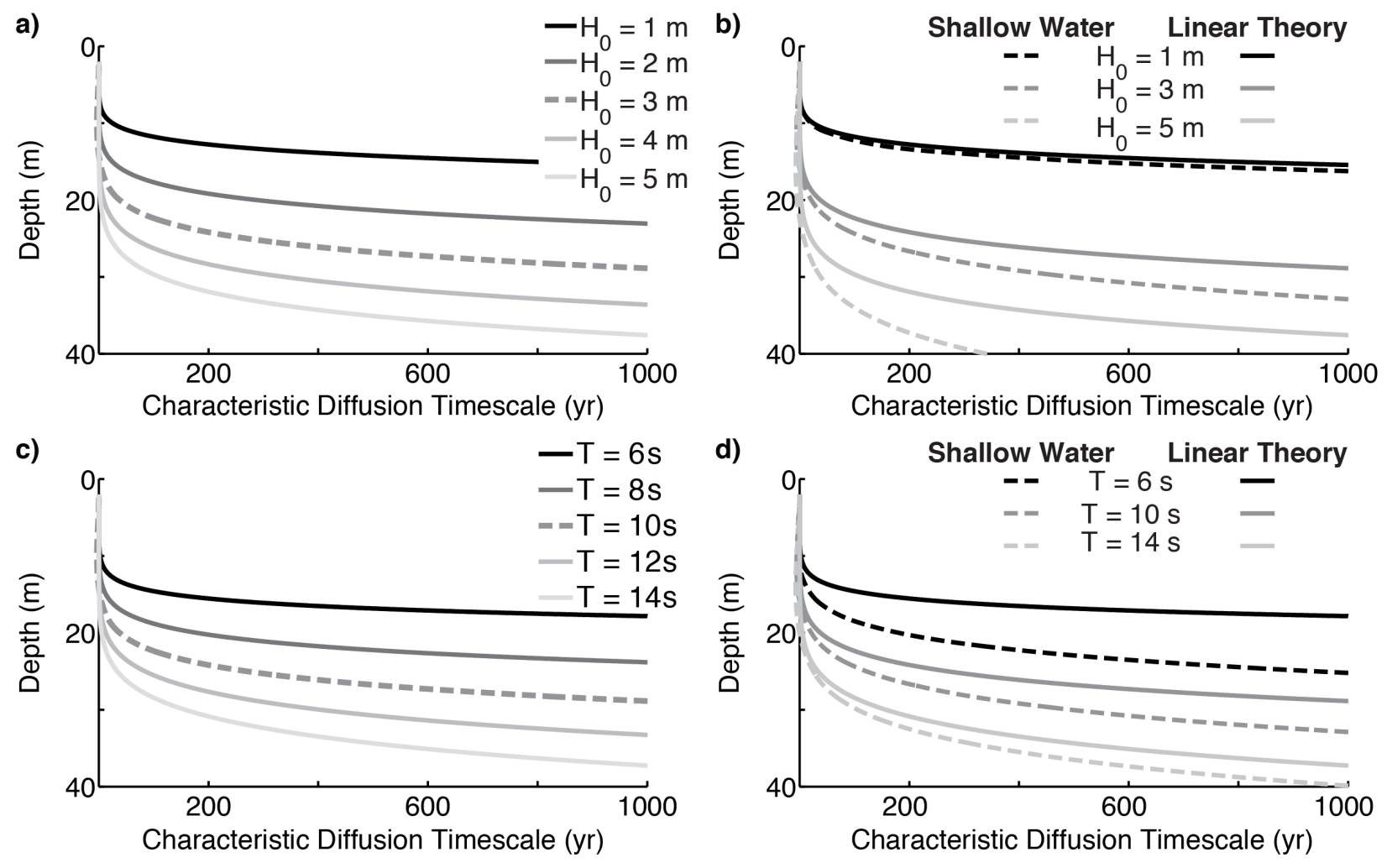

Figure 4. Computed characteristic timescale of diffusion using linear theory over depth with varying (a) deep-water wave height with $T=10 \mathrm{~s}$ and (c) varying wave period with $H_{0}$ $=3 \mathrm{~m}$. Comparison of linear theory to shallow-water assumptions with varying (b) wave height with $T=10 \mathrm{~s}$ and with varying (d) wave period with $H_{0}=3 \mathrm{~m}$. 

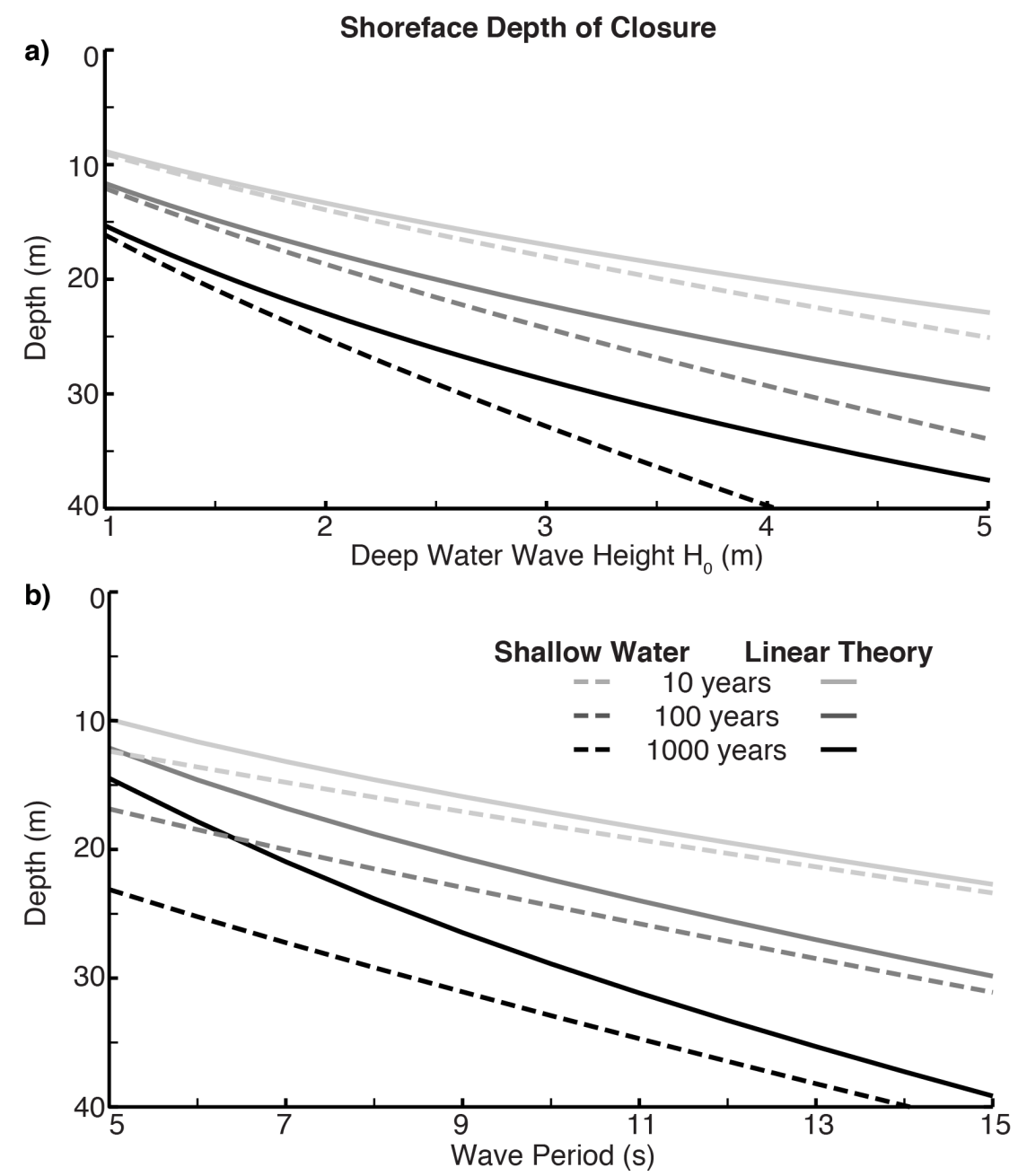

Figure 5. Computed morphodynamic closure depths using shallow-water wave assumptions (dashed lines) and linear theory (solid lines) for (a) varying deep-water wave height (with $T=10 \mathrm{~s}$ ) and (b) varying wave period (with $H_{0}=3 \mathrm{~m}$ ). 


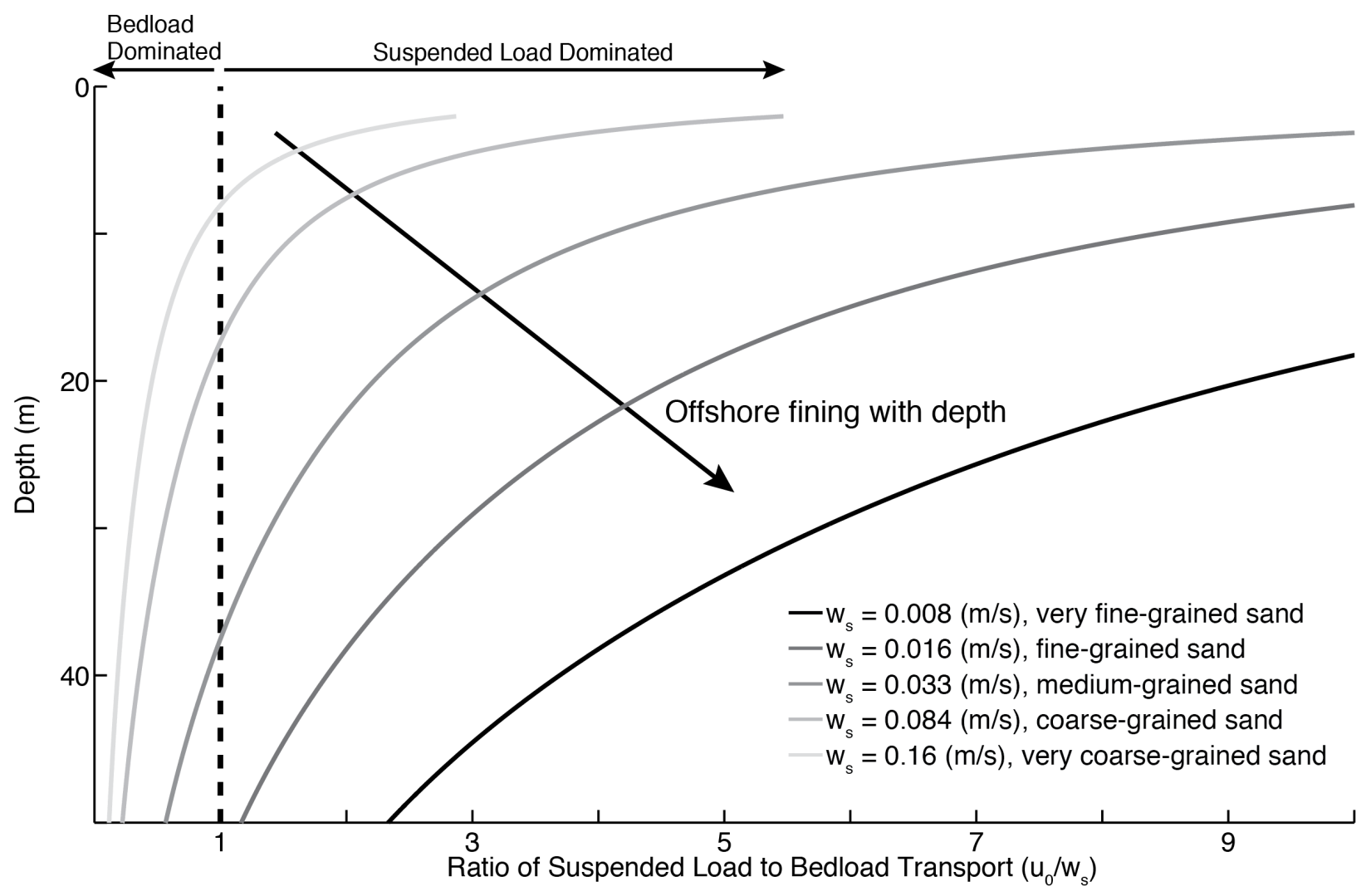

Figure 6. Ratio of suspended load to bedload transport over depth for $H_{0}=5 \mathrm{~m}$ and $T=9 \mathrm{~s}$ for varying fall velocity. 

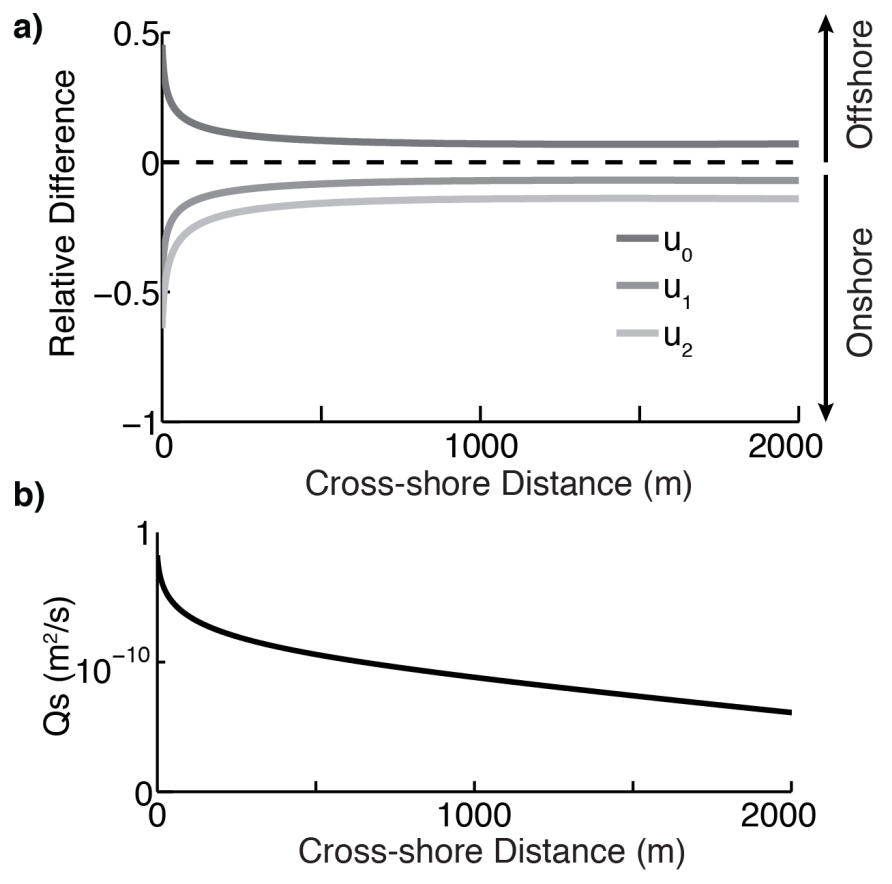

Figure 7. Computed effect of $1 \mathrm{~m}$ of sea-level rise on an equilibrium profile of $w_{s}=0.033 \mathrm{~m} / \mathrm{s}$ using linear theory on (a) components of cross-shore sediment transport and (b) total cross-shore sediment transport (positive direction is offshore) for $H_{0}=3 \mathrm{~m}$ and $T=10 \mathrm{~s}$. 

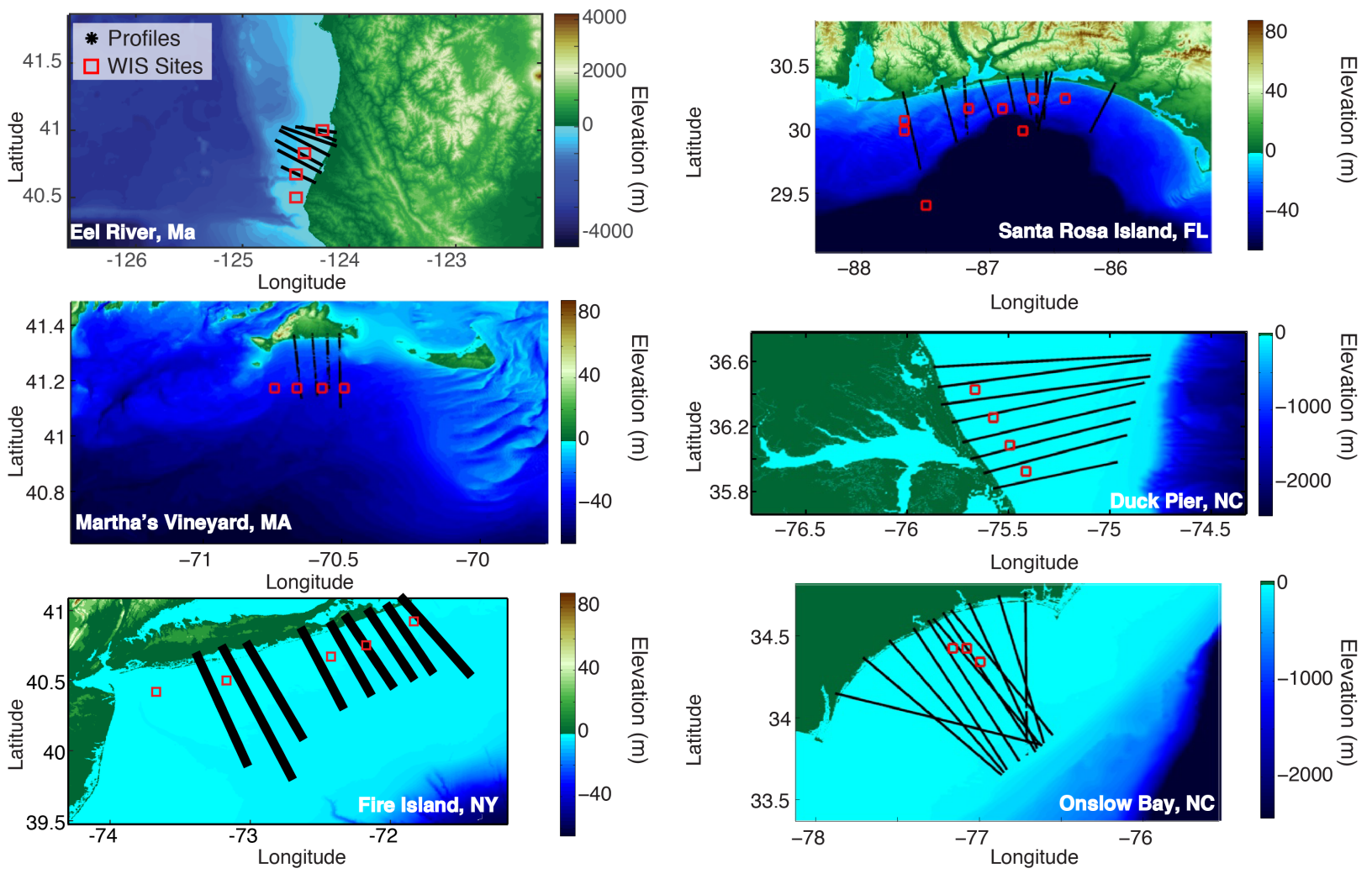

Figure 8. The six analysis locations showing bathymetric data, topographic data, extracted shelf profiles, and the location of the virtual WIS buoys. 

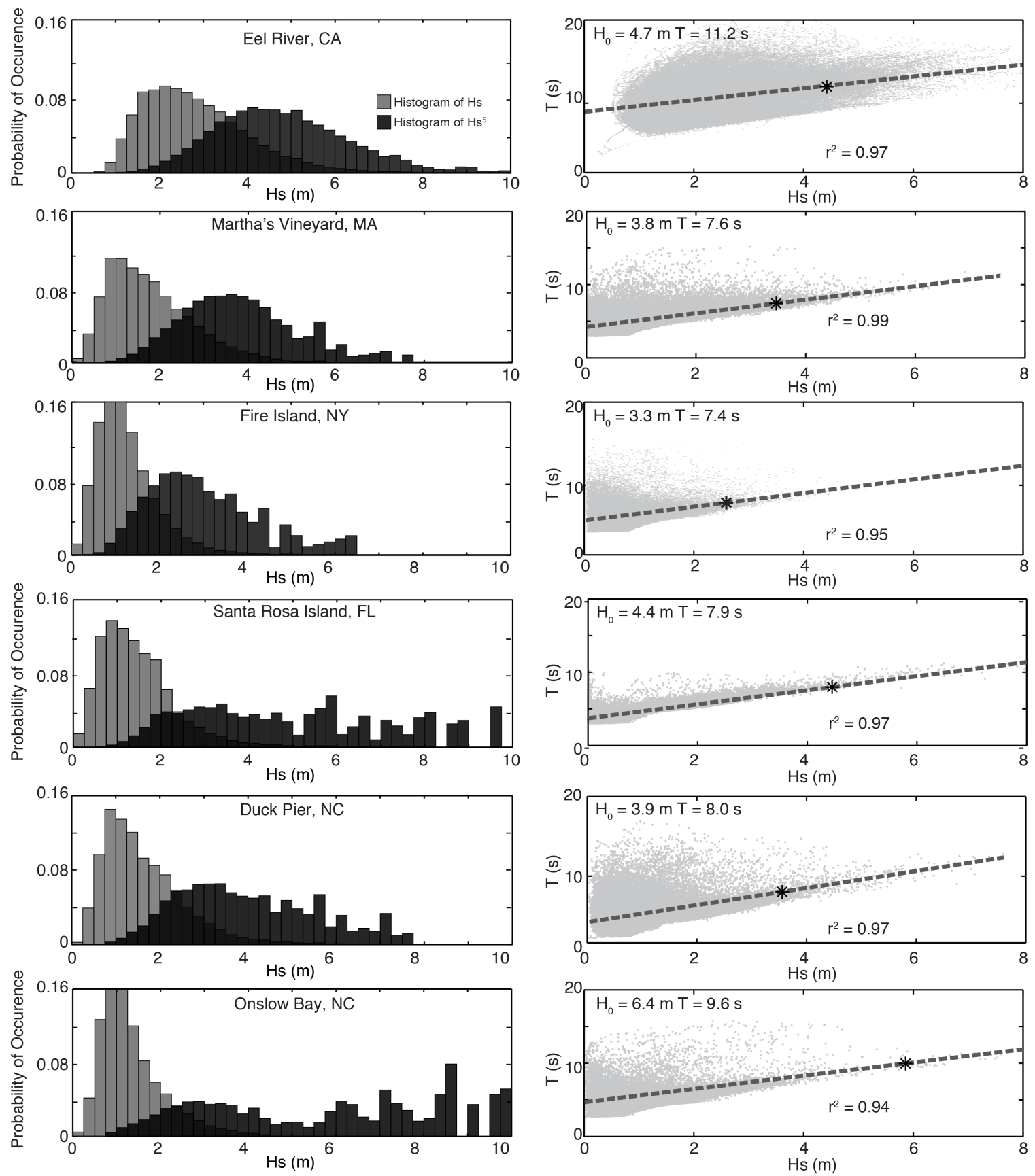

Figure 9. Wave event analysis for the 20-year hindcasted dataset, plotting (left) probability distribution functions of the wave height weighted by the mean wave height $(H$, grey) and $H^{5}$ (black) and (right) wave height versus wave period with linear fit with calculated characteristic morphodynamic wave period (black star) based on the median of the weighted probability distribution function of wave height to the fifth power (from the black histogram plotted on the left). 


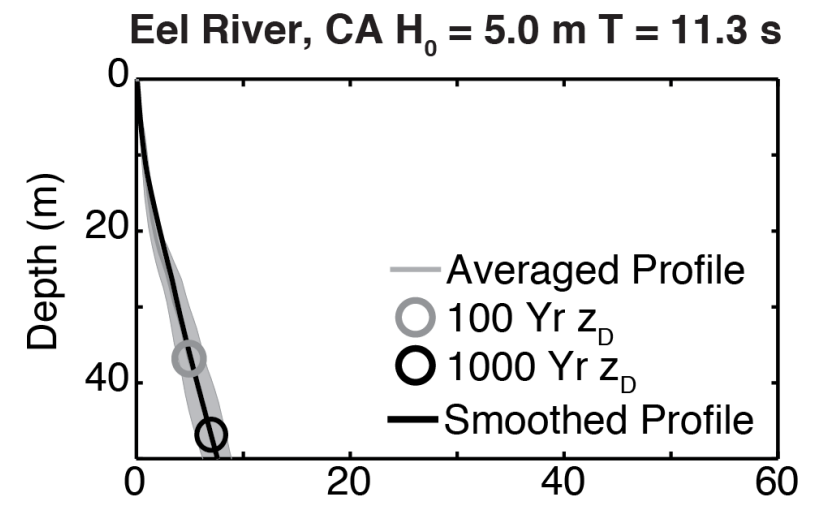

Santa Rosa Island, $F L H_{0}=4.4 \mathrm{~m} \mathrm{~T}=7.9 \mathrm{~s}$

Martha's Vineyard, MA $H_{0}=3.8 \mathrm{~m} \mathrm{~T}=7.6 \mathrm{~s}$
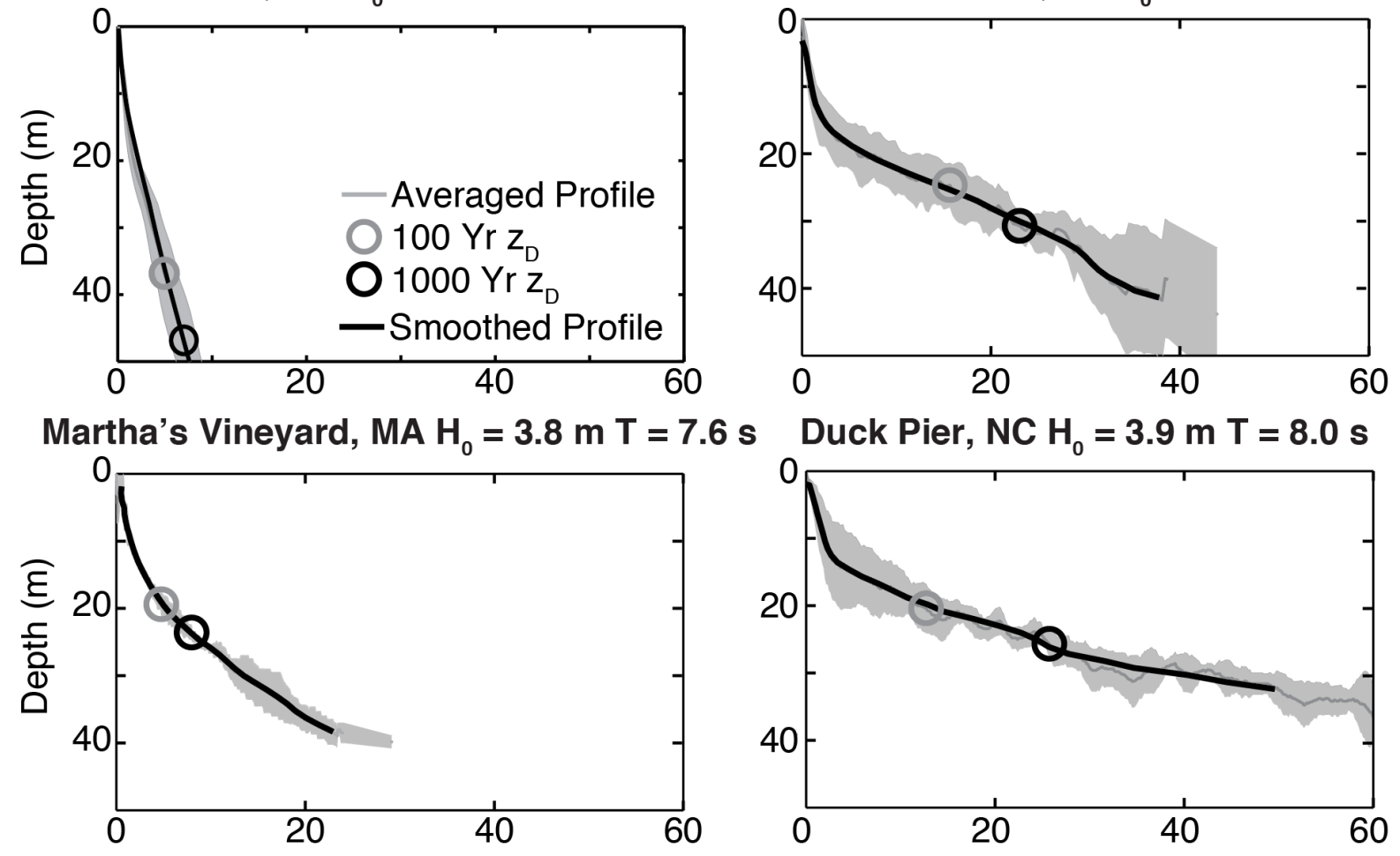

Fire Island, $N Y H_{0}=3.3 \mathrm{~m} \mathrm{~T}=7.4 \mathrm{~s}$
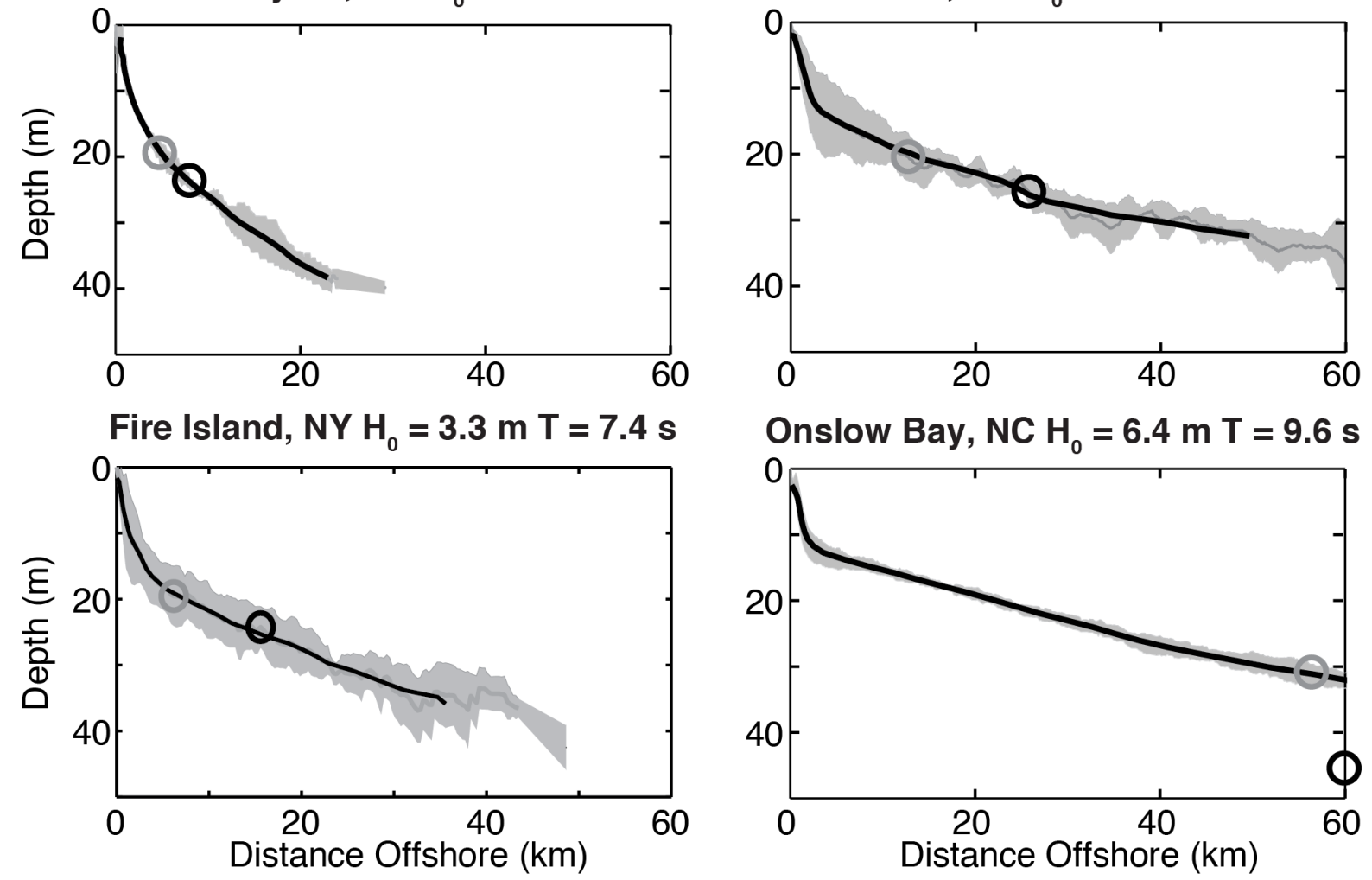

Onslow Bay, $\mathrm{NC} \mathrm{H}_{0}=6.4 \mathrm{~m} \mathrm{~T}=9.6 \mathrm{~s}$

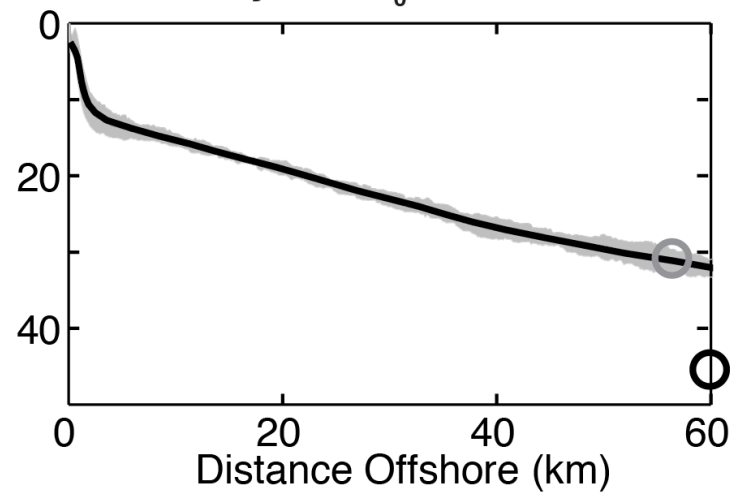

Figure 10. Smoothed and averaged profiles for six field sites with markers indicating the computed morphodynamic depth of closure for characteristic diffusion timescales at 100 years and 1,000 years $\left(z_{D}\right)$. 

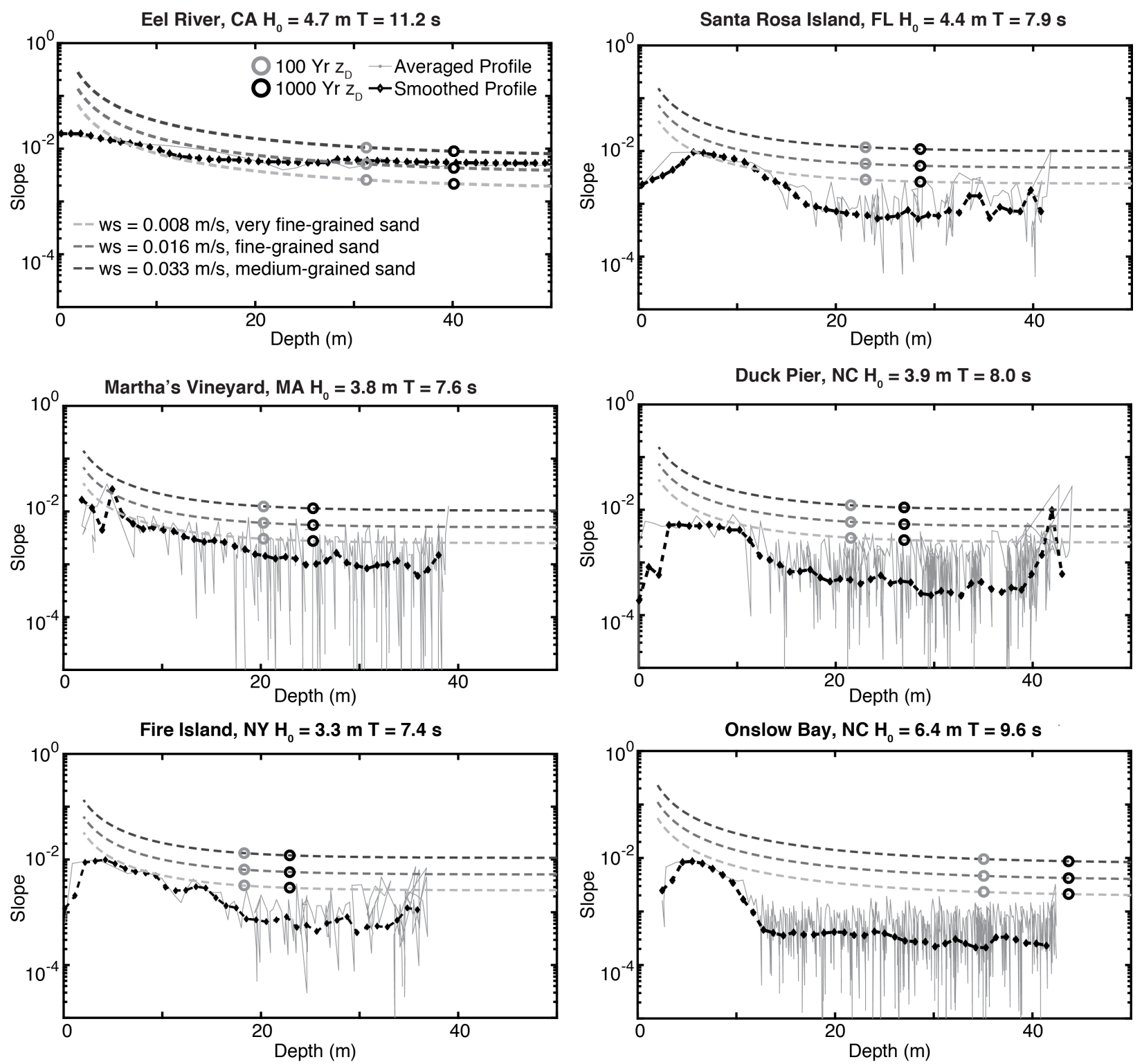

Figure 11. Derivative of computed steady-state profiles with varying fall velocities compared with smoothed (using a moving average filter with a $10 \%$ span) averaged profiles for six study sites. Included are computed morphodynamic depth of closure values for characteristic diffusion timescales at 100 years and 1,000 years. 


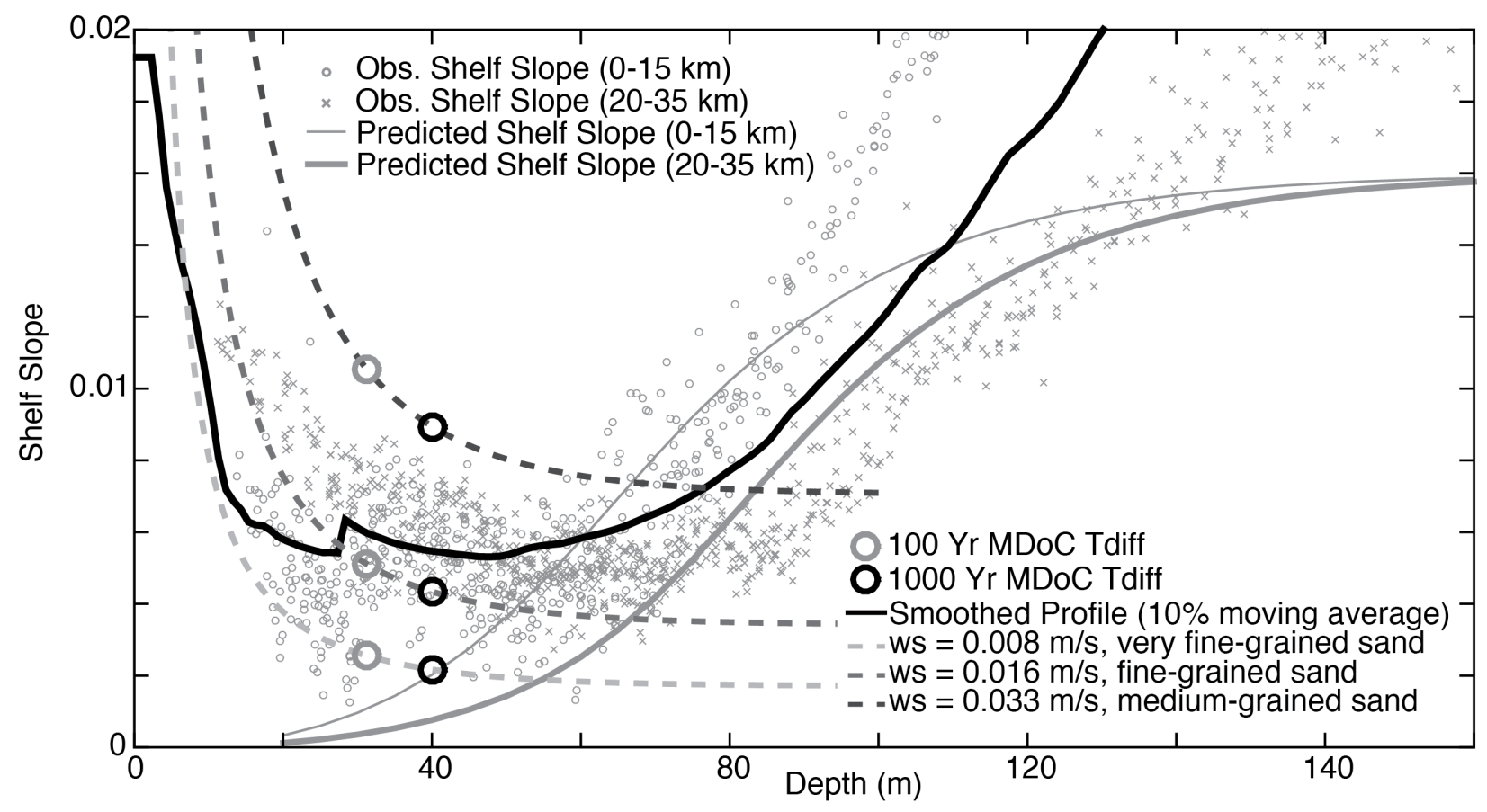

Figure 12. For Eel River, CA comparison of measured slopes with predicted equilibrium shoreface slopes (dash lines) and computed morphodynamic depth of closure to predicted equilibrium shelf slopes adapted after Friedrichs and Wright (2004) Figure 4. 
Eel River, $\mathrm{CA} \mathrm{H}_{0}=4.7 \mathrm{~m} \mathrm{~T}=11.2 \mathrm{~s}$

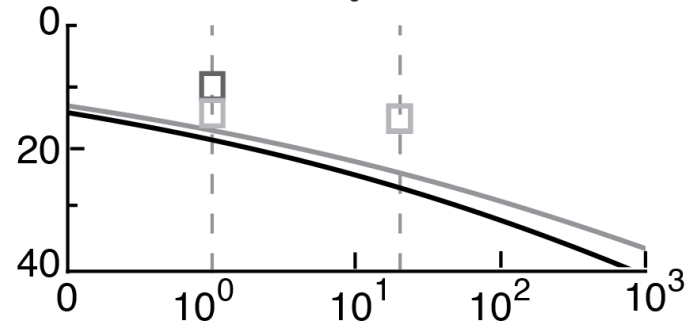

Santa Rosa Island, $\mathrm{FL} \mathrm{H}_{0}=4.4 \mathrm{~m} \mathrm{~T}=7.9 \mathrm{~s}$

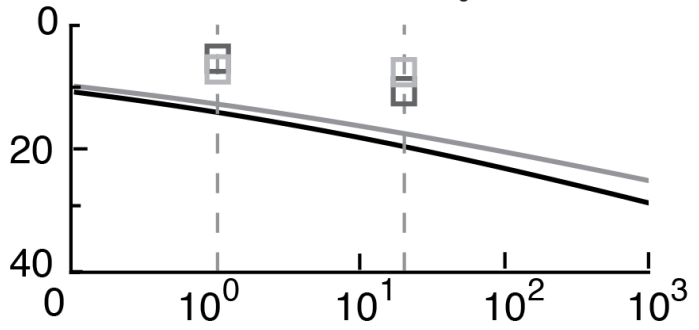

Martha's Vineyard, MA $H_{0}=3.8 \mathrm{~m} \mathrm{~T}=7.6 \mathrm{~s}$
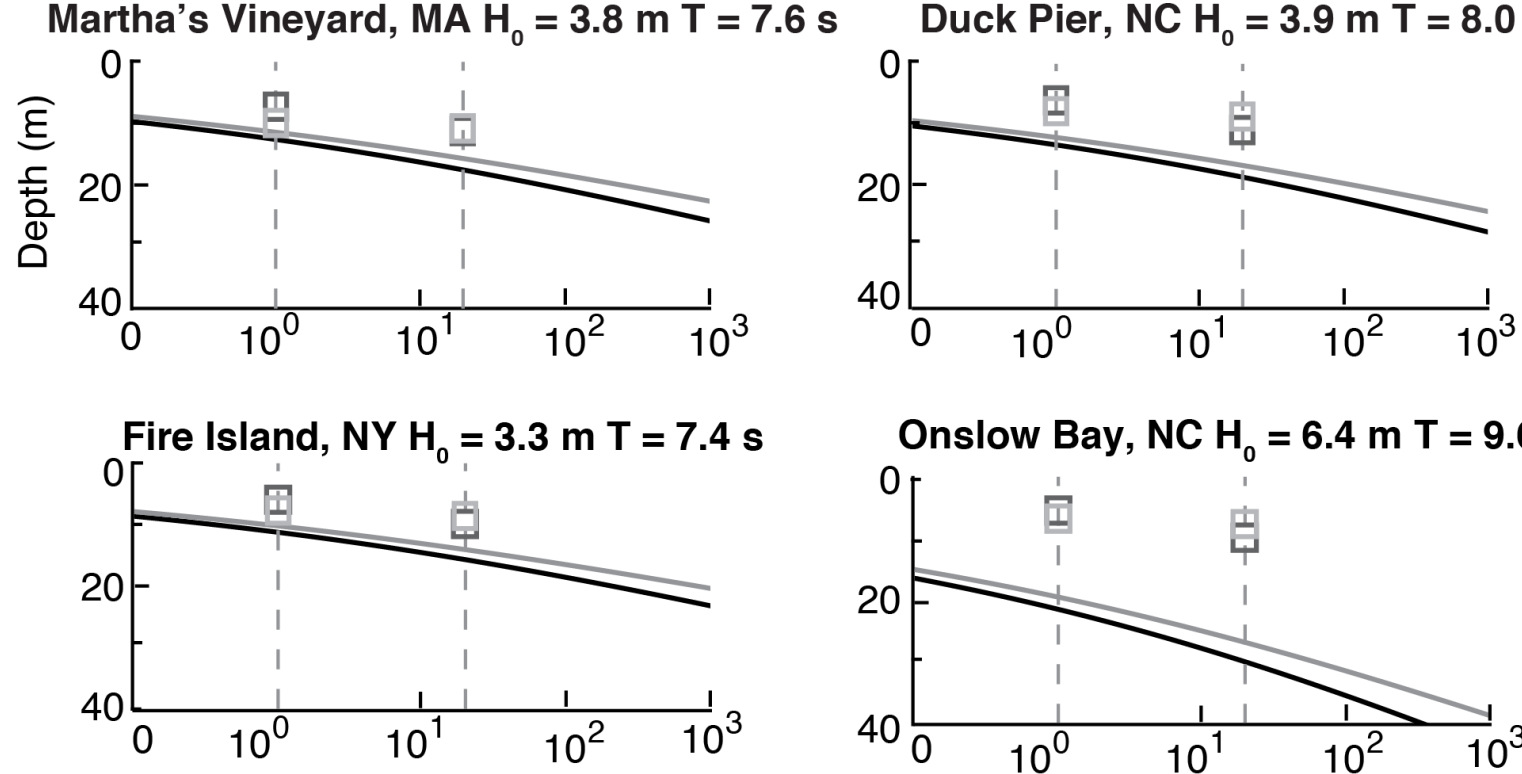

Time (yr)

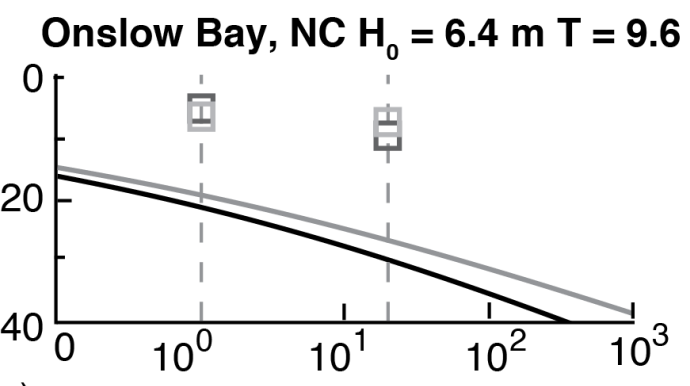

Estimated Depth of Closure - std. deviation of $\mathrm{Hs}$ - Timescale of $\mathrm{t}_{\mathrm{K}}$ Equilibrium Profile

Estimated Depth of Closure - $12 \mathrm{hr}$. exceedence - Timescale of $\tau_{D}$ Equilibrium Profile

Figure 13. Theoretical computations of characteristic timescales of diffusion and kinematic celerity using linear theory compared to computations of depth of closure using Hallermeier (1978) and Birkemeier (1985) for 1 year and 20 years for six field locations and $w_{s}=0.033 \mathrm{~m} / \mathrm{s}$. 


\section{Supporting Information}

The supporting section details all of the equations used in wave calculations. Both linear Airy wave theory and shallow water wave assumptions are detailed for wave shoaling (assuming shore-normal waves and therefore no refraction). In addition, this supporting document contains values for the derivatives of the wave velocity components used in the bed evolution formulation for linear waves (eq. 8-11 in the main text). Last, for completeness we present plots of the diffusivity and advection terms as a function of depth for different wave and sediment characteristics.

\section{Wave Equations}

The following section describes the calculations of the deep-water wave variables and depth-dependent shoaling computations for both linear Airy wave theory and shallowwater wave assumptions.

\subsection{Deep Water Wave Parameters}

For a given a wave period $(T)$ and a deep-water wave height $\left(H_{0}\right)$, deep-water wavelength is:

$$
L_{0}=\frac{g \mathrm{~T}^{2}}{2 \pi}
$$

The wave celerity is given by:

$$
C_{0}=\frac{L_{0}}{T}
$$

which enables the calculation of the group wave speed:

$$
C_{g 0}=n_{0} C_{0}
$$

with the wave dispersion factor $n_{0}=0.5$ for deep-water waves. 


\subsection{Linear Airy Wave Theory}

The Eckart equation (1952) is used to estimate the local wavelength, for a given deep water wavelength $\left(L_{0}\right)$ as a function of the depth $(\mathrm{z})$ :

$$
L(z)=L_{0} \sqrt{\tanh \left(\frac{2 \pi z}{L_{0}}\right)} .
$$

Other methods for analytically estimating local wavelength besides the Eckart equation were investigated (including the Soulsby (2006) and Fenton and McKee (1990)) and there was less than $5 \%$ variation on the calculated sediment transport $\left(q_{s}\right)$ flux. The wave speed or celerity is then calculated as:

$$
C(z)=\frac{L(z)}{T}
$$

The wave group speed, $\mathrm{C}_{\mathrm{g}}$, is calculated using the dispersion relationship:

$$
n(z)=\frac{1}{2}\left(1+\frac{2 k z}{\sinh (2 k z)}\right)
$$

where the wave number is:

$$
k=\frac{2 \pi}{L(z)}
$$

such that the group wave celerity is:

$$
C_{g}(z)=n(z) C(z)
$$

Conservation of energy then leads local wave height $(H)$ at each depth where:

$$
H(z)=H_{0} \sqrt{\frac{C_{g 0}}{C_{g}(z)}} .
$$




\subsection{Shallow-water Wave Assumptions}

For shallow-water wave assumptions, the wavelength computation simplifies to:

$$
L(z)=\mathrm{T} \sqrt{g z}
$$

and wave celerity becomes:

$$
C(z)=n \sqrt{g z} .
$$

Because $n=1$ in shallow water, group speed simplifies to:

$$
C_{g}=\sqrt{g z}
$$

The local wave height is therefore:

$$
\mathrm{H}(\mathrm{z})=\mathrm{H}_{0} \sqrt{\frac{0.5 L_{0}}{L(z)}} .
$$

\section{Full Exner Equation for Bed Evolution}

Here we provide the full values for the spatial derivative terms in the equation for bed evolution arising from the derivative of sediment flux with respect to cross-shore distance:

$\frac{\partial z}{\partial t}=\mathrm{K} \frac{u_{0}^{2}}{\varepsilon_{o} w_{s}}\left[\left(-5 u_{1}^{\prime} u_{0}-15 u_{o}^{\prime} u_{1}-3 u_{2}^{\prime} u_{0}-9 u_{0}^{\prime} u_{2}+\frac{5 \beta_{0}}{w_{s}} u_{0}^{\prime} u_{0}^{2}\right) \frac{\partial z}{\partial x}+\left(\frac{u_{0}^{3}}{w_{s}}\right) \frac{\partial^{2} z}{\partial x^{2}}\right]$

where the single apostrophe denotes:

$$
u_{i}^{\prime}=\frac{\partial u_{i}}{\partial z}
$$


These derivatives are complex because each wave component is a function of depth, as are the terms inside each component, i.e. wavelength, wave number, and wave height. Using linear Airy wave theory to compute the wave components and using the product and chain rule, the cross-shore derivative for the wave orbital velocity is:

$u_{o}^{\prime}=-\frac{\pi \operatorname{csch}(\mathrm{kz})}{\mathrm{TL}^{2}}\left[-\mathrm{L}^{2} \mathrm{H}^{\prime}-2 \pi z \mathrm{HL}^{\prime} \operatorname{coth}(\mathrm{kz})+2 \pi \mathrm{HL} \operatorname{coth}(\mathrm{kz})\right]$

The wave drift term is then:

$u_{1}{ }^{\prime}=-\frac{3 \pi^{2} \mathrm{Hcsch}^{2}(\mathrm{kz})}{4 \mathrm{TL}^{3}}\left[-2 \mathrm{~L}^{2} \mathrm{H}^{\prime}+\mathrm{HLL}^{\prime}-4 \pi z \mathrm{HL}^{\prime} \operatorname{coth}(\mathrm{kz})+4 \pi \mathrm{HLcoth}(\mathrm{kz})\right]$.

Finally, the wave asymmetry term is:

$u_{2}^{\prime}=-\frac{3 \pi^{2} \mathrm{Hcsch}^{4}(\mathrm{kz})}{4 \mathrm{TL}^{3}}\left[-2 \mathrm{~L}^{2} \mathrm{H}^{\prime}+\mathrm{HLL}^{\prime}-8 \pi z \mathrm{HL}^{\prime} \operatorname{coth}(\mathrm{kz})+8 \pi \mathrm{HL} \operatorname{coth}(\mathrm{kz})\right]$.

In these equations (16-18), the $H^{\prime}$ term denotes the derivative of wave height with respect to $z$ such that:

$$
H^{\prime}=\frac{-H_{0} L_{0}\left[L^{\prime}+8 \pi \operatorname{csch}(2 k z)-16 \pi k z\left(1-\frac{L^{\prime}}{L}\right) \operatorname{coth}(2 k z) \operatorname{csch}(2 k z)\right]}{2[8 \pi z \operatorname{csch}(2 k z)+L]^{2} \sqrt{\frac{L_{0}}{8 \pi z \operatorname{csch}(2 k z)}+L}}
$$

and $L^{\prime}$ denotes the derivative of the wave length with respect to $\mathrm{z}$ :

$$
L^{\prime}=\frac{\pi \operatorname{sech}^{2}\left(2 \pi \frac{Z}{L_{0}}\right)}{\sqrt{\tanh \left(2 \pi \frac{Z}{L_{0}}\right)}}
$$


It is important to note that in the above equations of the derivative of the wave components (equations 16-18), the terms containing the derivative of wave height $\left(H^{\prime}\right)$ and wavelength $\left(L^{\prime}\right)$ are of secondary importance in determining the magnitude, typically accounting for $40 \%$ of the total magnitude. The equilibrium bed slope is calculated using first order Eulerian integration of the bed depth.

\section{Advection-Diffusion Equation Terms}

Here we provide plots of the depth dependence of the advection and diffusion terms. We investigate the dependence of bed evolution and how those terms respond to changes in wave climate or grain size. Kinematic bed celerity is sensitive to wave height and period, but not settling velocity (Figure S1). Compared to the wave period and grain size, at a depth of $20 \mathrm{~m}$ the advection term ranges with 4 orders of magnitude as $H_{0}$ varies from 1 - $5 \mathrm{~m}$. As water depth increases, however, wave period has the strongest control on the advection term. By $50 \mathrm{~m}$, kinematic celerity ranges 8 orders of magnitude between $6 \mathrm{~s}$ and $14 \mathrm{~s}$ waves.
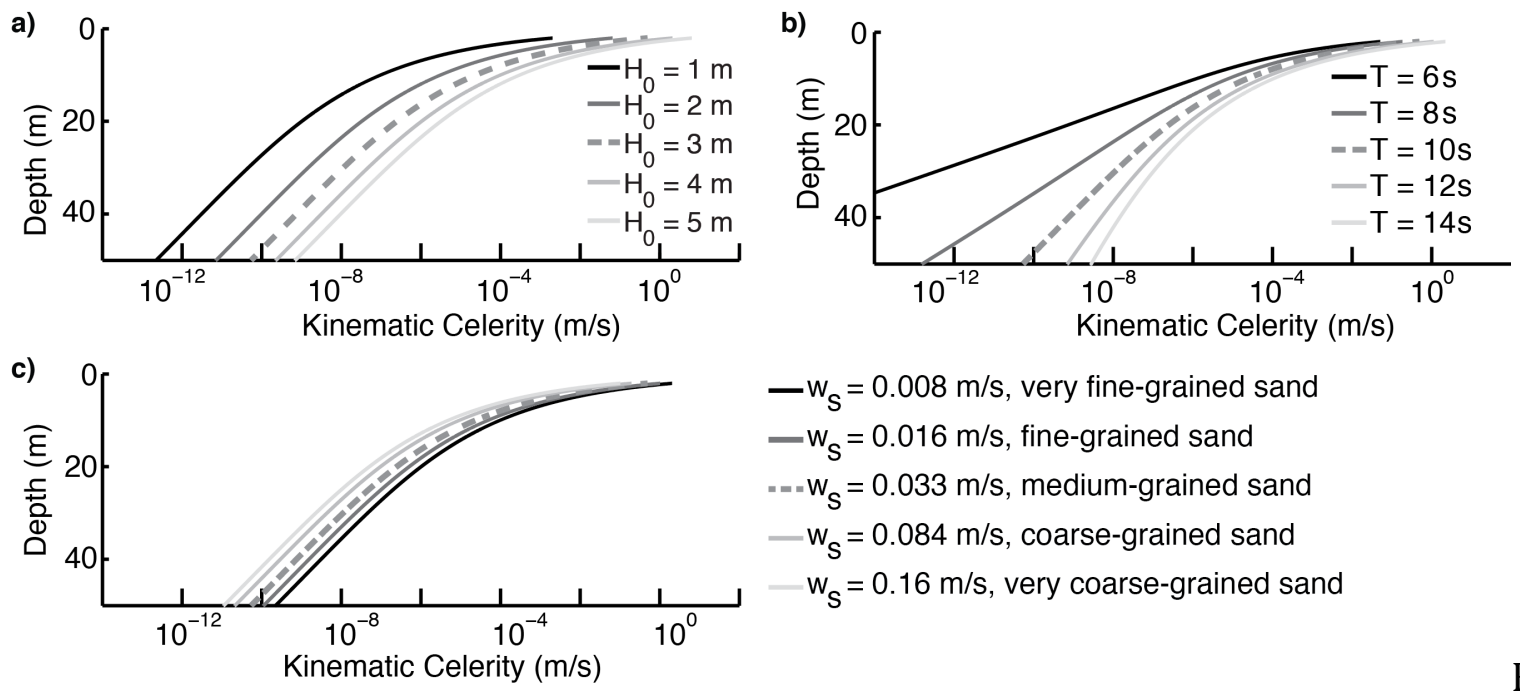

$$
\begin{aligned}
-w_{S} & =0.008 \mathrm{~m} / \mathrm{s}, \text { very fine-grained sand } \\
-w_{S} & =0.016 \mathrm{~m} / \mathrm{s}, \text { fine-grained sand } \\
--w_{S} & =0.033 \mathrm{~m} / \mathrm{s}, \text { medium-grained sand } \\
-w_{S} & =0.084 \mathrm{~m} / \mathrm{s}, \text { coarse-grained sand } \\
-w_{S} & =0.16 \mathrm{~m} / \mathrm{s}, \text { very coarse-grained sand }
\end{aligned}
$$

S1. Kinematic celerity of an equilibrium shoreface computed using linear theory over depth with varying (a) deep-water wave height, (b) wave period, (c) and sediment fall velocity.

Diffusivity also varies over depth (Figure S2). At shallow depths, the deep-water wave height provides a strong control on the diffusivity, with wave period exerting 
stronger control with depth, much like for the kinematic celerity. Note that the diffusivity is more sensitive to sediment size than the advection term. Given a morphodynamic Péclet number less than unity, the system is dominated by diffusive processes. Thus, when looking at the predicted timescale of kinematic celerity (Figure S3), the depths at which this values asymptotes are much shallower. In essence, the kinematic celerity (or advection term) predicts a shallower morphodynamic depth of closure. This shallower MDOC indicates these there would be more predicted shoreface activity assuming the shoreface is advection dominated.

a)
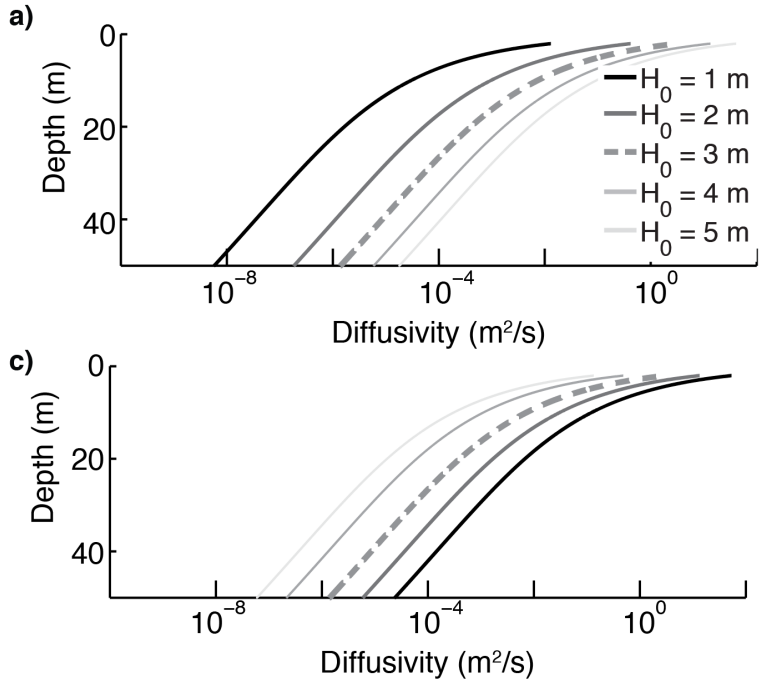

b)

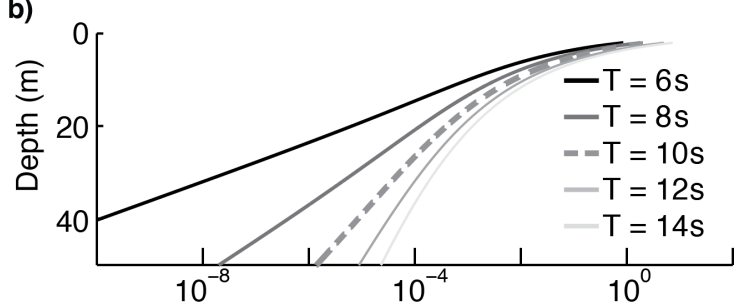

Diffusivity $\left(\mathrm{m}^{2} / \mathrm{s}\right)$

$-w_{s}=0.008 \mathrm{~m} / \mathrm{s}$, very fine-grained sand

$-\mathrm{w}_{\mathrm{s}}=0.016 \mathrm{~m} / \mathrm{s}$, fine-grained sand

$=-\mathrm{W}_{\mathrm{S}}=0.033 \mathrm{~m} / \mathrm{s}$, medium-grained sand

$-\mathrm{w}_{\mathrm{s}}=0.084 \mathrm{~m} / \mathrm{s}$, coarse-grained sand

$-w_{\mathrm{s}}=0.16 \mathrm{~m} / \mathrm{s}$, very coarse-grained sand

Figure S2. Diffusivity of equilibrium shoreface computed using linear theory over depth with varying (a) deep-water wave height, (b) wave period, and (c) fall velocity. 

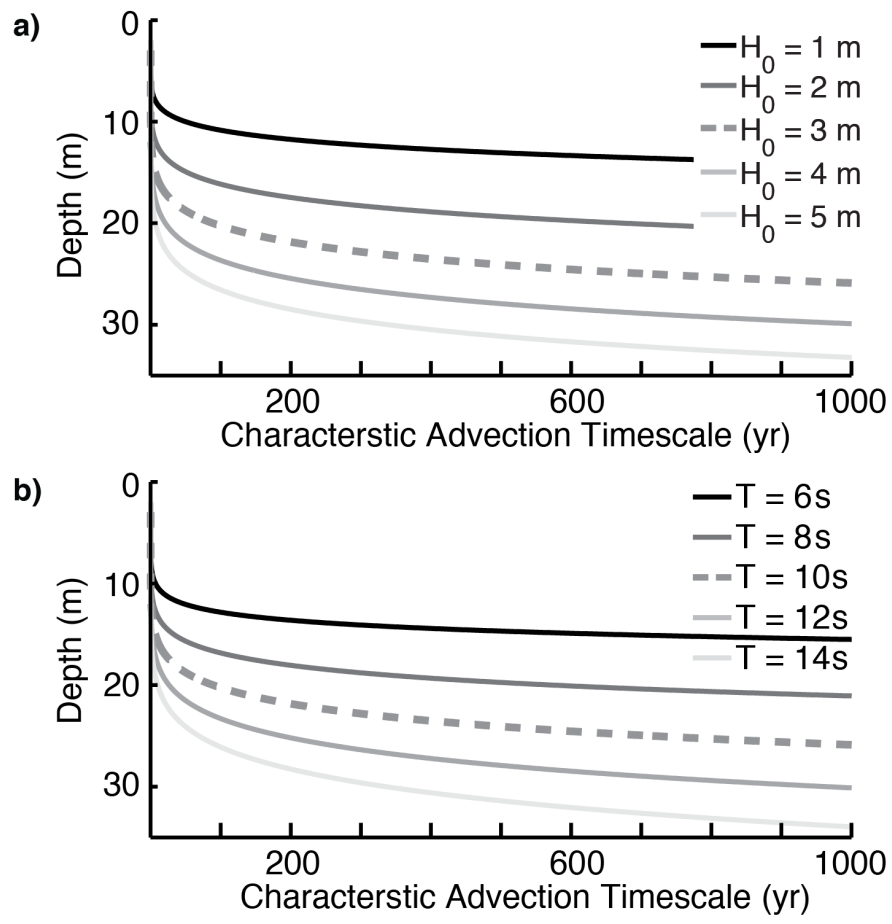

Figure S3. Computed characteristic timescale of kinematic celerity using linear theory over depth with varying (a) deep-water wave height with $T=10 \mathrm{~s}$ and (c) varying wave period with $H_{0}=1 \mathrm{~m}$.

\section{References}

Aagaard, T., 2014, Sediment supply to beaches: Cross-shore sand transport on the lower shoreface: Journal of Geophysical Research: Earth Surface, v. 119, no. 4, p. 913-926, doi: 10.1002/2013JF003041.

Aagaard, T., Sorensen, P., and Sørensen, P., 2012, Coastal profile response to sea level rise: a process-based approach: Earth Surface Processes and Landforms, v. 37, no. 3, p. 354-362, doi: 10.1002/esp.2271.

Ashton, A.D., and Giosan, L., 2011, Wave-angle control of delta evolution: Geophysical Research Letters, v. 38, no. 13, p. 6, doi: 10.1029/2011GL047630.

Ashton, A.D., and Murray, A.B., 2006, High-angle wave instability and emergent shoreline shapes: 1. Modeling of sand waves, flying spits, and capes: Journal of Geophysical Research-Earth Surface, v. 111, no. F4, p. 19, doi: F04011 10.1029/2005jf000422.

Ashton, A.D., and Ortiz, A.C., 2011, Overwash controls coastal barrier reponse to sea-level rise, in Coastal Sediments, ASCE, Miami, FL, p. 230-243. 
Ashton, A.D., Walkden, M.J.A.A., and Dickson, M.E., 2011, Equilibrium responses of cliffed coasts to changes in the rate of sea level rise: Marine Geology, v. 284, no. 1-4, p. 217-229, doi: http://dx.doi.org/10.1016/j.margeo.2011.01.007.

Bagnold, R.A., 1963, Mechanics of marine sedimentation, in Hill, M.N. ed., Physics of Sediment Transport by Wind and Water, John Wiley \& Sons, New York, p. 188-230.

Bailard, J.A., and Inman, D.L., 1981, An energetics total load sediment transport model for a plane sloping beach: Journal of Geophysical Research, v. 86, no. 80, p. 2035-2043, doi: 10.1029/JC086iC11p10938.

Birkemeier, W.A., 1985, Field data on seaward limit of profile change: Journal of Waterway, Port, Coastal, and Ocean Engineering, v. 111, no. 3, doi:

http://dx.doi.org/10.1061/(ASCE)0733-950X(1985)111:3(598).

Bowen, A.J., 1980, Simple models of nearshore sedimentation; beach profiles and longshore bars, in The Coastline of Canada, Littoral Processes and Shore Morphology, Halifax, Nova Scotia, p. 1-11.

Bray, M.J., and Hooke, J.M., 1997, Prediction of Soft-Cliff Retreat with Accelerating Sea-Level Rise: Journal of Coastal Research, v. 13, no. 2, p. 453-467, doi: 10.2307/4298640.

Brunsden, D., and Thornes, J.B., 1979, Landscape sensitivity and change: Transactions of the Institute of British Geographers, v. 4, no. 4, p. 463-484.

Bruun, P., 1983, Review of conditions for uses of the Bruun rule of erosion: Coastal Engineering, v. 7, no. 1, p. 77-89, doi: 10.1016/0378-3839(83)90028-5.

Bruun, P., 1962, Sea Level Rise as a Cause of Shore Erosion: Journal of the waterways and harbors division, American Society of Civil Engineers, v. 88, no. WW1, p. 13.

Bruun, P., 1988, The Bruun rule of erosion by sea-level rise: a discussion on large-scale two- and three-dimensional usages: Journal of Coastal Research, v. 4, no. 4, p. 627-648.

Cooper, J.A.G., and Pilkey, O.H., 2004, Sea-level rise and shoreline retreat: time to abandon the Bruun Rule: Global and Planetary Change, v. 43, no. 3-4, p. 157-171, doi:

10.1016/j.gloplacha.2004.07.001.

Cowell, P.J., Roy, P.S., and Jones, R.A., 1995, Simulation of large-scale coastal change using a morphological behaviour model: Marine Geology, v. 126, no. 1-4, p. 45-61, doi: 10.1016/0025-3227(95)00065-7.

Cowell, P.J., Stive, M.J.F., Niedoroda, A.W., Swift, D.J.P., Vriend, H.J. De, Buijsman, M.C., Nicholls, R.J., Roy, P.S., Kaminsky, G.M., Cleveringa, J., Reed, C.W., and Boer, P.L. De, 2006a, The Coastal-Tract ( Part 2 ): Applications of Aggregated Modeling of Lower-order Coastal Change: Journal of Coastal Research, v. 19, no. Table 1, p. 828-848. 
Cowell, P.J., Stive, M.J.F., Niedoroda, A.W., Vriend, H.J. De, Swift, D.J.P., Kaminsky, G.M., and Capobianco, M., 2006b, The Coastal-Tract ( Part 1 ): A Conceptual Approach to Aggregated Modeling of Low-Order Coastal Change: Journal of Coastal Research, v. 19, no. 4, p. 812-827, doi: $10.2307 / 4299222$.

Davidson-Arnott, R.G.D., 2005, Conceptual Model of the Effects of Sea Level Rise on Sandy Coasts: Journal of Coastal Research, v. 21, no. 6, p. 1166-1172, doi: 10.2112/03-0051.1.

Dean, R.G., 2002, Beach Nourishment: Theory and Practice: World Scientific.

Dean, R.G., 1991, Equilibrium Beach Profiles: Characteristics and Applications: Journal of Coastal Research, v. 7, no. 1, p. 53-84.

Dean, R.G., and Dalrymple, R.A., 1991, Water wave mechanics for engineers and scientists.: Singapore; Teaneck, NJ : World Scientific, c1991.

Dean, R.G., and Maurmeyer, E.M., 1983, Models for Beach Profile Response, in Komar, P.D. ed., CRC handbook of coastal processes and erosion, p. 151-165.

Dickson, M.E., Bristow, C.S., Hicks, D.M., Jol, H., Stapleton, J., and Todd, D., 2009, Beach Volume on an Eroding Sand-Gravel Coast Determined Using Ground Penetrating Radar: Journal of Coastal Research, p. 1149-1159, doi: 10.2112/08-1137.1.

Donnelly, C., Kraus, N., and Larson, M., 2006, State of Knowledge on Measurement and Modeling of Coastal Overwash: , p. 965-991, doi: 10.2112/04-0431.1.

Dott, R. H., J., and Bourgeois, J., 1982, Hummocky stratification: Significance of its variable bedding sequences: Geological Society of America Bulletin, v. 93, no. 8, p. 663-680, doi: 10.1130/0016-7606(1982)93.

Duke, W.L., 1985, Hummocky cross-stratification, tropical hurricanes, and intense winter storms: Sedimentology, v. 32, no. 2, p. 167-194, doi: 10.1111/j.1365-3091.1985.tb00502.x.

Eckart, C., 1952, The propagation of waves from deep to shallow water, in Standards, N.B. of ed., Proceedings of the NBS Semicentennial Symposium on Gravity Waves, NBS, p. 165.

Fenneman, N.M., 1902, Development of the Profile of Equilibrium of the Subaqueous Shore Terrace: The Journal of Geology, v. 10, no. 1, p. 1-32.

Fenton, J.D., and McKee, W.D., 1990, On calculating the lengths of water waves: Coastal Engineering, v. 14, no. 6, p. 499-513.

Fredsoe, J., and Deigaard, R., 1992, Mechanics of Coastal Sediment Transport (P. L.-F. Liu, Ed.): World Scientific Publishing Co Pte Ltd. 
Friedrichs, C.T., and Wright, L.D., 2004, Gravity-driven sediment transport on the continental shelf: implications for equilibrium profiles near river mouths: Coastal Engineering, v. 51, no. 8-9, p. 795-811, doi: 10.1016/j.coastaleng.2004.07.010.

Hallermeier, R.J., 1981, A profile zonation for seasonal sand beaches from wave climate: Coastal Engineering, v. 4, p. 253-277.

Hallermeier, R.J., 1978, Uses for a calculated limit depth to beach erosion, in Coastal Engineering Proceedings, p. 1493-1512.

Haxby, W.F., 2012, GeoMapApp:.

Holthuijsen, L.H., 2007, Waves in Oceanic and Coastal Waters: Cambridge University Press.

Hutton, E.W.H.H., and Syvitski, J.P.M.M., 2008, Sedflux 2.0: An advanced process-response model that generates three-dimensional stratigraphy: Computers \& Geosciences, v. 34, no. 10, p. 1319-1337, doi: 10.1016/j.cageo.2008.02.013.

Jenkins, S.A., and Inman, D.I., 2005, Thermodynamic solutions for equilibrium beach profiles: Journal of Geophysical Research, v. 111, no. C2, doi: 10.1029/2005JC002899.

Jensen, R.E., 2010, Wave Information Studies (U. S. A. C. of Engineers, Ed.):

Jimenez, J., and Sanchez-Arcilla, A., 2004, A long-term (decadal scale) evolution model for microtidal barrier systems: Coastal Engineering, v. 51, no. 8-9, p. 749-764, doi: 10.1016/j.coastaleng.2004.07.007.

Jin, D., Ashton, A.D., and Hoagland, P., 2013, Optimal responses to shoreline changes: an integrated economic and geologic model with applications to curved coasts: Natural Resource Modeling, v. 26, no. 4, p. 572-604, doi: 10.1111/nrm.12014.

Kemp, A.C., Horton, B.P., Donnelly, J., Mann, M.E., Vermeer, M., and Rahmstorf, S., 2011, Climate related sea-level variations over the past two millennia: PNAS, v. 108, no. 27, doi: 10.1073/pnas. 1015619108 .

Kleinhans, M.G., 2002, Sediment dynamics on the shoreface and upper continental shelf: a review: Utrecht University.

Komar, P.D., 1991, The Response of Beaches to Sea-Level Changes : A Review of Predictive Models: Journal of Coastal Research, v. 7, no. 3, p. 895-921.

Larson, M., Kraus, N.C., and C. Kraus, N., 1995, Prediction of cross-shore sediment transport at different spatial and temporal scales: Marine Geology, v. 126, no. 1-4, p. 111-127, doi: http://dx.doi.org/10.1016/0025-3227(95)00068-A. 
Leont'yev, I.O., 2012, Modeling Beach Profile Evolution at Centennial to Millennial Scales: Marine Geology, v. 52, no. 4, p. 550-560, doi: 10.1134/S0001437012040054.

Limber, P.W., Brad Murray, A., Adams, P.N., and Goldstein, E.B., 2014, Unraveling the dynamics that scale cross-shore headland relief on rocky coastlines: 1 . Model development: Journal of Geophysical Research: Earth Surface, v. 119, no. 4, p. 854-873, doi: 10.1002/2013JF002950.

List, J.H., Sallenger, A.H., Hansen, M.E., and Jaffe, B.E., 1997, Accelerated relative sea-level rise and rapid coastal erosion: testing a causal relationship for the Louisiana barrier islands: Marine Geology, v. 140, no. 3-4, doi: 10.1016/S0025-3227(97)00035-2.

Longuet-Higgins, M.S., 1957, The mechanics of the boundary-layer near the bottom in a progressive wave, in 6th International Conference on Coastal Engineering, Miami, FL, p. 184-193.

Lorenzo-Trueba, J., and Ashton, A.D., 2014, Rollover, drowning, and discontinuous retreat: Distinct modes of barrier response to sea-level rise arising from a simple morphodynamic model: Journal of Geophysical Research: Earth Surface, v. 119, no. 4, p. 779-801, doi: 10.1002/2013JF002941.

Madsen, O.S., 1991, Mechanics of cohesionless sediment transport in coastal waters, in Coastal Sediments, ASCE, p. 15-27.

McCave, I.N., 1985, Sedimentology: Hummocky sand deposits generated by storms at sea: Nature, v. 313, no. 6003, p. 533-533, doi: 10.1038/313533b0.

METI, and NASA, 2011, ASTER Global Digital Elevation Map:.

Moore, L.J., List, J.H., Williams, S.J., and Stolper, D., 2010, Complexities in barrier island response to sea level rise: Insights from numerical model experiments, North Carolina Outer Banks: Journal of Geophysical Research, v. 115, no. F3, doi: 10.1029/2009JF001299.

Nicholls, R.J., Birkemeier, W. a., and Hallermeier, R.J., 1996, Application of the Depth of Closure Concept, in Coastal Engineering Proceedings, p. 3874-3887.

Nicholls, R.J., Birkemeier, W. a., and Lee, G., 1998, Evaluation of depth of closure using data from Duck, NC, USA: Marine Geology, v. 148, no. 3-4, p. 179-201, doi: 10.1016/S00253227(98)00011-5.

Nichols, G., 1999, Sedimentology and stratigraphy: Blackwell, Oxford.

Niedoroda, A.W., and Swift, D.J.P., 1991, Shoreface Processes, in Handbook of coastal and ocean engineering, p. 736-769. 
Patterson, D., 2012, Shoreward sand transport outside the surfzone, northern Gold Coast, Australia: Coastal Engineering Proceedings, v. 1, no. 33, doi:

10.9753/icce.v33.sediment.26.

Pelletier, J.D., and Perron, T., 2012, Analytic solution for the morphology of a soil-mantled valley undergoing steady headward growth: Validation using case studies in southeastern Arizona: Journal of Geophysical Research, v. 117, doi: 10.1029/2011JF002281.

Perron, J.T., Dietrich, W.E., and Kirchner, J.W., 2008, Controls on the spacing of first-order valleys: Journal of Geophysical Research, v. 113, no. F4, p. F04016, doi: 10.1029/2007JF000977.

Peters, S.E., and Loss, D.P., 2012, Storm and fair-weather wave base: a relevant distinction? Geology, v. 40, no. 6, doi: 10.1130/G32791.1.

Pilkey, O.H., Cooper, J.A.G., and Lewis, D.A., 2009, Global Distribution and Geomorphology of Fetch-Limited Barrier Islands: Journal of Coastal Research, p. 819-837, doi: doi:10.2112/08-1023.1.

Pritchard, D., Roberts, G.G., White, N.J., and Richardson, C.N., 2009, Uplift histories from river profiles: Geophysical Research Letters, v. 36, no. 24, doi: 10.1029/2009GL040928.

Ranasinghe, R., Duong, T.M., Uhlenbrook, S., Roelvink, D., and Stive, M.J.F., 2012, Climatechange impact assessment for inlet-interrupted coastlines: Nature Climate Change, v. 3, no. 1, p. 83-87, doi: 10.1038/nclimate1664.

Sageman, B.B., 1996, Lowstand tempestites: Depositional model for Cretaceous skeletal limestones, Western Interior basin: Geology, v. 24, no. 10, p. 888-892, doi: 10.1130/00917613(1996)024.

Sherwood, C.R., Long, J.W., Dickhudt, P.J., Dalyander, P.S., Thompson, D.M., and Plant, N.G., 2014, Inundation of a barrier island (Chandeleur Islands, Louisiana, U.S.A.) during a hurricane: Observed water-level gradients and modeled seaward sand transport: JGR: Earth Surface, v. 119, no. 7, doi: 10.1002/2013JF003069.

Soulsby, R.L., 2006, Simplified calculation of wave orbital velocities:.

Stive, M.J.F., Nicholls, R.J., and Vriend, H.J. De, 1991, Sea-level rise and shore nourishment: a discussion: Coastal Engineering, v. 16, no. 1, doi: 10.1016/0378-3839(91)90057-N.

Stive, M.J.F., and de Vriend, H.J., 1995, Modelling shoreface profile evolution: Marine Geology, v. 126, no. 1-4, p. 235-248, doi: 10.1016/0025-3227(95)00080-I.

Stolper, D., T, J.H.L., and Thieler, E.R., 2005, Simulating the evolution of coastal morphology and stratigraphy with a new morphological-behaviour model ( GEOMBEST ): Marine Geology, v. 218, p. 17 -36, doi: 10.1016/j.margeo.2005.02.019. 
Sullivan, T. (USDA F.S., and Lucas, W. (USDA F.S., 2007, Chronic Misapplication of the Relationship between Magnitude and Frequency in Geomorphic Processes, As Illustrated in Fluvial Processes in Geomorphology by Leopold, Wolman and Miller (1964): Advancing the Fundamental Sciences: Proceedings of the Forest Service National Earth Sciences Conference, p. 4-6.

Swenson, J.B., Paola, C., Pratson, L., Voller, V.R., and Murray, A.B., 2005, Fluvial and marine controls on combined subaerial and subaqueous delta progradation: Morphodynamic modeling of compound-clinoform development: Journal of Geophysical Research, v. 110, p. 1-16, doi: 10.1029/2004JF000265.

Swift, D.J.P., Niedoroda, A.W., Vincent, C.E., and Hopkins, T.S., 1985, Barrier island evolution, middle Atlantic shelf, U.S.A. Part I: Shoreface Dynamics: Marine Geology, v. 63, no. 1-4, doi: 10.1016/0025-3227(85)90089-1.

Thieler, E.R., Brill, A.L., Clearly, W.J., Hobbs III, C.H., and Gammisch, R.A., 1995, Geology of the Wrightsville Beach, North Carolina shoreface: implications for the concept of shoreface profile of equilibrium: Marine Geology, v. 126, no. 1-4, p. 271-287, doi: 10.1016/00253227(95)00082-A.

Thieler, E.R., Pilkey, O.H., Clearly, W.J., and Schwab, W.C., 2001, Modern sedimentation on the shoreface and inner continental shelf at wrightsville beach, North Carolina, USA: journal of sedimentary research, v. 71, no. 6, doi: 10.1306/032101710958.

Vermeer, M., and Rahmstorf, S., 2009, Global sea level linked to global temperature: PNAS, v. 2009, no. 9, p. 1-6, doi: 10.1073/pnas.0907765106.

Wallace, D.J., Anderson, J.B., and Fernández, R.A., 2010, Transgressive Ravinement versus Depth of Closure: A Geological Perspective from the Upper Texas Coast: Journal of Coastal Research, v. 26, p. 1057-1067, doi: 10.2112/JCOASTRES-D-10-00034.1.

Wolinsky, M.A., 2009, A unifying framework for shoreline migration : 1 . Multiscale shoreline evolution on sedimentary coasts: Journal of Geophysical Research, v. 114, p. 1-12, doi: $10.1029 / 2007 J F 000855$.

Wolinsky, M.A., and Murray, A.B., 2009, A unifying framework for shoreline migration : 2 . Application to wave-dominated coasts: Journal of Geophysical Research, v. 114, p. 1-13, doi: 10.1029/2007JF000856.

Wolman, M.G., and Gerson, R., 1978, Relative scales of time and effectiveness of climate in watershed geomorphology: Earth Surface Processes, v. 3, p. 189-208, doi: 10.1002/esp.3290030207.

Wolman, M.G., and Miller, J.P., 1960, Magnitude and Frequency of Forces in Geomorphic Processes: Journal of Geology, v. 68, no. 1, p. 54-74. 
Wright, L.D., Boon, J.D., Kim, S.C., and List, J.H., 1991, Modes of cross-shore sediment transport on the shoreface of the Middle Atalantic Bight: Marine Geology, v. 96, doi: $10.1016 / 0025-3227(91) 90200-\mathrm{N}$.

Zenkovitch, V.P., 1946, On the study of shore dynamics: Trans. Inst. Okeanol., Akad. Nauk SSSR, v. 1, p. 99-112.

Zhang, K., Douglas, B.C., and Leatherman, S.P., 2004, Global warming and coastal erosion: Climatic Change, v. 64, no. 1-2, p. 41-58, doi: 10.1023/B:CLIM.0000024690.32682.48. 


\title{
Chapter 3: The Magnitude and Recurrence of Formative Drivers of Alongshore and Cross- shore Coastal Evolution
}

\begin{abstract}
In order to understand the driving timescale of coastal evolution, we calculate the magnitude and recurrence interval of formative wave events, or the effective wave parameters, impacting the alongshore shore evolution and cross-shore shoreface evolution. The frequency of effective wave parameters is used to understand whether the background wave climate or infrequent extreme events are the most important in driving coastal change. Using long-term (32year) hindcasted wave record for forty-three different locations around the US, we investigate which processes are dominant in shaping the coast. Utilizing a long-term wave record allows us to define a mean wave climate based on the unweighted median of frequency of wave heights. We apply frequency-magnitude analysis to compute the effective wave parameters that drive long-term sediment transport in both the along- and cross-shore direction. We find that alongshore shoreline evolution scales with the mean wave climate, whereas the tails of the distribution (extreme events) dominate cross-shore evolution. Furthermore, calculating the recurrence intervals of the representative wave parameters, we find that the alongshore characteristic wave conditions are exceeded on monthly timescales (at temporal scales similar to the autocovariance of the wave signal itself). On the other hand, the cross-shore effective wave values recur on multi-annual (4-9 years) timescales, further suggesting that cross-shore evolution is controlled by storm events. Because the alongshore shoreline evolution scales with the mean wave climate, we are able to predict the frequency and magnitude of the formative wave event for alongshore change. In the cross-shore direction, we find a strong link between a bimodal distribution of weighted wave heights and the prevalence of tropical storms.
\end{abstract}




\section{$1 \quad$ Introduction}

Waves transport sediment onshore, offshore, and alongshore in the coastal environment. Although waves are not the only mechanisms for shoreface and shoreline evolution, they are the primary control on long-term sediment transport and geomorphic evolution. Wave conditions are constantly changing along the coast, and extreme storm events result in drastic increases in wave height and sediment mobility. Do storms dominate alongshore sediment transport? How does the recurrence of formative events vary between shoreline (alongshore) or shoreface (cross-shore) change? More importantly, when modeling or predicting the response of coastal systems to changing climate, should extreme events be considered or does the background wave climate dominate the system?

Given the importance of waves on the long-term evolution of coastal environments, here we apply frequency and magnitude analysis to understand the fundamental question of whether extreme events like hurricanes or nor'easters or the background wave climate do the most work in shaping the coast.

\section{Background}

Extreme events, like hurricanes, can transport large amounts of sediment in both the cross-shore and alongshore, more than one order of magnitude larger than is transported by mean wave conditions. Many therefore hypothesize that extreme events are the main drivers in coastal evolution due to the amount of sediment that is mobilized (Holman and Stanley, 2007). While large storm events move significant amounts of sediment on the shoreface and shoreline (Holman and Stanley, 2007; Davis and Fox, 1975; Thom and Hall, 1991), frequently the fairweather or background wave climate restores the shoreface and shoreline to pre-storm conditions (List et al., 2006; Fucella and Dolan; Tebbens et al., 2002). Recently, Peters and Loss (2012), analyzing wave buoy data, suggested that modern open ocean wave distributions may not clearly distinguish between fair-weather and storm conditions, questioning the fair versus storm wave distinction often applied to sedimentary records. Their analysis, however, focused on wave height distributions whereas sediment transport processes typically scale nonlinearly with wave height (i.e. with wave height to an exponent larger than 1).

Our question is which process is more important in shaping the evolution of the shoreface and shoreline. By analyzing storm-driven versus decadal shoreline change along the North 
Carolina coast, Lazarus et al. (2012) suggests that while storms may reshape the shoreline in the short-term, long-term shoreline evolution is controlled by the background wave climate. Gunawardena (2008), when studying 22 years of field-collected beach profiles from Duck, NC, emphasizes importance of looking at cross-shore and alongshore evolution differently, as the timescales that operate on the cross-shore and alongshore range from monthly to annual.

In the shoreface, there can be limited evidence of geometry that is scale independent (Gunawardena et al., 2008; Li et al., 2005; Southgate and Möller, 2000), but further offshore dominant timescales may determine the profile evolution. Southgate and Möller (2000) find that the scale-independent behavior of the cross-shore is weak and is only strong where the temporal variation of wave forcing is relatively weak, implying that the crossshore may have a strong temporal or spatial dependence. Li et al. (2005) find that there is a strong pattern of intermittency to cross-shore signal possibly implying the importance of extreme events in shaping the shoreface rather than a time-invariant process. Using singular spectrum analysis on 16 years of beach surveys, Rozynski et al. (2001) found a correlation of shoreline position with average wave conditions for decadal timescales arguing that the beach at Lubiatowo, Poland has selforganizing behavior. Shoreline change has been shown to exhibit power law behavior (Tebbens et al., 2002; Lazarus et al., 2011) and to possibly be temporally independent. Power law behavior is typically taken to mean that a quantity is scale independent, reflecting the dominance of a single dynamic process (Murray, 2007). Lazarus et al. (2011), by investigating the long-term variance of shoreline change for the Outer Banks of North Carolina, argue that shorelines evolve by accumulation of change over time as might be demonstrated by a power law rather than being dominated by changes at small spatial scales.

A distinction is often made between fair-weather and storm-wave base in the sedimentological record. The fair-weather wave base is defined as the depth at which the background wave climate interacts with the bed, and is associated with a change of sedimentary structures from wave ripples and dunes to hummocky cross-stratification (Dott, R. H. and Bourgeois, 1982; Duke, 1985; McCave, 1985). The depth at which typical storm waves interact with the bed is thought to define the storm wave base, a transition that is also associated with a change in bed sedimentology from hummocky cross-stratification to mostly muddy or silty sediments (Sageman, 1996). 
Debate exists over changes in storm frequency over the past century for both tropical and extratropical (also called nor'easters in the Eastern US) storms. Davis et al. (1993) find an increase in frequency of winter storms (extratropical) from 1965-1984 for the Atlantic coast and in particular an increase in the frequency of the most severe storms from the 1950's to 1980s. However, Hirsch et al. (2001) found no significant trends in the frequency of storms from the 1950 s to the 1990 s when looking directly at storm category rather than using wave height as a proxy (Davis et al., 1993; Mather et al., 1964). Keim et al. (2004) finds that in general there has been little change or possibly a slight downward trend of extratropical storms in the North Atlantic Basin overall, but an increase in frequency of the extreme storms at the same time. However, recent analysis by Komar and Allan (2008) suggest an increase in large waves during summer months (possibly linked with tropical cyclones) over the last 30 years for the East Atlantic coast of the US. In addition to a change in magnitude of waves along the US East Atlantic coast, there has been an increase in the asymmetry of the direction of waves (Johnson et al., 2015; Moore et al., 2013) leading to a shift in the coastline erosion and accretion locations of the Outer Banks.

Climate change models vary on their prediction of future frequency and intensity of tropical cyclones and other extreme events (IPCC, 2007; Knutson et al., 2010; Emanuel, 2005). It appears that most models, however, predict an increase in the intensity of tropical cyclones, a shift in the magnitude of storms to more intense events, overall there will be increased tropical cyclone activity. This could impact coastal evolution significantly, particularly if the shoreface or shoreline evolution is driven by extreme events.

\subsection{Sediment Transport}

Understanding the long-term effects of processes on coastal change is the underpinning of coastal geomorphology. Basic sediment transport relationships provide a means to parameterize the potential geomorphic work in different domains. Alongshore sediment transport, $q_{s l}$, typically scales with wave energy density $\left(H^{2}\right)$ or wave energy flux at breaking $\left(H^{5 / 2}\right)$, where $H$ is wave height. Recasting the common Coastal Engineering Research Center (CERC) equation to deep-water wave heights, Ashton and Murray (2006a) derive a dependence of $q_{s l}$ on $H^{12 / 5}$ (see Supplemental Information). This scaling is within the range of other equations 
describing the alongshore sediment transport such as those of Kamphius (1991) or Bailard (1984) (Ashton and Murray, 2006b).

In the cross-shore direction, waves transport sediment through a combination of orbital bed agitation and net onshore motion driven by processes such as wave asymmetry and bed streaming, offset by offshore downslope gravitational transport. There are many possible approaches to describe the shoreface sediment flux, including an energetics-based approach (Bowen, 1980; Bailard and Inman, 1981; Swenson et al., 2005) or by considering bed shear stress (Madsen, 1991). Using an energetics-based cross-shore sediment transport formulation, the suspended sediment flux, $q_{s x}$, depends on $H^{5}$ (see Supplemental Information). In Chapter 2, we similarly suggest that the timescale over which a sandy, wave-dominated shoreface evolves, and correspondingly the morphodynamic depth of closure, can be described by a diffusivity timescale, $T_{\text {diff, }}$, that also has a dependence on wave height to the fifth power (see Supplemental Information).

For both alongshore and cross-shore transport, the transport potential scales with an exponent larger than unity, with alongshore sediment transport scaling slightly larger than wave energy density $\left(H^{2}\right)$ and cross-shore transport exhibiting an even stronger scaling. If exceedence of bottom shear stress were used instead of an energetics-based equation, sediment transport in the cross-shore direction (an $H^{3}$ scaling with wave height) would still be larger than the alongshore dependence. Similar to Stive and deVriend (1995), we weight the wave heights by a power that is representative of sediment transport rather than Aagaard and Sorenson (2012) who weight wave heights by wave energy $\left(H s^{2}\right)$. These strong scaling relationships lead us to investigate whether the frequency and magnitude of the effective wave conditions reflects the scaling relationships.

\section{$3 \quad$ Methods}

Frequency and magnitude analysis is a long-standing and well-known tool in geomorphology which characterizes the relative rate of work done on a landscape by specific events (Brunsden and Thornes, 1979; Sullivan and Lucas, 2007; Wolman and Gerson, 1978; Wolman and Miller, 1960); in this case, how much sediment is transported by waves of a given height and wave period. Wolman and Miller (1960) use this analysis to calculate the characteristic flood event for rivers and investigate the development of an equilibrium beach 
profile based on wave steepness (the ratio of wave height to wave length). They argue that the cross-shore equilibrium beach profile should be determined by moderately strong winds producing storm waves, not the background wind (and wave) climate but not the extreme (very severe) waves either. Using a similar approach, we weight the frequency of the wave height and wave period by the amount of potential sediment transported in both the cross-shore and alongshore direction.

The Wave Information Studies (WIS) crafted a database of hindcasted virtual wave buoys around the US based on wind data (Jensen, 2010). The virtual WIS buoys contain 32 years of hourly wave data and enable a high resolution, long-duration dataset. From this dataset, fortythree different locations were chosen with varying wave climates. In particular, we highlight four sites that best illustrate different trends in the data. There are three locations on the passive margin of the Atlantic Ocean: Martha's Vineyard, MA (MV), North Cape, NC (NC), and Onslow Bay, NC (OB). The mouth of the Columbia River, WA (CR) is on the active Cascadia margin of the Pacific Ocean. We chose a larger number of sites for a sampling of diverse wave climates: there are a total of 20 sites along the Eastern US Atlantic Coast, 12 sites in the Gulf of Mexico, and 11 sites along the Western US Pacific coast (Figure 1).

For each of the forty-three sites, the data from several WIS buoys are analyzed to calculate the morphodynamically characteristic wave height and wave period. Averaging $H_{s}$ over the entire database allows us to define the "mean" wave height. We calculate a weighted histogram of the significant wave height to twelve-fifths and the fifth power for each buoy and then calculate the median of each of these histograms, labeled as $H_{L}$ and $H_{x}$ respectively. We then average all the $H_{x}$ and $H_{L}$ associated with a given site to find the characteristic morphodynamic wave conditions for each site.

We then calculate the recurrence intervals for the morphodynamically significant waves. Hourly wave events are typically not independent over shorter time periods like hours to days. To determine event independence, we calculate temporal lags and define the autocovariance timescale as the first minima below an autocovariance of 0.25 (See Supplemental Information). For the majority of the sites, the autocovariance timescale is 10 days or less, except for the West Coast sites that have an average autocovariance timescale of 19 days with several locations showing a longer autocovariance timescale of 30 days. To calculate the recurrence interval or return period for given characteristic wave parameters, we use the peak wave events over time 
lengths longer than this autocovariance temporal scale (using 30 day spans) such that wave events are independent.

\section{Results}

As the morphodynamic weighting of wave heights increases, the patterns of the histograms change, as does characteristic wave height $\left(H_{L}\right.$ and $\left.H_{x}\right)$. The magnitude of the characteristic wave parameters (wave height and wave period) calculated for the cross-shore direction is always larger than the values for the characteristic wave height in the alongshore orientation (Figure 2). Weighting wave heights to the fifth power accentuates the importance of extreme wave events in a record, and emphasizes the tail of the distribution (Figure 2)

Distributions of both the mean wave height and alongshore-scaled wave height are welldefined and unimodal. Similarly, for cross-shore scaling, the Columbia River, Lake Erie, Duck Pier, and Martha's Vineyard show a unimodal wave height distribution (Figure 2 e, f, b, and a). However, both Santa Rosa and Onslow Bay have a bimodal wave distribution for the cross-shore direction implying the importance of both extreme events (Figure $2 \mathrm{~d} \& \mathrm{c}$ ). In particular, both Santa Rosa has the largest difference between the two different effective wave heights for the alongshore and cross-shore, implying a very low magnitude of background wave climate.

Across the entire database, there is a strong linear correlation between the mean wave parameters and the alongshore characteristic wave parameters, yielding the empirical relationship $H_{L}=(1.22 \pm 0.04) H_{m}+(0.38 \pm 0.07)$ for the effective alongshore wave height and $T_{L}=(0.98 \pm 0.02) T_{m}+(0.7 \pm 0.1)$ for the effective alongshore wave period, where the mean wave height $\left(H_{m}\right)$ and mean wave period $\left(T_{m}\right)$ are calculated from the median of the unweighted histogram (Figure 3). The alongshore direction scales linearly with the mean wave climate. However, for cross-shore evolution, the mean wave climate is not a good predictor of the morphodynamically effective wave.

There is a geographic grouping of the characteristic wave parameters for both the wave height and wave period in both the cross-shore and alongshore directions (Figure 3). The effective cross-shore and alongshore wave period increases moving into larger basins (from the Gulf of Mexico to the Atlantic to the Pacific Ocean). This same relationship is also true for the effective wave heights. The largest variation in effective cross-shore wave heights is in the Gulf Coast sites, where effective wave heights range from $1.5 \mathrm{~m}$ to $7.5 \mathrm{~m}$ (Figure 3). This variance 
between the effective cross-shore wave height $\left(H_{X}\right)$ and the mean wave height $\left(H_{m}\right)$ is due to the very low background wave heights compared to the larger storm wave heights within this basin.

Looking at the recurrence intervals, the alongshore-effective wave conditions occur frequently, on the order of the autocovariance scale of the data itself (Table 1). In the crossshore, the larger effective wave events have a much longer recurrence interval, typically between 4-9 years, while the alongshore recurrence interval recurs on a much shorter time-scale (1-3 months) similar to the background wave climate. These general results are similar to results by Różyński et al. (2001) who suggested that shoreface and shoreline change on the Baltic Sea is on 9 and 30 year cycles, which they argue is due to storm events.

\section{Discussion}

There are several clear trends in the data that correspond to large scale differences in the cross-shore and alongshore evolution timescales. The Gulf of Mexico has the smallest $H_{L}$ and the Pacific Ocean (the largest basin) has the largest $H_{L}$. Overall, even as the alongshore effective wave height (and the mean wave height) varies for each basin (Figure 3a), the recurrence interval for the alongshore effective wave height is similar for each basin and is on the order of the autocovariance timescale, 1-3 months (Supplemental Table). This suggests that effective alongshore sediment transport events occur many times per year and intense storms do not dominate alongshore sediment fluxes. Shoreline change due to alongshore sediment transport gradients therefore can be well approximated as a continuous long-term process. As a consequence, short-term processes tend to be smoothed out of the shoreline.

There is a clear north-south trend in the percentage of large waves that occur in the winter vs. the summer (a proxy for extratropical storms, locally called nor'easters, vs. hurricanes or other tropical storms) (Figure 4). Moving south along the East Coast, there is an increasing amount of large wave events that occur due to hurricanes during the summer. The alongshore effective wave height parallels the cross-shore effective wave height for all the sites. We see that the Duck Pier histogram for the cross-shore direction is more similar to Martha's Vineyard than Onslow Bay (a much closer location) with a smooth more unimodal histogram. Both Onslow Bay and Santa Rosa have a bimodal distribution in the cross-shore histogram and see a much larger percentage of large waves occurring in the summer ( $75 \%$ and $90 \%$ respectively), during 
hurricane season. This result suggests that hurricanes produce a secondary peak in the histogram while nor'easters do not have such a strong signal.

Previous work has also shown the importance of the background wave climate in shaping the alongshore coastline evolution. List and Farris (1999) and List et al. (2006) found that stormdriven shoreline changes often cancel out over a period of weeks. Lazarus et al. (2011) see that shoreline evolution consists of accumulation over less than a decade of change. Together, these suggest that the background wave climate is perhaps the most important in shaping in the alongshore coastline rather than extreme events. If shoreline evolution were determined by the decadal storm, the constant accumulation of shoreline smoothing would not be seen. Lazarus et al. (2012) find that the diffusive smoothing is key to alongshore shoreline evolution. This implies the importance of the mean climate in the alongshore direction as extreme events might tend to exagerate the coastline rather than smooth it. Both Tebbens et al. (2002) and Lazarus et al. (2011) find that an apparent power law describes shoreline change in the alongshore direction implying a scale-independent process, possibly diffusion, that is not episodic.

The cross-shore recurrence intervals for all basins are extremely similar, though the Gulf has possibly the largest recurrence intervals (Supplemental Information Table). These similar recurrence intervals imply that the Gulf sites are not experiencing longer times between storms but rather that within this enclosed basin the difference between the background and storm wave climate is large. In the cross-shore, the recurrence intervals for effective wave height are much larger than the alongshore effective recurrence intervals and are on the order of 6-7 years. The Gulf of Mexico, however, has a longer recurrence interval for the cross-shore (average of 9 years for the basin) but locations with quite large cross-shore effective wave heights (Santa Rosa, SR, or Southern Texas, TXS as listed in the Supplemental Information Table) implying that infrequent intense storms are important in the Gulf.

Santa Rosa has the longest recurrence interval for the cross-shore wave height implying that the extreme events, like hurricanes, recur infrequently but very large cross-shore effective wave heights (Table 1). On the other hand, Martha's Vineyard has the shortest recurrence interval for the cross-shore effective wave implying large waves originate from frequent large storms such as nor'easters. Onslow Bay, which also has a large cross-shore wave height, has a longer recurrence interval, suggesting that the storm events impacting Onslow Bay are more 
infrequent such as hurricanes instead of Martha's Vineyard where both hurricanes and nor'easters as may be impacting the recurrence interval.

The return intervals and patterns of effective cross-shore transport wave occurrence have several potential implications in terms of shoreface dynamics and the definition of different effective "wave bases." For some examples (Martha's Vineyard and Duck Pier), weighting leads to broad and, in some cases, bimodal populations (Onslow Bay and Santa Rosa) of effective wave events, which would be suggestive of a clear distinction between storm and fair-weather wave base. However, even for more evenly distributed wave distributions, the long (4-9 year) intervals between effective cross-shore events suggests a dominance of storms in affecting shoreface evolution. Between storm events, background wave conditions would be expected to affect upper portions of the shoreface, and these conditions could define a shoreface whose short-term evolution is dominated by the background wave conditions. We argue that the distinct storm wave base seen in some sites may be due to the frequency of extra-tropical storms hitting the sites.

\section{Conclusions}

Appropriate scaling of the morphodynamic effective wave parameters and the timescales over which they occur is extremely important for accurate forecasting and modeling of both cross-shore and alongshore coastal evolution. Our analysis has shown that there can be a significant difference in the characteristic wave parameters for the cross-shore and alongshore coastal evolution. In particular, alongshore coastline evolution scales with the mean wave climate whereas storm events or extreme events are most important for the cross-shore coastal evolution. Different ocean basins significantly change the effective wave heights in both the alongshore and cross-shore direction. Weighted histograms of wave height illustrate the importance of different storm climates, such as at Martha's Vineyard or Santa Rosa, and the impact on the effective cross-shore wave heights.

\section{$7 \quad$ Acknowledgements}

This material is based upon work supported by the National Science Foundation under grant CNH-0815875 and the Strategic Environment Research and Development Program. Any 
opinions, findings, and conclusions or recommendations expressed in this material are those of the authors and do not necessarily reflect the views of the National Science Foundation. 


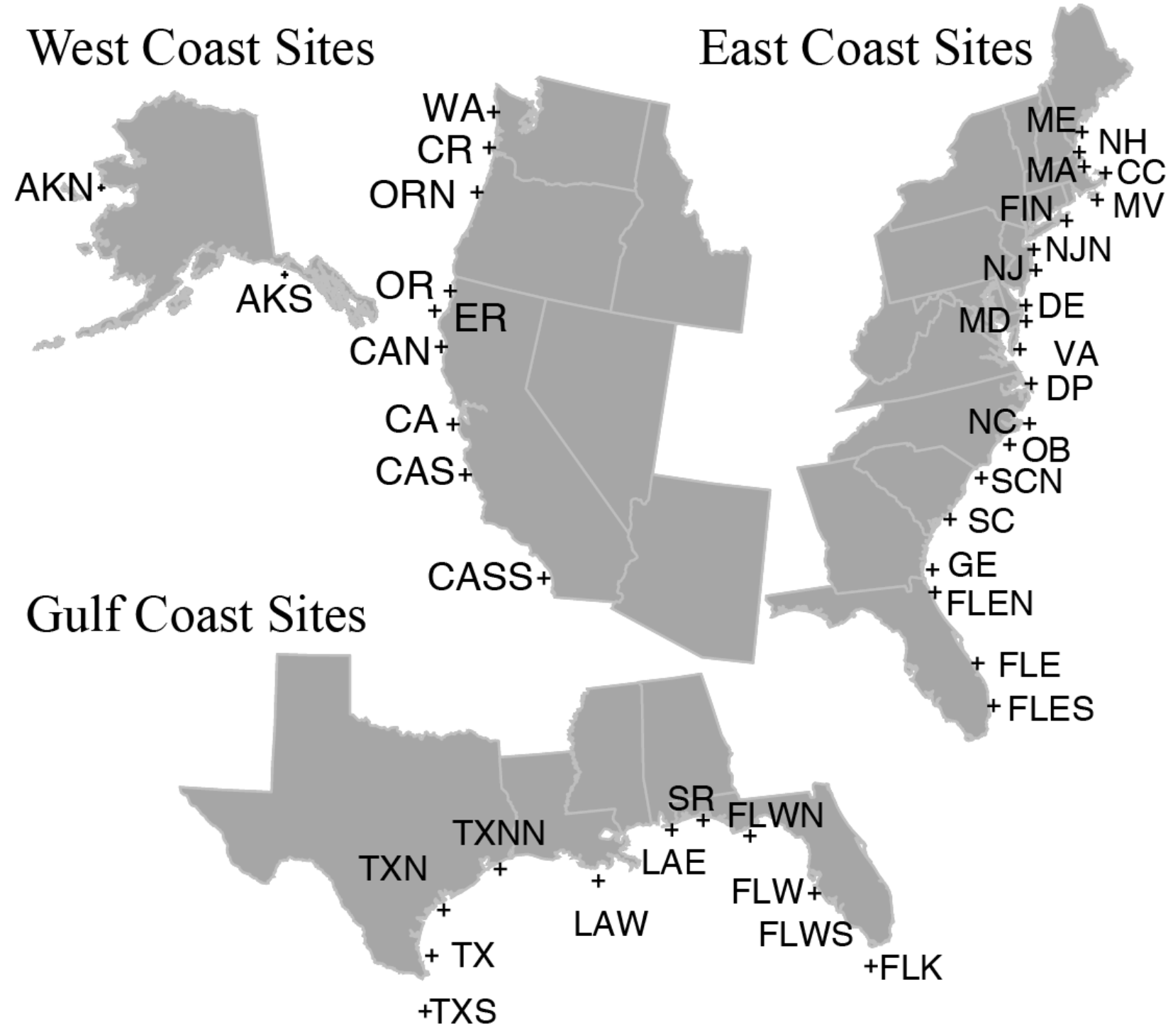

Figure 1. Map of 42 data locations around US, separated into 3 groups of East coast sites, West coast sites, and Gulf coast sites and WIS buoy locations denoted by black cross. 
A) Martha's Vineyard, MA

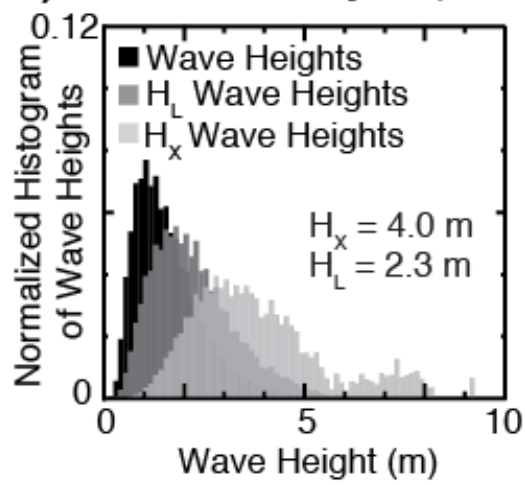

D) Santa Rosa, FL

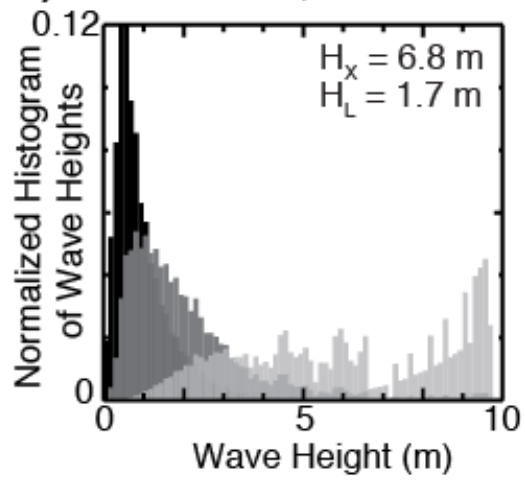

B) Duck Pier, NC

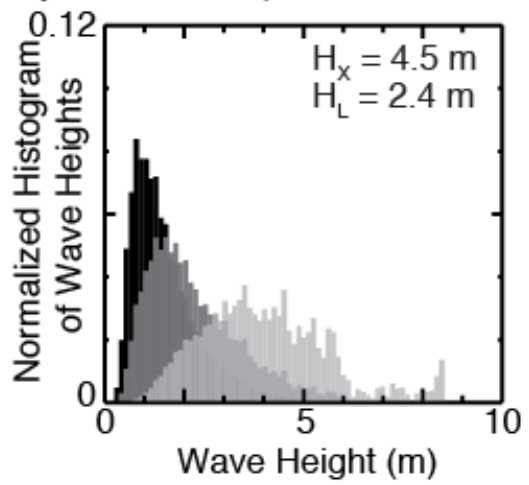

E) Columbia River, WA

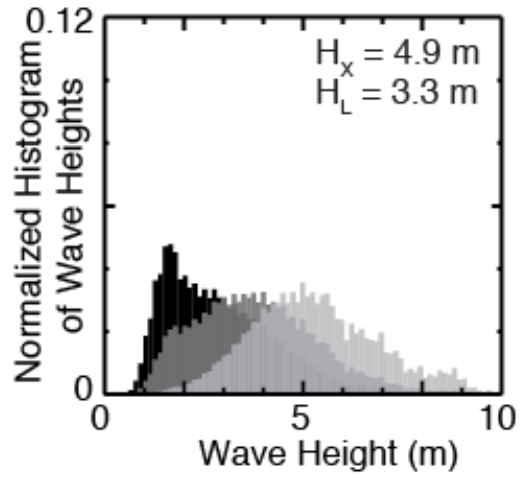

C) Onslow Bay, NC

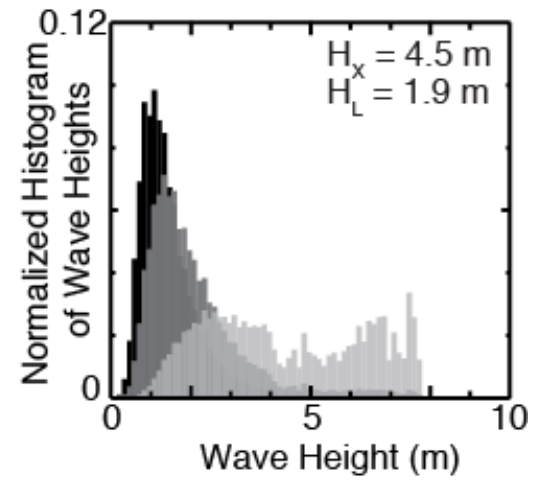

F) Lake Erie, PA

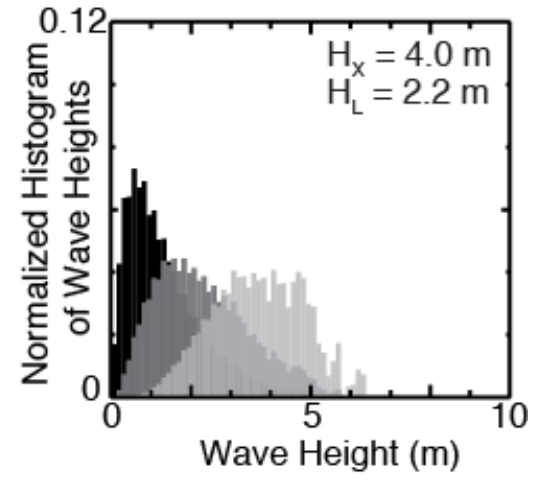

Figure 2. Weighted histogram of wave heights using cross-shore weighting (light gray, $H_{x}=H s^{5}$ ) and alongshore weighting (dark gray, $H_{L}=H s^{12 / 5}$ ) for six buoy locations with unweighted, mean, histogram of wave heights (black, $H_{m}$ ). 

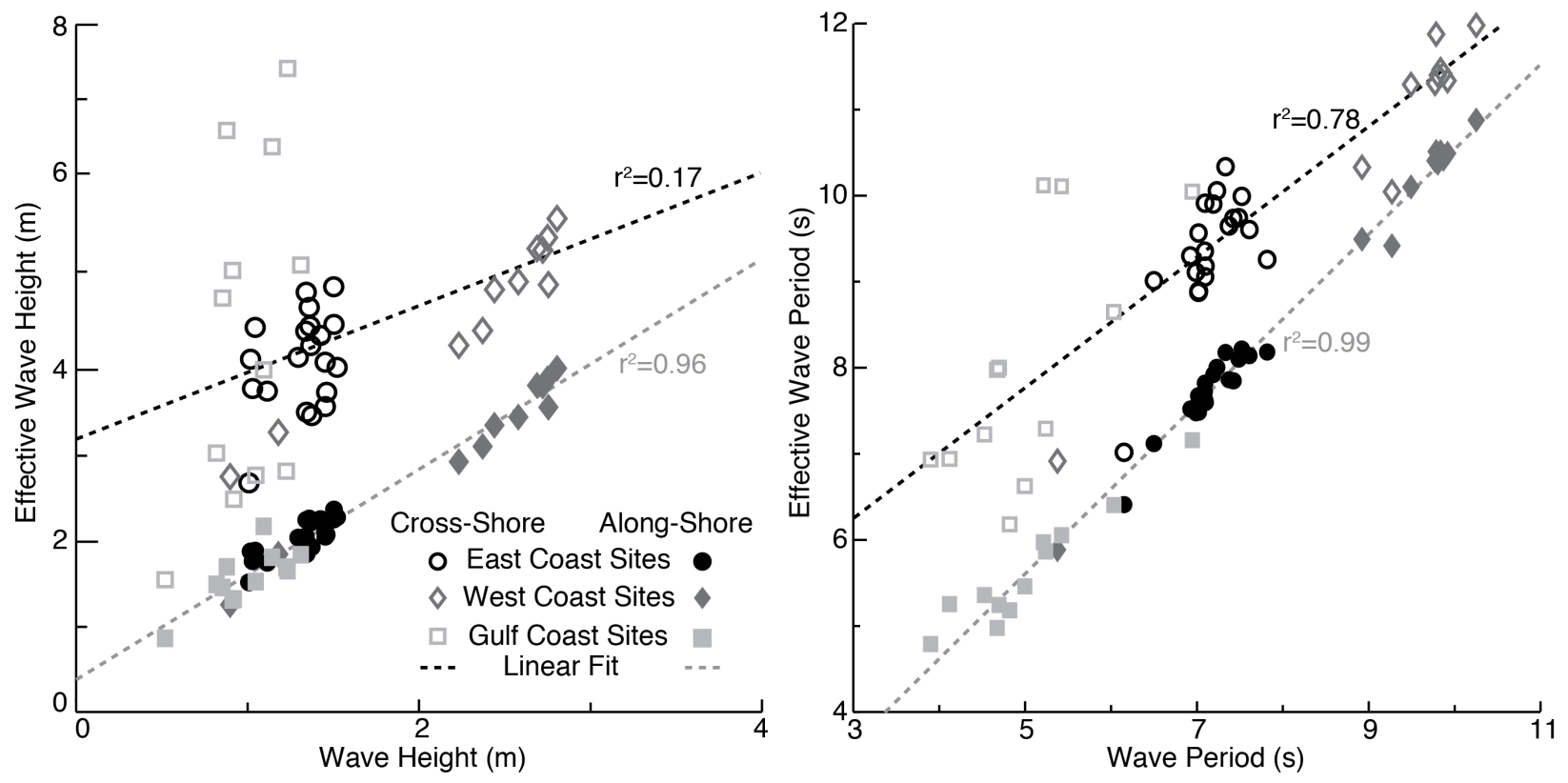

Figure 3. Effective wave parameters versus mean wave parameters for both alongshore and cross-shore sediment transport for 42 different locations. 


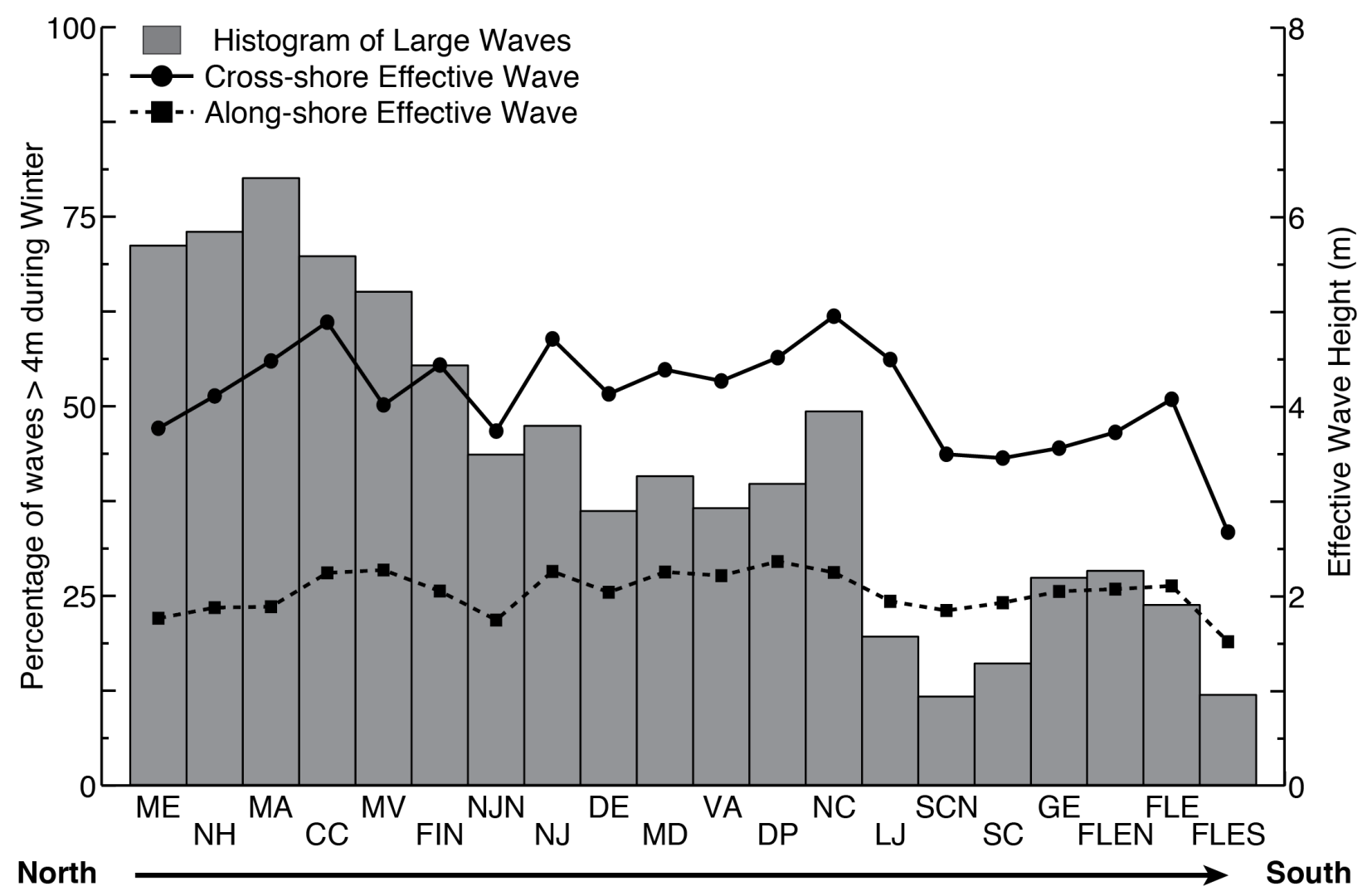

Figure 4. Histogram of percent of large waves that occur during winter months along East coast ordered from north to south (left y-axis). Plotted cross-shore effective wave height (solid black line) and alongshore effective wave height (dashed black line) (right y-axis). 
Table 1. Estimated recurrence intervals with varying frequency of peak events

\begin{tabular}{cccccc}
\hline \hline & \multicolumn{2}{c}{ Effective Wave Height (m) } & $\begin{array}{c}\text { Recurrence } \\
\text { Site }\end{array}$ & Rerval & $\begin{array}{c}\text { Recurrence } \\
\text { Interval }\end{array}$ \\
& Mean & $\begin{array}{c}\text { Along } \\
\text { shore }\end{array}$ & $\begin{array}{c}\text { Cross- } \\
\text { shore }\end{array}$ & $\begin{array}{c}\text { Alongshore } \\
\text { (days) }\end{array}$ & $\begin{array}{c}\text { Cross-shore } \\
\text { (days) }\end{array}$ \\
\hline Martha's Vineyard, MA & 1.5 & 2.3 & 4.0 & 50 & 1880 \\
Santa Rosa Island, FL & 0.9 & 1.5 & 4.8 & 50 & 3390 \\
Duck Pier, NC & 1.5 & 2.4 & 4.5 & 60 & 2730 \\
Onslow Bay, NC & 1.4 & 1.9 & 4.5 & 50 & 2920 \\
Columbia River, WA & 2.4 & 3.3 & 4.9 & 40 & 2460 \\
Lake Erie, PA & 1.1 & 2.2 & 4.0 & 80 & 2800 \\
\hline \hline
\end{tabular}

\section{Supplemental Information}

\subsection{Sediment Transport Equations}

We use the CERC equation for alongshore sediment transport (Komar, 1971; U S Army Corps Of Engineers, 2002) transformed by Ashton and Murray (2006a) for deep-water wave heights:

$$
q_{s l}=\mathrm{K}_{2} \mathrm{H}_{0}^{\frac{12}{5}} \mathrm{~T}^{\frac{1}{5}} \cos ^{\frac{6}{5}}\left(\phi_{0}-\theta\right) \sin \left(\phi_{0}-\theta\right)
$$

where $K_{2}$ is a constant, $H_{0}$ is the deep water wave height, $T$ is the wave period, $\phi_{0}$ is the deep water wave angle, and $\theta$ is the shoreline angle.

For the cross-shore, we choose an energetics-based cross-shore sediment transport equation,

$q_{s x}=-\mathrm{K} \frac{\pi^{3} \mathrm{H}^{3}}{\mathrm{~T}^{3} \mathrm{w}_{s} \sinh ^{3}(\mathrm{kz})}\left[\frac{15 \pi^{2} \mathrm{H}^{2}}{4 \mathrm{TL} \sinh ^{2}(\mathrm{kz})}+\frac{9 \pi^{2} \mathrm{H}^{2}}{4 \mathrm{TLsinh}{ }^{4}(\mathrm{kz})}+\frac{\pi^{2} \mathrm{H}^{2} \beta}{w_{s} \mathrm{~T}^{2} \sinh ^{2}(\mathrm{kz})}\right]($ Chapter 2$)$ 
with the coefficient $K$, where $e_{S}$ is the suspended sediment transport efficiency factor $(0.01), C_{s}$ is a bed friction factor $(0.01), \rho$ is the seawater density $\left(1.04 \mathrm{~g} / \mathrm{cm}^{3}\right), \rho_{s}$ is the sediment density (assumed to be quartz, $\left.2.65 \mathrm{~g} / \mathrm{cm}^{3}\right), g$ is acceleration by gravity $\left(9.81 \mathrm{~m} / \mathrm{s}^{2}\right), \beta$ is the local bed slope, $w_{s}$ is the sediment fall velocity $(\mathrm{m} / \mathrm{s}), H$ is the local wave height $(\mathrm{m}), T$ is the wave period $(\mathrm{s}), k$ is the wave number $\left(\mathrm{m}^{-1}\right), L$ is the wavelength $(\mathrm{m})$ (Longuet-Higgins, 1957), and $z$ is the local water depth $(\mathrm{m})$.

\subsection{Additional Results}

Figure S1 shows a list of all the locations and the abbreviations used. It also includes crosses indicating the location of all of the WIS buoys used in the analysis for each site. Figure S2 shows a sample autocovariance plot, demonstrating the strong initial drop in covariance for the Duck Pier location (Figure S2). 


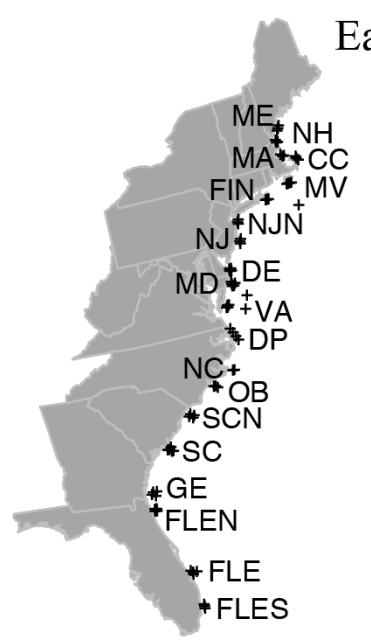

\section{East Coast Sites}

Maine (ME)

New Hampshire (NH)

Massachusetts (MA)

Cape Cod (CC)

Martha's Vineyard (MV)

Fire Island North (FIN)

New Jersey North (NJN)

New Jersey (NJ)

Deleware (DE)

Maryland (MD)

Virgina (VA)

Duck Pier (DP)

North Carolina (NC)

Onslow Bay (OB)

South Carolina North (SCN)

SouthCarolina (SC)

Georgia (GE)

Florida East North (FLEN)

Florida East (FLE)

Florida East South (FLES)

\section{West Coast Sites}

Alaksa North (AKN)

Alaska South (AKS)

Washington (WA)

Columbia River (CR)

Oregon North (ORN)

Oregon (OR)

Eel River (ER)

California North (CAN)

California (CA)

California South (CAS)

California South South (CASS)

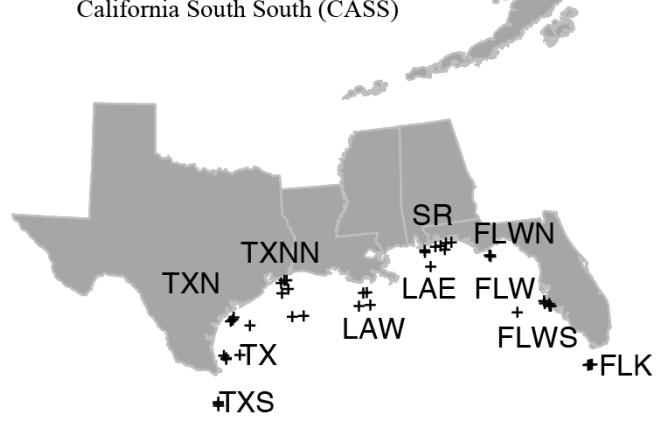

Gulf Coast Sites

Florida Keys (FLK)

Florida West South (FLWS)

Florida West (FLW)

Florida West North (FLWN)

Santa Rosa Island (SR)

Louisiana East (LAE)

Louisiana West (LAW)

Texas North North (TXNN)

Texas North (TXN)

Texas (TX)

Texas South (TXS)

Figure S1. Map of 42 data locations around US, separated into 3 groups of East coast sites, West coast sites, and Gulf coast sites with abbreviations and all WIS buoy locations used denoted by black cross. 


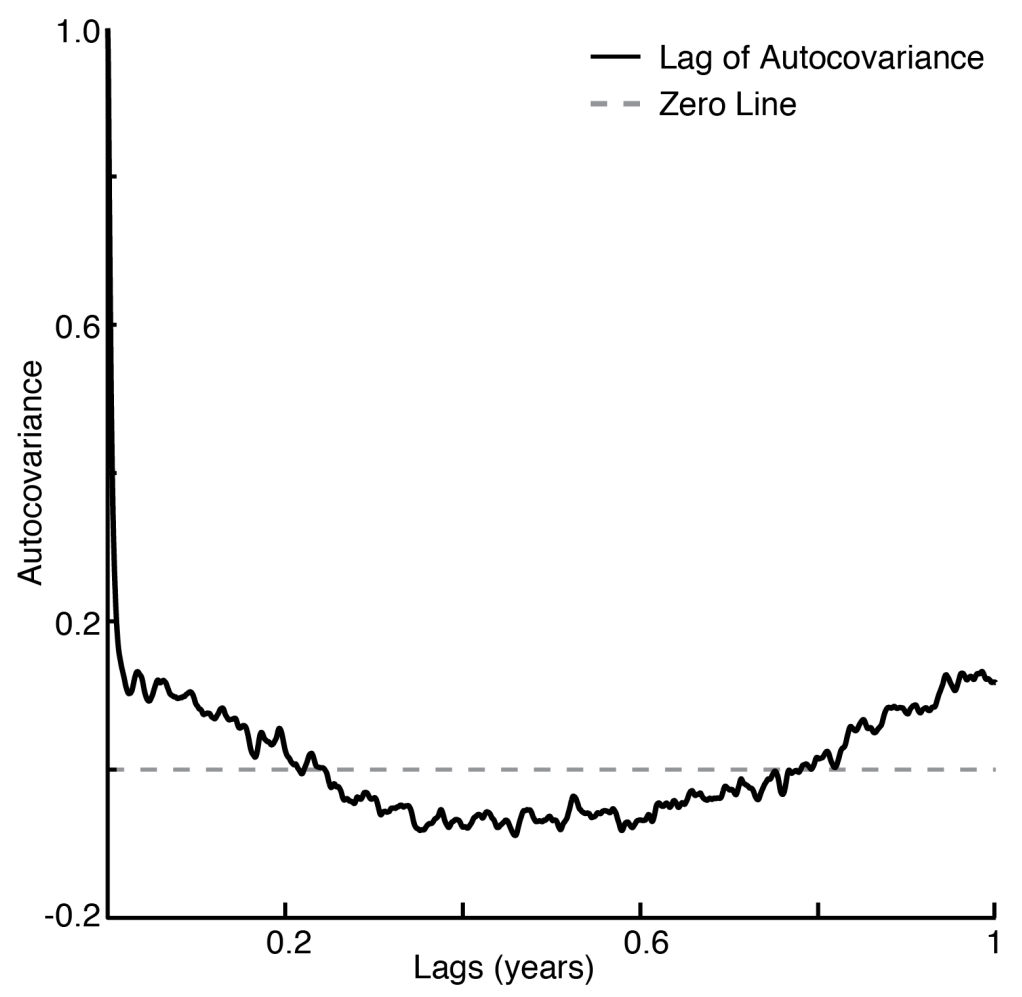

Figure S2. Autocovariance of wave height for 31 years of hindcasted wave data at Duck Pier. 


\begin{tabular}{|c|c|c|c|c|c|c|}
\hline \multirow{2}{*}{ Basin } & \multirow{2}{*}{ Site } & \multicolumn{3}{|c|}{ Effective Wave Height (m) } & \multirow{2}{*}{$\begin{array}{c}\text { Recurrence Interval } \\
\text { Alongshore (days) }\end{array}$} & \multirow{2}{*}{$\begin{array}{l}\text { Recurrence Interval } \\
\text { Cross-shore (days) }\end{array}$} \\
\hline & & Mean & Alongshore & Cross-shore & & \\
\hline \multirow{20}{*}{$\begin{array}{l}\text { East } \\
\text { Coast }\end{array}$} & ME & 1.0 & 1.8 & 3.8 & 60 & 1990 \\
\hline & $\mathrm{NH}$ & 1.0 & 1.9 & 4.1 & 60 & 2080 \\
\hline & MA & 1.0 & 1.9 & 4.5 & 60 & 2870 \\
\hline & $\mathrm{CC}$ & 1.3 & 2.2 & 4.9 & 60 & 2740 \\
\hline & MV & 1.5 & 2.3 & 4.0 & 50 & 1880 \\
\hline & FIN & 1.3 & 2.0 & 4.4 & 50 & 2690 \\
\hline & NJN & 1.1 & 1.7 & 3.7 & 50 & 2700 \\
\hline & NJ & 1.4 & 2.3 & 4.7 & 60 & 2060 \\
\hline & $\mathrm{DE}$ & 1.3 & 2.0 & 4.1 & 60 & 2760 \\
\hline & MD & 1.4 & 2.3 & 4.4 & 60 & 2010 \\
\hline & VA & 1.4 & 2.2 & 4.3 & 70 & 2740 \\
\hline & $\mathrm{DP}$ & 1.5 & 2.4 & 4.5 & 80 & 2880 \\
\hline & $\mathrm{NC}$ & 1.5 & 2.2 & 5.0 & 60 & 2790 \\
\hline & OB & 1.4 & 1.9 & 4.5 & 70 & 3080 \\
\hline & $\mathrm{SCN}$ & 1.3 & 1.8 & 3.5 & 50 & 2760 \\
\hline & $\mathrm{SC}$ & 1.4 & 1.9 & 3.5 & 60 & 2010 \\
\hline & GE & 1.5 & 2.0 & 3.6 & 60 & 1990 \\
\hline & FLEN & 1.5 & 2.1 & 3.7 & 60 & 2730 \\
\hline & FLE & 1.5 & 2.1 & 4.1 & 60 & 2120 \\
\hline & FLES & 1.0 & 1.5 & 2.7 & 60 & 2680 \\
\hline \multicolumn{2}{|c|}{ Average } & 1.3 & 2.0 & 4.1 & 60 & 2500 \\
\hline \multirow{11}{*}{$\begin{array}{l}\text { West } \\
\text { Coast }\end{array}$} & $\mathrm{AKN}$ & 0.9 & 1.3 & 2.7 & 50 & 2770 \\
\hline & $\mathrm{AKS}$ & 2.4 & 3.1 & 4.4 & 50 & 2590 \\
\hline & WA & 2.2 & 2.9 & 4.3 & 50 & 2690 \\
\hline & $\mathrm{CR}$ & 2.4 & 3.3 & 4.9 & 60 & 2600 \\
\hline & ORN & 2.8 & 3.6 & 5.0 & 60 & 2700 \\
\hline & OR & 2.6 & 3.4 & 5.0 & 60 & 1900 \\
\hline & ER & 2.7 & 3.8 & 5.4 & 60 & 2680 \\
\hline & CAN & 2.7 & 3.8 & 5.4 & 70 & 2970 \\
\hline & $\mathrm{CA}$ & 2.8 & 4.0 & 5.7 & 60 & 2250 \\
\hline & CAS & 2.8 & 3.9 & 5.5 & 60 & 2590 \\
\hline & CASS & 1.2 & 1.8 & 3.3 & 60 & 2630 \\
\hline \multicolumn{2}{|c|}{ Average } & 2.3 & 3.2 & 4.7 & 58 & 2600 \\
\hline \multirow{12}{*}{$\begin{array}{l}\text { Gulf } \\
\text { Coast }\end{array}$} & LE & 1.1 & 2.2 & 4.0 & 80 & 2800 \\
\hline & FLK & 0.9 & 1.3 & 5.1 & 60 & 3830 \\
\hline & FLWS & 0.5 & 0.9 & 1.5 & 70 & 2700 \\
\hline & FLW & 0.8 & 1.5 & 3.0 & 70 & 2090 \\
\hline & FLWN & 0.9 & 1.5 & 4.8 & 60 & 3560 \\
\hline & SR & 0.9 & 1.7 & 6.8 & 80 & 4400 \\
\hline & LAE & 1.1 & 1.8 & 6.6 & 60 & 4150 \\
\hline & LAW & 0.9 & 1.3 & 2.5 & 50 & 2690 \\
\hline & TXNN & 1.0 & 1.5 & 2.8 & 50 & 1920 \\
\hline & TXN & 1.2 & 1.7 & 2.8 & 50 & 2580 \\
\hline & $\mathrm{TX}$ & 1.3 & 1.8 & 5.2 & 50 & 2970 \\
\hline & TXS & 1.2 & 1.6 & 7.5 & 50 & 4920 \\
\hline \multicolumn{2}{|c|}{ Average } & 1.0 & 1.6 & 4.4 & 61 & 3200 \\
\hline
\end{tabular}




\section{References}

Aagaard, T., Sorensen, P., and Sørensen, P., 2012, Coastal profile response to sea level rise: a process-based approach: Earth Surface Processes and Landforms, v. 37, no. 3, p. 354-362, doi: 10.1002/esp.2271.

Ashton, A.D., and Murray, a. B., 2006a, High-angle wave instability and emergent shoreline shapes: 1. Modeling of sand waves, flying spits, and capes: Journal of Geophysical Research, v. 111, no. F4, p. 2006-2007, doi: 10.1029/2005JF000422.

Ashton, A.D., and Murray, A.B., 2006b, High-angle wave instability and emergent shoreline shapes: 2. Wave climate analysis and comparisons to nature: Journal of Geophysical Research: Earth Surface (2003-2012), v. 111, no. F4.

Bailard, J.A., and Inman, D.L., 1981, An energetics total load sediment transport model for a plane sloping beach: Journal of Geophysical Research, v. 86, no. 80, p. 2035-2043, doi: 10.1029/JC086iC11p10938.

Bowen, A.J., 1980, Simple models of nearshore sedimentation; beach profiles and longshore bars, in The Coastline of Canada, Littoral Processes and Shore Morphology, Halifax, Nova Scotia, p. 1-11.

Brunsden, D., and Thornes, J.B., 1979, Landscape sensitivity and change: Transactions of the Institute of British Geographers, v. 4, no. 4, p. 463-484.

Davis, R.E., Demme, G., and Dolan, R., 1993, Synoptic climatology of atlantic coast NorthEasters: International Journal of Climatology, v. 13, no. 2, p. 171-189, doi: 10.1002/joc.3370130204.

Davis, R.A., and Fox, W.T., 1975, Process-response patterns in beach and nearshore sedimentation; I, Mustang Island, Texas: Journal of Sedimentary Research , v. 45 , no. 4 , p. 852-865, doi: 10.1306/212F6E65-2B24-11D7-8648000102C1865D.

Dott, R. H., J., and Bourgeois, J., 1982, Hummocky stratification: Significance of its variable bedding sequences: Geological Society of America Bulletin, v. 93, no. 8, p. 663-680, doi: 10.1130/0016-7606(1982)93.

Duke, W.L., 1985, Hummocky cross-stratification, tropical hurricanes, and intense winter storms: Sedimentology, v. 32, no. 2, p. 167-194, doi: 10.1111/j.1365-3091.1985.tb00502.x.

Emanuel, K., 2005, Increasing destructiveness of tropical cyclones over the past 30 years: Nature, v. 436, no. 7051, p. 686-688, doi: 10.1038/nature03906.

Fucella, J.E., and Dolan, R. Magnitude of subaerial beach disturbance during northeast storms: Journal of Coastal Research, v. 12, no. 2, p. 420-429. 
Gunawardena, Y., Ilic, S., Southgate, H.N., and Pinkerton, H., 2008, Analysis of the spatiotemporal behaviour of beach morphology at Duck using fractal methods: Marine Geology, v. 252, no. 1-2, p. 38-49, doi: 10.1016/j.margeo.2008.03.013.

Hirsch, M.E., DeGaetano, A.T., and Colucci, S.J., 2001, An East Coast Winter Storm Climatology: Journal of Climate, v. 14, no. 5, p. 882-899, doi: 10.1175/15200442(2001)014<0882:AECWSC >2.0.CO;2.

Holman, R.A., and Stanley, J., 2007, The history and technical capabilities of Argus: Coastal Engineering, v. 54, no. 6-7, p. 477-491, doi: 10.1016/j.coastaleng.2007.01.003.

IPCC, 2007, Climate Change 2007 - Impacts, Adaptation, and Vulnerability: Working Group II contribution to the Fourth Assessment Report of the IPCC : United Nations.

Jensen, R.E., 2010, Wave Information Studies (U. S. A. C. of Engineers, Ed.):.

Johnson, J.M., Moore, L.J., Ells, K., Murray, A.B., Adams, P.N., MacKenzie, R.A., and Jaeger, J.M., 2015, Recent shifts in coastline change and shoreline stabilization linked to storm climate change: Earth Surface Processes and Landforms, v. 40, no. 5, p. 569-585, doi: 10.1002/esp.3650.

Keim, B.D., Muller, R.A., and Stone, G.W., 2004, Spatial and temporal variability of coastal storms in the North Atlantic Basin: Marine Geology, v. 210, no. 1-4, p. 7-15, doi: 10.1016/j.margeo.2003.12.006.

Knutson, T.R., McBride, J.L., Chan, J., Emanuel, K., Holland, G., Landsea, C., Held, I., Kossin, J.P., Srivastava, A.K., and Sugi, M., 2010, Tropical cyclones and climate change: Nature Geoscience, v. 3, doi: 10.1038/ngeo779.

Komar, P.D., 1971, The mechanics of sand transport on beaches: Journal of Geophysical Research, v. 76, no. 3, p. 713-721.

Komar, P.D., and Allan, J.C., 2008, Increasing Hurricane-Generated Wave Heights along the U.S. East Coast and Their Climate Controls: Journal of Coastal Research, p. 479-488, doi: 10.2112/07-0894.1.

Lazarus, E.D., Ashton, A.D., and Murray, A.B., 2012, Large-Scale Patterns in Hurricane-Driven Shoreline Change, in Extreme Events and Natural Hazards: The Complexity Perspective, American Geophysical Union, p. 127-138.

Lazarus, E., Ashton, A., Murray, A.B., Tebbens, S., and Burroughs, S., 2011, Cumulative versus transient shoreline change: Dependencies on temporal and spatial scale: Journal of Geophysical Research: Earth Surface (2003-2012), v. 116, no. F2, doi: 10.1029/2010JF001835. 
Li, Y., Lark, M., and Reeve, D., 2005, Multi-scale variability of beach profiles at Duck: A wavelet analysis: Coastal Engineering, v. 52, no. 12, p. 1133-1153, doi: 10.1016/j.coastaleng.2005.07.002.

List, J.H., and Farris, A.S., 1999, Large-scale shoreline response to storms and fair weather, in Coastal Sediments (1999), ASCE, p. 1324-1338.

List, J.H., Farris, A.S., and Sullivan, C., 2006, Reversing storm hotspots on sandy beaches: Spatial and temporal characteristics: Marine Geology, v. 226, no. 3-4, p. 261-279, doi: 10.1016/j.margeo.2005.10.003.

Longuet-Higgins, M.S., 1957, The mechanics of the boundary-layer near the bottom in a progressive wave, in 6th International Conference on Coastal Engineering, Miami, FL, p. 184-193.

Madsen, O.S., 1991, Mechanics of cohesionless sediment transport in coastal waters, in Coastal Sediments, ASCE, p. 15-27.

Mather, J.R., Adams III, H., and Yoshioka, G.A., 1964, Coastal storms of the eastern United States: Journal of Applied Meteorology, v. 3, no. 6, p. 693-706.

McCave, I.N., 1985, Sedimentology: Hummocky sand deposits generated by storms at sea: Nature, v. 313, no. 6003, p. 533-533, doi: 10.1038/313533b0.

Moore, L.J., McNamara, D.E., Murray, A.B., and Brenner, O., 2013, Observed changes in hurricane-driven waves explain the dynamics of modern cuspate shorelines: Geophysical Research Letters, v. 40, no. 22, p. 5867-5871, doi: 10.1002/2013GL057311.

Murray, A.B., 2007, Two paradigms in landscape dynamics: Self-similar processes and emergence, in Nonlinear Dynamics in Geosciences, Springer, p. 17-35.

Peters, S.E., and Loss, D.P., 2012, Storm and fair-weather wave base: a relevant distinction? Geology, v. 40, no. 6, doi: 10.1130/G32791.1.

Różyński, G., Larson, M., and Pruszak, Z., 2001, Forced and self-organized shoreline response for a beach in the southern Baltic Sea determined through singular spectrum analysis: Coastal Engineering, v. 43, no. 1, p. 41-58, doi: 10.1016/S0378-3839(01)00005-9.

Sageman, B.B., 1996, Lowstand tempestites: Depositional model for Cretaceous skeletal limestones, Western Interior basin: Geology, v. 24, no. 10, p. 888-892, doi: 10.1130/00917613(1996)024.

Southgate, H.N., and Möller, I., 2000, Fractal properties of coastal profile evolution at Duck, North Carolina: Journal of Geophysical Research, v. 105, no. C5, p. 11489, doi: 10.1029/2000JC900021. 
Stive, M.J.F., and de Vriend, H.J., 1995, Modelling shoreface profile evolution: Marine Geology, v. 126, no. 1-4, p. 235-248, doi: 10.1016/0025-3227(95)00080-I.

Sullivan, T. (USDA F.S., and Lucas, W. (USDA F.S., 2007, Chronic Misapplication of the Relationship between Magnitude and Frequency in Geomorphic Processes, As Illustrated in Fluvial Processes in Geomorphology by Leopold, Wolman and Miller (1964): Advancing the Fundamental Sciences: Proceedings of the Forest Service National Earth Sciences Conference, p. 4-6.

Swenson, J.B., Paola, C., Pratson, L., Voller, V.R., and Murray, A.B., 2005, Fluvial and marine controls on combined subaerial and subaqueous delta progradation: Morphodynamic modeling of compound-clinoform development: Journal of Geophysical Research, v. 110, p. 1-16, doi: 10.1029/2004JF000265.

Tebbens, S.F., Burroughs, S.M., and Nelson, E.E., 2002, Wavelet analysis of shoreline change on the Outer Banks of North Carolina: An example of complexity in the marine sciences: Proceedings of the National Academy of Sciences, v. 99, no. suppl 1, p. 2554-2560, doi: 10.1073/pnas.012582699.

Thom, B.G., and Hall, W., 1991, Behaviour of beach profiles during accretion and erosion dominated periods: Earth Surface Processes and Landforms, v. 16, no. 2, p. 113-127, doi: 10.1002/esp.3290160203.

U S Army Corps Of Engineers, N., 2002, Coastal Engineering Manual: Coastal Engineering Manual, , no. August 2001, p. 1-62.

Wolman, M.G., and Gerson, R., 1978, Relative scales of time and effectiveness of climate in watershed geomorphology: Earth Surface Processes, v. 3, p. 189-208, doi: 10.1002/esp.3290030207.

Wolman, M.G., and Miller, J.P., 1960, Magnitude and Frequency of Forces in Geomorphic Processes: Journal of Geology, v. 68, no. 1, p. 54-74. 


\title{
Chapter 4: Exploring carbonate reef flat hydrodynamics and formation mechanisms of sub-aerial land
}

\begin{abstract}
Atolls are low-lying landforms consisting of reef-building corals extending to near sea level, backed by a shallow reef flat often mounted by sub-aerial islets, or motu, encircling a central lagoon. These motu consist of sand, gravel, and coral detritus, and sometimes are anchored by relict geologic features. We hypothesize a formation mechanism for motu development on a carbonate reef-platform and subsequent evolution of a motu on the reef flat and its relation to offshore wave climate and underlying system geometry. Here we use hydrodynamic modeling to better understand the role of waves, both storms and the background wave climate, on the formation of motu. Using XBeach, a two-dimensional model of infragravity wave propagation and sediment transport, we simulate the hydrodynamic impacts of waves on the reef flat, nearshore and beaches of motu. We investigate the effects of varying wave climate or storms on different representative profile morphologies (e.g. reef-flat width and water depth). We find that there is a critical reef-flat water depth and reef-flat width to which the system should self-organize that is dependent on the offshore wave climate and the sediment characteristics available in the system. Moreover, motu formation can be initiated by a change in offshore wave climate (like a storm) creating a nucleation site from coarse sediment being mobilized and deposited on the reef flat. Once a motu is present, reef-flat transport directions reverse and the reef-flat width is expected to decrease until reaching a relatively narrow critical width. Our conceptual model of reef-flat evolution and motu formation is governed by understanding the hydrodynamics of the system and subsequent effects on sediment transport.
\end{abstract}




\section{$1 \quad$ Introduction}

Despite the essential role atolls and the sub-aerial islets on the atoll reef platform, called motu, play as home to terrestrial ecosystems and human infrastructure, the morphologic processes and environmental forcings responsible for their formation and maintenance remain poorly understood. Given that predicted sea-level rise by the end of this century is at least half a meter (Horton et al., 2014), it is important to understand how motu and atolls will respond to accelerated sea-level rise for island nations where the highest elevation may be less than 5 meters (Nunn, 1998; Webb and Kench, 2010; Barnett and Adger, 2003). The anticipated principal impacts of climate change on atolls include shoreline erosion, inundation and flooding, and saltwater intrusion into the freshwater aquifers (Mimura, 1999).

Here, we conduct a series of modeling studies of wave hydrodynamics on prototype reef flat and reef island geometries to better understand the morphodynamic controls on these shallow-water systems. By investigating the effects of varying wave conditions, depth and width for reef flats both with and without islets (motu), we develop a process-grounded conceptual model of reef flat shoaling, lagoonwards reef flat growth, incipient motu formation and subsequent oceanwards growth. These results help inform both the past geologic evolution of reef flat environments as well as provide a framework to understand potential future evolution under sea-level rise.

\section{$2 \quad$ Background}

\subsection{Atolls, Reef Flats, and Motu}

Atolls are oceanic reef systems consisting of a shallow carbonate reef platform encircling a lagoon often containing multiple islets around the reef edge (Carter and Woodroffe, 1994). Atolls come in a variety of different shapes and sizes from circular to elliptical to rectangular. Some atolls are quite large with an inner lagoon longer than $50 \mathrm{~km}$, while others are less than 5 $\mathrm{km}$ across (Figure 1a and 1b). Starting from the ocean, atolls consist of four distinct geomorphic regions: fore reef, reef flat, subaerial landmass (if present), and inner lagoon. All of these features have different hydrodynamics driving long-term evolution.

Atolls may be located in very deep ocean basins, where, less than 1-2 km offshore, the water depth exceeds $1,000 \mathrm{~m}$, while the reef flat can be shallower than $1 \mathrm{~m}$. The majority of active coral growth occurs on the oceanwards edge of the reef flat (fore reef) rather than on the 
reef flat itself. The primary component of atolls are reef platforms, or flats, which are slightly submerged rims (typical depths of 1-2 m below sea level) that can extend from 100's of m to several $\mathrm{km}$ towards the atoll lagoon. At low tide, for example, on Ebeye Motu, the water depth is less than $0.5 \mathrm{~m}$ (Figure $2 \mathrm{c}$ and $2 \mathrm{~d}$ ). The reef flat tends to be comprised of growing coral and hard, cemented coral detritus as well as, moving lagoonwards, unconsolidated sandy sediment; throughout these environmental changes, the reef platform generally maintains a constant depth. Because reef flats are shallow, most ocean waves tend to break at the reef edge and do not propagate over the reef flat (Figure 2d).

Motu, cays, and reef islands are different names for geomorphic islets found atop reef flats. Mostly low-lying with a mean elevation of 1-2 m (Woodroffe, 2008), these islets are typically composed of coral reef sediment, dead micro-organisms living on the reef (such as forams), and rubble from the surrounding coral reefs (in this paper, we will use the term motu to refer to all types of reef islets) and are capable of sustaining vegetation. Motu are comprised primarily of coral detritus and carbonate sands; grain sizes, however, can vary from very finegrained sand to large boulder-sized pieces of coral detritus as seen in a cross-section of a trench from a motu on Fakarava Atoll in French Polynesia (Figure 2a) and a motu on Kwajalein Atoll in the Marshall Islands (Figure 2b). The ocean-side beach on the motu (Figure 2b) typically has an increase of elevation 1-2 m above sea level.

Motu often have seaward (ocean-side) shingle ridges and leeward (lagoon-side) sand deposits containing two different sediment sizes: fine-grained sand and large-grained coral rubble respectively (Murphy, 2009). These two grain sizes are hypothesized to be deposited and eroded by different processes. The coarse-grained rubble may be deposited on the reef rim during large storm events (e.g., tropical cyclones). Tropical cyclones may be extremely important in both the formation and the evolution of motu (Harmelin-Vivien and Laboute, 1986; Kench et al., 2006; Bourrouilh-Le Jan and Talandier, 1985). These high-energy events may easily transport fine-grained sand inwards towards the lagoon (Carter and Woodroffe, 1994). The fair-weather wave climate, on the other hand, tends to deposit the sand and fine-grained sediment on the motu (Stoddart et al., 1971).

Around a given atoll, the morphology of motu may change significantly from small (100s of $\mathrm{m}$ to several $\mathrm{km}$ ) individual islets or larger continuous islets that are more suitable for human habitation (Figure 1c and 1d). On the same atoll, motu can stretch for tens of kilometers long on 
one side but less than a half kilometer elsewhere (Figure 1c and 1d). Motu may provide the only emergent land for atoll island nations (Kench et al., 2014b) and hold the majority of freshwater available on atolls, as rainwater infiltrates through the partially lithified rubble and sand and then sits above the saltwater in an unconfined aquifer (Terry and Chui, 2012). Motu and atolls are morphologically dynamic landforms that respond to external forcing like sea-level change or a change in wave climate.

Motu, comprised of carbonate sediment produced from the surrounding reef from the skeletal remains of coral and organisms living on the reef (Ford, 2014), can have large amount of sediment sourced locally. For example in the Maldives, $75 \%$ of the estimated annual sand-sized sediment budget on the reef flat was produced on the reef-flat rim (ocean-side) (Perry et al., 2015). The rate of motu formation on the atolls varies greatly from decadal to millennial timescales (Kench et al., 2014a; Woodroffe and Morrison, 2001; Woodroffe et al., 2007; Ford and Kench, 2014).

Sea level is an important factor controlling atoll growth and formation (Toomey et al., 2013), and knowing the water depth that specific corals grow to, past sea level can be estimated for different locations by radiometric dating of corals. Atolls in the Pacific experienced a sealevel highstand, about $1 \mathrm{~m}$ higher than modern sea-level, in the late Holocene due to equatorial ocean siphoning (Mitrovica and Milne, 2002; Nunn, 1990; Pirazzoli and Montaggioni, 1986; Dickinson, 2003; Peltier, 2001; Rashid et al., 2014). Since then, sea level has primarily been falling for the Pacific atolls. Some authors argue that reef island formation is dependent on the falling sea level (Dickinson, 2009; Yasukochi et al., 2014; Dickinson, 2003), although modern observations demonstrate that motu formation can happen during rising sea level (Kench et al., 2005; Mandlier and Kench, 2012). For the last 100 years, there has been a $2.9 \mathrm{~mm} / \mathrm{yr}$ rise in sealevel based on tidal gauges from Pipette, French Polynesia (Church et al., 2006).

Researchers predict at least a half a meter rise in eustatic sea-level by the end of the century (Kopp et al., 2014; Horton et al., 2014). A survey of atolls over the last 60 years using historical photographs and satellites found that $86 \%$ of the atolls surveyed either increased their land mass or their area stayed the same (Webb and Kench, 2010). The authors conclude that these islands are geomorphically resilient and dynamic landforms; for example, on Nadikdik Atoll in the Marshall Islands a motu formed and stabilized over the past 61 years (Ford and Kench, 2014). However, other authors predict more worrying trends, such as increased 
inundation and salinization of aquifers, which suggests a threat to the long term survivability of these islands (Dickinson, 1998; Yamano et al., 2007; IPCC, 2013).

Tropical cyclones are hypothesized to be extremely important in both the formation and the evolution of motu (Harmelin-Vivien and Laboute, 1986; Kench et al., 2006; Bayliss-Smith, 1988; Stoddart et al., 1971). While motu are hypothesized to form and be replenished by tropical cyclone activity, the response of these islets to an increase in storm activity or intensity is unknown. Cowell and Kench (2001) simulate the response of motu to changes in sea level using the modified Shoreface Translation Model (STM), and see an extreme sensitivity of motu to sediment availability. Their modeling finds that, for all cases, sea-level rise should drive shoreline recession, thus widening of the reef-flat (Kench and Cowell, 2001). Barry et al. (2008), using a non-linear Sediment Allocation Model (SAM), simulate a pattern of motu growth characterized by rapid lateral expansion and diminishing vertical accretion assuming constant sediment supply and static accommodation space. Mandlier and Kench (2012) simulate wave refraction in planform over varying reef-platform shapes and argue that focal points or zones of wave convergence cause sub-aerial landmass formation on a reef platform.

\subsection{Reef Hydrodynamics}

Transformation of waves over the reef flat is characterized by increased wave energy dissipation (Kench and Brander, 2006; Monismith et al., 2013) due to increased bottom friction and wave breaking at the edge of the reef flat (Péquignet et al., 2011; Lugo-Fernández et al., 1998; Becker et al., 2014). Bottom friction factors are found to be at least an order of magnitude greater than for sandy bottoms, but with significant variability (Quataert et al., 2015; LugoFernández et al., 1998). In addition, the water depth over the reef flat is seen to control the wave energy and wave height (Péquignet et al., 2011; Kench and Brander, 2006), and as water depth increases there is decreased set-up on the reef flat and decreased wave energy dissipation (LugoFernández et al., 1998). Gelfenbaum et al. (2011) model varying geometries of incised channels and fringing coral reefs using Delft3D and find that landward-narrowing embayments increase wave inundation and that increasing reef-flat width increases wave dissipation. Van Dongeren et al. (2013), modeling wave dynamics over a fringing coral reef, find the increasing importance of infra-gravity (IG) waves over the reef flat. Moreover, IG waves are strongly modulated by depth 
variations because of frictional dissipation and can contribute more than half of the total bottom shear stress.

XBeach is a two-dimensional numerical model of wave propagation, sediment transport, and morphologic response of the nearshore, beach and backbarrier during storms (Roelvink et al., 2009). XBeach models IG wave dynamics in a system and has been used previously to model waves transformation over a fringing coral reef (Van Dongeren et al., 2013). It was found that IG waves dominated the bottom shear stress and sediment transport within the lagoon, but short waves dominated the bottom shear stress in the fore-reef and reef crest. XBeach has also been used to look at the effect of alongshore topographic variation on dune overwash and morphologic evolution in Santa Rosa, FL during an extreme event (McCall et al., 2011). They found that the preexisting topography influences the backbarrier and lagoon but not the foreshore or fore-dunes response to overwash during the hurricane. We use XBeach to see how different storm conditions affect the wave and morphologic conditions of an atoll.

\subsection{Outline}

In this chapter, using XBeach, we investigate wave-driven reef flat hydrodynamics to better understand reef flat evolution and potentially how motu form and evolve. To do this, we explore a range of external forcing and underlying geometry for prototype reef flat systems. First, we explain the underlying model framework and reasons for choosing it. Then we detail results, showing how varying offshore wave climate, reef-flat water depth, and reef flat width affects local hydrodynamics. We then add a subaerial landmass, representing a motu, on the reef flat and rerun the simulations to see how the presence of land affects local hydrodynamics. These results are then interpreted to develop a conceptual model reef flat development and motu formation and evolution.

\section{$3 \quad$ Methods}

Given the constraints of the geometry of the reef flat and motu, we developed a simplified bathymetry for the XBeach modeling. XBeach was chosen because it specifically models infragravity waves (Roelvink et al., 2009), which have been shown in the field to be important in energy transfer and bottom shear stress across the reef flat (Pomeroy et al., 2012; Van Dongeren et al., 2013). Utilizing XBeach, we numerically model wave propagation and transformation over 
generic reef platforms with and without sub-aerial landmasses (representing motu). For our simulations, we vary the geometry of the reef flat system (water depth over the reef flat, presence of a motu, etc.) and the external forcings (offshore wave heights). Our objective is not to simulate any specific atoll, but rather to investigate how different reef geometries affect wave transformation and hydrodynamics, with a goal to better understand the impact of reef flat geometry on sediment transport. Also, by using a simple model of a reef platform and sub-aerial landmass, we are able to quickly run simulations for a large range of morphologies.

XBeach is run in 1-D profile mode with a flat and constant-depth reef platform on top of which there may be sub-aerial landmass of a constant elevation (Figure 3). Because most atolls, such as those in the Marshall Islands and French Polynesia, have a very steep bathymetric profile (less than $2 \mathrm{~km}$ offshore of atoll the bathymetry can be over 1,000 $\mathrm{m}$ deep) the offshore geometry is steep, shoaling from a depth of $1000 \mathrm{~m}$ over the $2 \mathrm{~km}$ offshore model domain. The offshore profile then reaches the constant-depth reef flat $\left(h_{r}\right)$. The $2 \mathrm{~km}$ domain offshore of the reef flat was also found to be important to avoid ocean-side boundary affects, particularly for the IG waves. The reef flat terminates in a backbarrier lagoon with a water depth of $40 \mathrm{~m}$, extending past the reef flat for a distance of $200 \mathrm{~m}$. The lagoon width also allows us to avoid land-side boundary effects. We do not model tidally driven flows or locally generated waves, and for all runs the water level in the lagoon is held at a constant value. The latter assumes that the lagoon is well-drained, even during storm events. The presence of a free, deep lagoon behind the reef flat affected the model results, if the simulations were run with no backbarrier lagoon (i.e. the model bathymetry input ended at the back edge of the reef flat) there was a decrease in the bottom shear stress over the reef-flat of around 5\%.

The offshore waves are generated using the XBeach built-in JONSWAP spectrum for a wave period $(T)$ of 10 seconds and, to simulate both background and storm conditions, varying offshore wave height $\left(H_{0}\right)$ from $0.5-6 \mathrm{~m}$. We vary the geometry of the system: the water depth over the reef flat $\left(h_{r}\right)$ from 0.1 to $5 \mathrm{~m}$, the width of the reef flat $\left(w_{r}\right)$ from 0.1 to $1.5 \mathrm{~km}$, and the motu height a $\left(h_{m}\right)$ from 0 (no motu present) to $2 \mathrm{~m}$ (fully subaerial motu). Horizontal resolution varies to increase model run time from 100 to $2 \mathrm{~m}$; in areas of interest, horizontal resolution is high at 2 meters. Each XBeach simulation is for 6 hours of model time and variables are output every 10 seconds of model time. Output data at each spatial location is averaged over all time steps for each output parameter to compute values of temporal mean and standard deviation. 
Although XBeach has the capability to model morphodynamic evolution of sandy environments, reef flats are heterogeneous, containing corals, concreted bed material, and variable sediment distribution. Therefore, we run XBeach with no morphodynamics or sediment transport to focus on the hydrodynamic transformation across the reef flat. However, the effects of waves and currents on potential sediment transport can be investigated as XBeach calculates the bottom shear stress $\left(\tau_{\mathrm{b}}\right)$ based on the near bottom orbital velocity (generated by the waves) and the mean Eulerian velocity (generated by any induced currents).

$$
\tau_{b}=c_{f} \rho u_{u e} \sqrt{u_{r m s}^{2}+\left(u_{u e}+a b s\left(u_{u e}\right)\right)^{2}}
$$

Where $c_{f}$ is the bed friction coefficient associated with mean currents and IG waves, 0.1 (Van Dongeren et al., 2013), $\rho$ is the density of saltwater, $1.027 \mathrm{~g} / \mathrm{cm}^{3}, u_{e u}$ is the mean Eulerian velocity (Figure $4 \mathrm{c}$ ), and $u_{r m s}$ is the near-bottom orbital velocity (Figure $4 \mathrm{~d}$ ). To account for wave induced mass-flux and subsequent return flows, the mean Eulerian current is the shortwave averaged velocity $\left(u_{e u}\right)$, and sets the direction of bottom shear stress. The sign of bottom shear stress indicates the direction of transport where negative bottom shear stress is offshoredirected (oceanwards) and positive is landward-directed (lagoonwards).

While we do not explicitly model sediment transport, we can infer how wave-driven processes may affect sediment transport based on the modeled bottom shear stress. Initiation of motion of sediment can be estimated using a critical bottom shear stress criterion (Miller et al., 1977; Fredsoe and Deigaard, 1992). Direction of modeled bottom shear stress $\left(\tau_{\mathrm{b}}\right)$ indicates the potential direction of transport of sediment (either oceanwards for negative shear stress, $\tau_{b}<0$, or landwards for positive shear stress, $\tau_{\mathrm{b}}>0$,). Critical shear stress, $\tau_{\mathrm{cr}}$, values vary greatly depending on the density and grain size of the bed sediment. In atolls, sediment ranges from very fine-grained sand $(1 / 16 \mathrm{~mm})$ of primarily carbonates to large pieces of coral rubble, from gravel to boulder-sized pieces $(15-300 \mathrm{~mm}$ ) (Perry et al., 2011). The density also ranges from 1.1 to $2.4 \mathrm{~g} / \mathrm{cm}^{3}$ for coral clasts, limestone, and beach rock sediment compared to a typical density of quartz sand of $2.65 \mathrm{~g} / \mathrm{cm}^{3}$. The critical shear stress calculated to initiate movement of the sediment ranges from 1.2 to $230 \mathrm{~N} / \mathrm{m}^{2}$ utilizing Shield's method (Madsen, 1991; Fredsoe and Deigaard, 1992).

The XBeach model results were most sensitive to the run time of the model, the friction coefficients used in calculating bottom shear stress, and the presence of a backbarrier lagoon. We 
ran the model for 6 hours so that the reef-flat was fully saturated. We found that if the model was run for less time there were variations of about 10-20\% in computed mean bottom shear stress between runs for the same initial inputs. For longer model runs (10 or 24 hours), the variation in mean bottom shear stress was significantly less $(<2 \%)$; simulations run for 6 hours enabled us to run multiple simulations and scenarios relatively quickly.

There are two friction coefficients that are used by XBeach in the calculation of wave height and bottom shear stress that affect modeled wave transformation over the reef flat. XBeach was originally designed for a sandy bottom where friction is much less than a hard coral reef-flat bed, typically at least an order of magnitude smaller (Gelfenbaum et al., 2011; Kunkel et al., 2006; Brander et al., 2004; Lugo-Fernández et al., 1998). Following the model calibration of Van Dongeren et al. (2013) for a fringing coral reef, we used a short-wave friction coefficient $\left(f_{w}\right)$ of 0.6 , used in the calculation of wave dissipation, and a bed friction coefficient $\left(c_{f}\right)$ of 0.1 , used in the calculation of bed shear stress (1). The default values used by XBeach are an order of magnitude lower $\left(c_{f}=0.003\right.$ and $\left.f_{w}=0\right)$, which corresponds to a significant decrease in bottom shear stress over the entire reef flat (sample runs suggest at least a $25 \%$ reduction).

\section{$4 \quad$ Reef-flat Hydrodynamic Modeling}

\subsection{Results - Reef-flat Hydrodynamics}

The shallow reef flat $\left(h_{r}\right)$ filters the wave field as short-period waves break on the shallow fore-reef (Figure 4). As waves shoal, wave height, water level, and near bottom orbital velocity peak at ocean-side edge of the reef flat. If only short waves were present, shallow-water waves would be expected to completely break at the reef interface for shallow reefs. However, water level oscillations associated with infragravity waves allow incident waves to penetrate into the reef flat; infragravity waves account for $25 \%$ of the water set up (Supplemental Information, Figure S2). These waves then slowly decay over the reef flat (Figure $4 \mathrm{a}$ and $4 \mathrm{~d}$ ). Deeper reefs allow short-period waves to penetrate further onto the reef flat. There is always a large, narrow peak of offshore-directed bottom shear stress at the ocean-side edge of the reef flat. Vigorous wave breaking at the fore-reef sets up the water elevation, which drives an onshore flow (Figure $4 \mathrm{~b}$ and $5 \mathrm{c})$.

\subsection{Results: Changing Reef-flat Depth}


Increasing the water depth over the reef flat increases both the wave heights (Figure 4a) and the near-bottom orbital velocities over the reef flat (Figure 4d). Increasing the water depth, however, decreases the setup (Figure 4b), thus decreasing the current generated over the reef flat (the mean Eulerian velocity) (Figure 4c). While all values peak at the ocean-side edge of the reef flat, for a shallow reef flat, there is a secondary peak at the lagoon-side edge of the mean Eulerian velocity. The shallow reef flat develops a considerable current due to the breakingwave-driven setup at the ocean-side of the reef flat. Cross-shore radiation stress drives the water setup at the ocean-side reef-flat edge and drives the mean Eulerian current (Supplemental Information, Figure $\mathrm{S} 1$ ). If the reef flat is sufficiently shallow, the flow accelerates towards the lagoon as decreases in the setup reduce ambient water elevations. Becker et al. (2014), measuring water level variations and waves over reef flats in the Marshall Islands and Mariana Islands, find that as water levels over a reef flat increase, there is a corresponding decrease in setup of the water level, exactly as we see in the simulations (Figure 4b).

Increasing the water depth over the reef flat decreases the magnitude and temporal variability of the bottom shear stress (Figure 5). Moreover, except for the initial large local minima in offshore-directed bottom shear stress at the ocean edge of the reef flat, bottom shear stress stays positive (onshore-directed sediment transport) for the entire width of the reef flat. After the large minimum at the reef-flat ocean edge, there is a corresponding local maximum near the reef-flat ocean edge. Bottom shear stress than decreases over the width of the reef flat, but for shallow depths (less than 1-2 $\mathrm{m}$ ) there is a secondary peak of bottom shear stress at the reef-flat edge at the lagoon. This secondary peak is due to the large current, $u_{e u}$, generated for very shallow reef flats (Figure 4c). IG waves account for $50 \%$ of bottom shear stress across the reef flat and are important in sediment transport capacity (Supplemental Information Figure S3).

To capture how fair and storm waves interact with the reef flat, we also investigated how different wave heights affect bottom shear stress. As expected, increasing the offshore wave height increases the bottom shear stress for all locations over the reef flat (Figure 6). For a given offshore wave height, the bottom shear stress curve increases with increasing water depth to a maximum at 1-2 $\mathrm{m}$ depth and then decreases with increasing depth. For offshore wave heights less than $2 \mathrm{~m}$, bottom shear stress is below the critical shear stress for moving sand $\left(\tau_{c r \text {, sand }}=1.5\right.$ $\mathrm{N} / \mathrm{m}^{2}$ ). As offshore wave heights increase the peak in bottom shear stress occurs at increasing depths. 


\subsection{Discussion: Reef-flat Depth}

At the oceanward side, coral growth and accumulation sets the elevation of the reef flat. In general, corals and coralline algae accumulate the reef to the intertidal region such that they remain submerged. Vigorous wave breaking on the fore reef does not generally limit coral accumulation, instead waves tend to break apart actively growing corals, creating a mix of sediment sizes, from sand to rubble (Perry et al., 2011). Coral growth continues behind the fore reef, where numerous processes, including bioerosion, Halimeda and Foraminifera growth, and Parrotfish grazing, bioerosion, tend to generate sand-sized particles. Reef flats then steadily blend, typically with little to no elevation change, into a sandy flat of constant depth extending into the lagoon.

The model results with changing reef flat depth provide a framework to explain the emergence of a near-constant elevation reef flat that extends in many cases for kilometers. Where the bottom shear stress exceeds a critical shear stress $\left(\tau_{b}>\tau_{c r}\right)$, sediment is mobilized and can be transported landwards by the wave-driven currents. There are two ways that sediment mobilization can set reef flat elevation. In the distal, sediment-rich portions of the reef flat, if bottom shear stress is below the critical shear stress $\left(\tau_{b}<\tau_{c r}\right)$, sediment is deposited. In coraland hard-bottom-dominated portions of the reef, if waves are able to move bed sediment on a regular basis, it will be difficult for the sediment to be cemented to the bed and moving sediment will abrade the reef framework and inhibit coral growth. Therefore we hypothesize the bed will erode if fair-weather wave conditions can surpass the critical sediment shear stress.

As stated earlier, the variety of sediment sizes upon a reef flat results in a large range of potential critical bottom shear stress, although production of sand-sized sediment is common. For a given critical shear stress, there may be two depths where the critical shear stress equals the bottom shear stress $\left(\tau_{b}=\tau_{c r}\right)$, corresponding to two equilibria points. This results in a model for reef flat elevation control similar to the model of Fagherazzi et al. (2006) for tidal flat elevations controlled by locally generated waves. If the reef flat is deeper than the unstable equilibrium but shallower than the stable equilibrium (where the bottom shear stress is greater than the critical shear stress), then the system will tend to erode and deepen, either through advection of bed sediment lagoonwards or erosion of the coral reef or reef hard-bottom, until the bottom shear stress equals the critical shear stress. If, on the other hand, the system is deeper than the stable 
equilibrium depth, the sediment will tend to deposit, shallowing until the bottom shear stress equals the critical shear stress at the stable equilibrium. In the distal reef flat, sediment may remain noncohesive; near the ocean, the sediment may be bound by coralline algae, solidifying the bed before the next storm event. The second, shallower, equilibrium point is unstable. If the reef flat is shallower than this unstable equilibrium depth, sediment can continue to deposit and thus continue to shallow the reef flat up to sea level, potentially becoming sub-aerial land. Of course, the sediment size and the critical shear stress are paramount in controlling how the system behaves.

Bottom shear stress varies along the reef flat (Figure 6). For a given grain size and density, there may be a distance landwards on the reef flat that the bottom shear stress no longer exceeds the critical shear stress where sediment would likely be deposited. This distance landward varies with water depth over the reef flat. For example, for a $5 \mathrm{~m}$ deep reef flat with a 2 $\mathrm{m}$ offshore wave height, sand would be predicted to be deposited around $0.8 \mathrm{~km}$ inland of the reef flat, but for any shallower reef flats or larger offshore wave heights, sand would only be deposited into the lagoon (Figure 6). For a sample critical shear stress, $\tau_{c r \text {, sand }}$, approximating a $2.0 \mathrm{~mm}$ grain of sand of the highest density $\left(\rho_{s}=2.65 \mathrm{~g} / \mathrm{cm}^{3}\right)$, waves with $H_{0}=2 \mathrm{~m}$ can mobilize sandy sediment across the entire $1 \mathrm{~m}$ deep reef flat (Figure 6). However, for a sample $\tau_{c r}$, boulder representing for a lightweight piece of coral rubble $\left(\rho_{s}=1.1 \mathrm{~g} / \mathrm{cm}^{3}\right.$ and $\left.d=30 \mathrm{~cm}\right)$, the mean shear stress never exceeds this critical shear stress, meaning that coarse gravel and coral rubble will not be easily mobilized by $2 \mathrm{~m}$ waves.

\subsection{Results: Changing Reef-flat Width}

Increasing the total reef-flat width decreases the overall bottom shear stress and decreases the positive peak of bottom shear stress (onshore-directed sediment transport) (Figure 7). Increasing the reef-flat width decreases the local maxima at lagoon edge of the reef flat. Similar to Gelfenbaum et al. (2011), we see that increasing the width of the reef flat decreases the wave height and water level over the reef flat with subsequent decrease of bottom shear stress.

Interpolating the bottom shear stress for different water depths over the reef flat and at different locations for varying reef-flat widths shows how reef flat geometry affects bottom shear stress (Figure 8). Larger offshore wave heights generate a significantly larger bottom shear stress over the entire phase space. For all reef-flat widths, increasing depth decreases the bottom shear 
stress. For the narrow reef-flat width $\left(w_{r}=250 \mathrm{~m}\right)$, there is increased bottom shear stress at all depths (the reef flat is much more energetic) compared to wider reef flats. When the reef flat is 1 $\mathrm{km}$ in width, it is much less active (much lower bottom shear stress). Interestingly, as the reefflat width increases, a saddle pattern of higher bottom shear stress emerges in depths of approximately 1-2 m, with two parabolas delineating the area of high bottom shear stress, one concave up, the other deeper in the water level convex down. The saddle pattern, or bow tie pattern, has higher bottom shear stress at either edge of the reef-flat (ocean-side and lagoon-side) that is connected by a narrow bridge in the mid part of the reef flat (most easily seen in Figure 8, $w_{r}=1.0 \mathrm{~km}, H_{0}=4 \mathrm{~m}$ ). This saddle pattern emerges for reef flats with a width greater than half a kilometer, and the cross-shore location of the minimum in bottom shear stress varies with reef flat width.

The location of the bottom shear stress minimum also varies with depth and offshore wave height (Figure 9a). For a wide reef flat $\left(w_{r}=1.0 \mathrm{~km}\right)$, as depth increases, the location of the minimum of bottom shear stress first moves oceanwards than steadily moves onshore until at the deepest water depths, the minimum in bottom shear stress is at the back edge of the reef flat (Figure 9a). For increasing offshore wave height, the location of the minimum of bottom shear stress moves oceanwards and deeper. The location for the minimum of bottom shear stress for varying total reef-flat widths and varying water levels over the reef flat follows a linear pattern (Figure 9b). At some distance landward of the reef flat edge, the location of the minima of bottom shear stress follows a strong linear trend that varies between $0.5-0.3$ of the total reef-flat width.

\subsection{Discussion: Reef-flat Width}

For a given grain size, if a reef-flat is narrow, high bottom shear stress will move sediment off the reef flat, extending the flat lagoonwards. As the reef flat widens, the bottom shear stress will decrease, and could eventually fall below the critical shear stress to mobilize sediment, most likely at the mid-flat where the bottom shear stress reaches a minimum. For given offshore wave conditions, there may be some landward distance over the reef flat that the mean grain size of sediment can be transported (where $\tau_{b}>\tau_{c r}$ ). This location of minimum bottom shear stress may serve as a locus of deposition. Beyond this landward distance over the reef flat, the mean bottom shear stress may be below the critical shear stress for initiation of 
motion of sediment resulting in no sediment transport under low offshore wave heights. For larger offshore waves (from a storm for example), sediment could be transported further onshore by larger bottom shear stress.

The minima in bottom shear stress for a given reef-flat width indicates locations of possible deposition (Figure 9). In other words, these minima might be the locations during a high-energy event (like a storm or extreme event) where the bottom shear stress falls below the critical shear stress for large sediment, resulting in deposition (Figure 15c). These potential depocenters tend to be on the order of half to a third of the total reef-flat width (Figure 9b). Once the large sediment is deposited (a pile of coral rubble), the local depth will be significantly shallower, possibly shallower than the unstable equilibrium depth for the mean wave climate (Figure 6), allowing even sand-size sediment to accrete, eventually causing a sub-aerial landmass to emerge, a proto-motu (Figure 15d and 15e).

\subsection{Discussion: Reef-flat Evolution}

Our model results suggest that, similar to tidal basins, there is a tendency for reef flats to develop towards constant depth based on the available sediment and the wave climate. For a given reef flat, if the water depth is deeper than the stable equilibrium for the dominant sediment in the system and wave climate, the reef flat can accrete, either through sediment deposition or through carbonate reef accumulation (coral growth, bed cementation) where bed shears are too low to agitate bed sediment and abrade a rocky bottom. On the other hand, reef flats shallower than the stable equilibrium (but deeper than the unstable equilibrium) will tend to deepen as sediment is continually mobilized by the high bottom shear stress (Figure 6b). If a flat is too shallow, waves do not frequently mobilize sediment, and the bed can accrete to sea level.

Any changes in local sea level, offshore wave climate, and sediment type would change the distance between a reef flat and the equilibrium depth. If relative sea level increases, than the reef flat should accrete to maintain an equilibrium depth. An increase in mean wave climate, however, or perhaps a shift in the frequency of storms should deepen the reef flat. Changes to the sediment supply from the reef edge, driven either by sea level and wave climate changes, or other environmental stressors such as bleaching, acidification, or changes in Parrotfish grazing, could also affect the reef flat. A shift in the type of sediment available (such as an increase in finer sediment) could be expected to deepen the reef flat (Figure 6). Conversely, if sediment 
production collapsed (as might happen from coral die-off), the subsequent decrease in sediment could halt the shallowing of a reef flat.

The narrower the reef-flat width, the higher the overall bottom shear stress and the increased sediment that is mobilized across the entire width of the reef flat (Figure 7 and Figure 8). Thus, narrow reef flats would be expected to widen, prograding lagoonwards as sediment is continually driven across the entire reef-flat and deposited at the lagoon-edge. This could continue until the reef-flat is sufficiently wide that the mid-reef minimum bottom shear stress falls below the critical bottom shear stress, perhaps depositing large-grained sediment during a storm (Figure 9). Similar to the above discussion, changes in the offshore wave climate, relative sea level, and sediment type could affect the critical width of the reef flat. Increasing the energy of the wave climate either by increasing the mean climate or frequency and severity of storms would be expected to decrease the width of the reef flat. Increasing the relative sea level would decrease the width of the reef flat. A reduction of sea level should decrease shear across the reef (Figure 8) and could increase the likelihood of mid-reef deposition. However, our conceptual model of motu formation suggests that reef widening may play a significant role in motu initiation. As such, our model for motu formation does not require local sea-level fall, in accordance with observations by Kench et al. (2014a), and in some cases might not need to be initiated by a storm event as the reef widens.

\section{$5 \quad$ Motu Evolution}

The previous XBeach model simulations were applied to a submerged, constant-depth reef flat. Using these results, we hypothesized a mechanism whereby subaerial land may emerge upon a reef flat at a location onshore of the reef edge, preferentially approximately halfway across the flat. Here, to explore the influence of motu on reef flat hydrodynamics, we add a rigid subaerial landmass atop the reef flat. As before, we explore how reef hydrodynamics and shear stresses are affected by different wave heights and changes to the depth and width of the reef flat (in this case the reef flat width in front of the motu).

\subsection{Results: Motu Effect on Hydrodynamics}

The presence of a subaerial landmass has little to no effect on wave heights or the nearbottom orbital velocities over the reef flat (Figure 10a and 10d). However, the emergent land 
blocks flow and therefore has a strong effect on both water-level elevation and the subsequent currents generated over the reef flat (Figure 10b and 10c). The presence of a landmass creates an increased and sustained elevation of the water level compared to a case where there is no motu. Currents generated over the reef flat with a motu are minimal.

The differences in mean Eulerian velocity translate to a significant reduction in the bottom shear stress across the entire flat (Figure 11a), including the strong initial peak of bottom shear stress near the edge of the reef flat. For almost all reef flat depths, the mean bottom shear stress is close to zero and rarely exceeds the critical shear stress for sand. Moreover, the bottom shear stress over the reef flat is no longer consistently positive (onshore-directed). For many water depths, the bottom shear stress is directed offshore, with the zero crossing occurring where bottom shear stress transitions from negative to positive moving landward with increasing reef flat depth.

For a reef flat with a motu, the bottom shear stress follows a generally linear trend, decreasing (becoming more negative) with decreasing depth (Figure 12). Moreover, moving further landwards on the reef flat decreases the magnitude of the bottom shear stress consistently. Also, bottom shear stresses transition from positive to negative (indicating a change in net stress direction) around 1.5-3 $\mathrm{m}$ depth (Figure 12).

Interpolating bottom shear stress across varying water depths and locations on the reef flats emphasizes the overall low magnitude of bottom shear stress across the reef flat regardless of offshore wave height or the reef flat geometry (Figure 13). This is especially evident when compared to the same simulations where there is no motu present (Figure 8). With increasing total reef-flat width, there is an increasing percentage of positive- (onshore) directed bottom shear stress (from $5 \%$ to $40 \%$ for $w_{r}=0.25$ and $1.0 \mathrm{~km}$ respectively) and a slight increase in the magnitude of bottom shear stress overall. Increasing the offshore wave height does also slightly increase the magnitude of bottom shear stress and expands the region of parameter space experiencing positive shear stress. The location of the zero crossing of bottom shear stress varies as the total reef-flat widens.

The location where shear stress changes from negative to positive moves steadily landward (towards the motu) with increasing depth (Figure 14a). Also, at depths greater than 3 $\mathrm{m}$, the bottom shear stress is negative across the entire reef flat. Plotting the location of the zero crossing of bottom shear stress for all possible widths reveals a strong dependence of this 
location on reef-flat depth (Figure 14b). A fairly straightforward deduction would be that positive (onshore-directed) shear stresses would tend to move sediment onshore, thus growing a motu shoreline. Similarly, negative (offshore-directed) stresses at the motu shoreline would suggest offshore sediment transport across the entire reef flat, which should result in motu erosion or at least a cessation of motu growth. Therefore, at the location of the reversal of bed shear, sediment transport should be an important location suggestive of continued growth or contraction of the motu.

In Figure 14b, along the 1:1 line, zero shear stress coincides with the shoreline location. Above this line, bed transport on the flat offshore of the motu is positive and onshore-directed (green and purple shading); below the line, shear is negative across the entire flat, suggesting offshore-directed sediment transport (blue shading). This implies that if there were motu fronted by a reef flat that is narrower than this steady-state line (in the blue shaded area), sediment would be driven offshore, thus contracting the width of the motu and widening the reef flat. Conversely, for a reef flat wider than the steady-state line (purple shading), sediment would be driven onshore by the positive shear stress thus accreting or prograding the motu and narrowing the reef flat.

The depth of the reef flat should affect motu extension, particularly for shallow flats (Figure 14b). For example, the modeling suggests that $1 \mathrm{~m}$ deep reef flat should extend to a maximum width of $200 \mathrm{~m}$ regardless of the offshore wave height. However, $2 \mathrm{~m}$ deep reef flat's critical width can be almost $600 \mathrm{~m}$ with a motu present. In this case, increasing the offshore wave height affects the location of the critical width. This is because deeper reef flats allow penetration of larger waves (Figure 14), whereas shallow reef flats more effectively filter waves.

\subsection{Discussion: Motu Evolution}

The presence of a motu on a reef flat significantly changes the hydrodynamics and sediment transport. Motu significantly decrease the magnitude of bottom shear stress and can drive negative bottom shear stress (offshore-directed sediment transport) over the reef flat (Figure 11a and Figure 14). The change in potential direction of sediment transport indicates a feedback that could develop for the reef flat with a motu present. If for example, the reef flat with a motu is wider than critical width, the bottom shear stress is positive and sediment is onshore-directed, and sediment would be expected to accretw on the motu shoreline, prograding 
and expanding the motu (Figure 15b). This would narrow the reef flat until it reaches the critical width. This suggests a feedback between motu formation and shoreline progradation. If, however, the motu were very wide with a corresponding reef-flat that is narrower than the critical width, the negative bottom shear stress would be expected to transport sediment offshore, removing it from the motu. This would tend to widen the reef flat fronting the motu. In both cases, feedbacks drive the reef flat to self-organize to a critical width.

Ford and Kench (2014) observe motu evolution from an "embryonic deposit", what we term a proto-motu (Figure 15d), to a vegetated motu over the course of 61 years on Nadikdik Atoll. They also report a progression of motu evolution from landward migration, to accretion, to elongation. All of these varying morphologic responses of motu could be easily placed in context of the equilibrium reef-flat width. Ford (2013) found that oceanside shorelines were primarily accretionary on Wotje Atoll over the last 67 years, during a period of rising sea level. This could also be explained by a simple response of the motu and reef flat to a critical width (Figure 14b). Similar to Woodroffe (2008) and McLean and Woodroffe (1994), reef flats with a motu are wider where there are no storms (or other high wave energy events); a similar trend can be seen in Figure 14b where the critical width for an offshore wave height of $2 \mathrm{~m}$ is larger than that for an offshore wave height of $4 \mathrm{~m}$.

\subsection{Discussion: Model Limitations}

It is important to note that our model is run in cross-section with no flow or sediment transport accounted for around the motu. However, if the motu are significantly elongate, then the effects of flow around the motu (in plan view) would be minimal in terms of changing our predicted and modeled behavior. There are elongated thin motu found on many atolls (Figure 1c) as well as much smaller motu (Figure 1d) that can be found on the same atoll (Figure 1b). Perhaps this change in motu morphology is linked to the forcing conditions of the system such as offshore wave climate or sediment type (although our field research has not found significant differences in sediment type corresponding to differences in motu and reef-flat morphology). We are currently researching this question to try to understand what factors most strongly influence motu morphology.

\section{Conceptual Model of Reef Flat and Motu Evolution}


The modeling results allow us to present a cohesive model of reef flat and motu evolution (Figure 15). We make three assumptions about reef platforms. First, primary carbonate production occurs at the ocean edge as a fringing reef approaches sea level, producing carbonate sediment ranging from fine sands to coarse gravel or boulders of coral detritus. Second, there is an inner shallower water body (lagoon) that is separated from the much deeper ocean by an existing reef-platform (i.e., the atoll is an "empty bucket"). Third, waves are the primary driver of sediment transport, determining the long-term geomorphic evolution of the reef flat system.

Given an initial reef platform, the reef flat initially grows vertically to an equilibrium depth determined by the hydrodynamics of the system (Figure 15a), similar to models of tidal flat equilibrium evolution (Fagherazzi et al., 2006). Reef flat depth can therefore be strongly influenced by local changes in sea level. Once the reef flat has reached steady-state depth, lateral growth widens the reef flat lagoonwards (Figure 15b). If the reef flat is too narrow (less than a critical width), mean bottom shear stress will exceed the critical shear stress, moving the sediment off of the reef flat and into the lagoon, thus, building out the reef flat laterally. During an extreme event (like a tropical cyclone), increased bottom shear stress can lead to mobilization of coarser-grained sediment that subsequently will be deposited some distance inland over the reef flat due to the mid-flat shear minimum (Figure 15c). After storm events, background wave conditions could lead to increased deposition of fine sediment over the coarse pile of sediment. This could lead to the development of a "proto-motu," an incipient subaerial landmass on the reef flat (Figure 15d). Continued deposition of sediment at the proto-motu, particularly if the coarsegrained storm deposit is shallower than the unstable equilibrium depth, can lead to the formation of a sub-aerial landmass, a new motu (Figure 15e). Finally, once in place, the subaerial motu blocks onshore currents, and the motu shoreline can prograde laterally over the reef flat from continued onshore sediment transport. This shoreline progradation ends once the reef flat reaches a critical width whereby wave-driven currents become net offshore-directed (Figure 14b and Figure 15f).

\section{$7 \quad$ Conclusions}


Our simple modeling of the hydrodynamics of reef flats and the interactions with motu emphasizes the self-organizing capability of these systems. Understanding the interplay between

hydrodynamics and geometry leads to insightful ideas of reef flat evolution and motu formation and underlines the importance of IG waves in sediment transport across a reef flat. Previous research has relied on wave crest convergence zones (Mandlier and Kench, 2012), the presence of extreme events (Harmelin-Vivien and Laboute, 1986), or falling sea level (Dickinson, 2009; Yasukochi et al., 2014) to form motu. We find that motu formation is dependent on offshore wave climate and sediment type available for transport and deposition. The higher-energy the offshore wave climate, the deeper the predicted reef-flat depth and wider the predicted reef-flat width. However, if motu are emplaced, reef flats fronting the motu would tend to be narrower for higher-wave energy systems, as increasing wave energy increases the onshore-directed bottom shear stress driving sediment towards the motu that should promote motu accretion. The larger the sediment or denser it is, the shallower the stable equilibrium depth for the reef flat and the narrower the predicted width for the reef flat. Once there is a motu present on the reef flat, the motu width interacts dynamically with the reef-flat width to an equilibrium width.

\section{Acknowledgements}

This material is based upon work supported by Strategic Environmental Research Development Program Project RC-2336, the Ocean Ventures Fellowship, the Coastal Studies Institute, and a Geological Society of America Research Grant. Any opinions, findings, and conclusions or recommendations expressed in this material are those of the authors and do not necessarily reflect the views of the funding institutions. We would like to thank Jeff Donnelly for helpful conversations. 


\section{$9 \quad$ Figures}

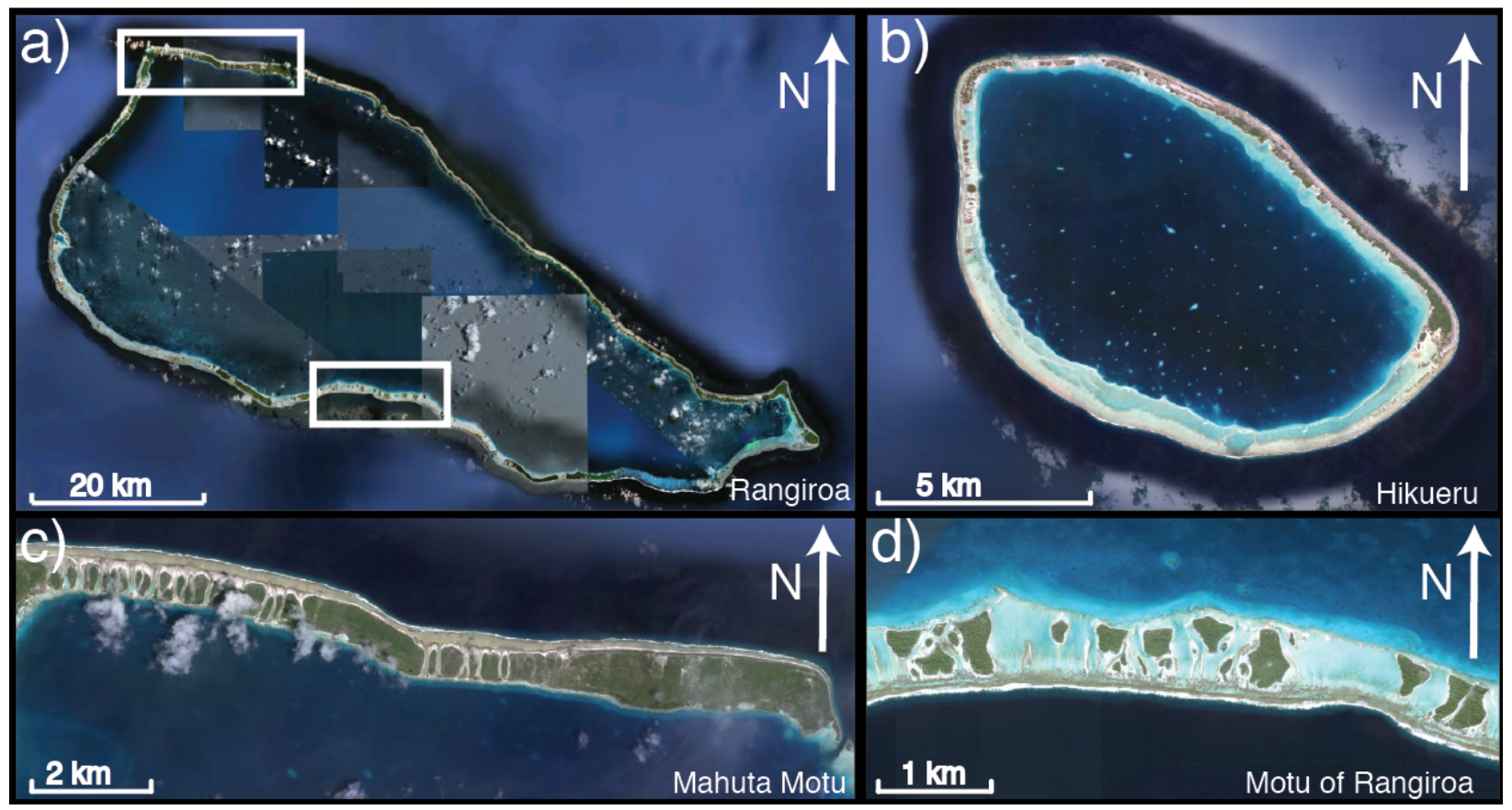

Figure 1. Aerial imagery of a) Rangiroa Atoll and b) Hikueru Atoll in French Polynesia. Varying motu morphology from Rangiroa atoll on the c) north-western coast and the d) south coast. 


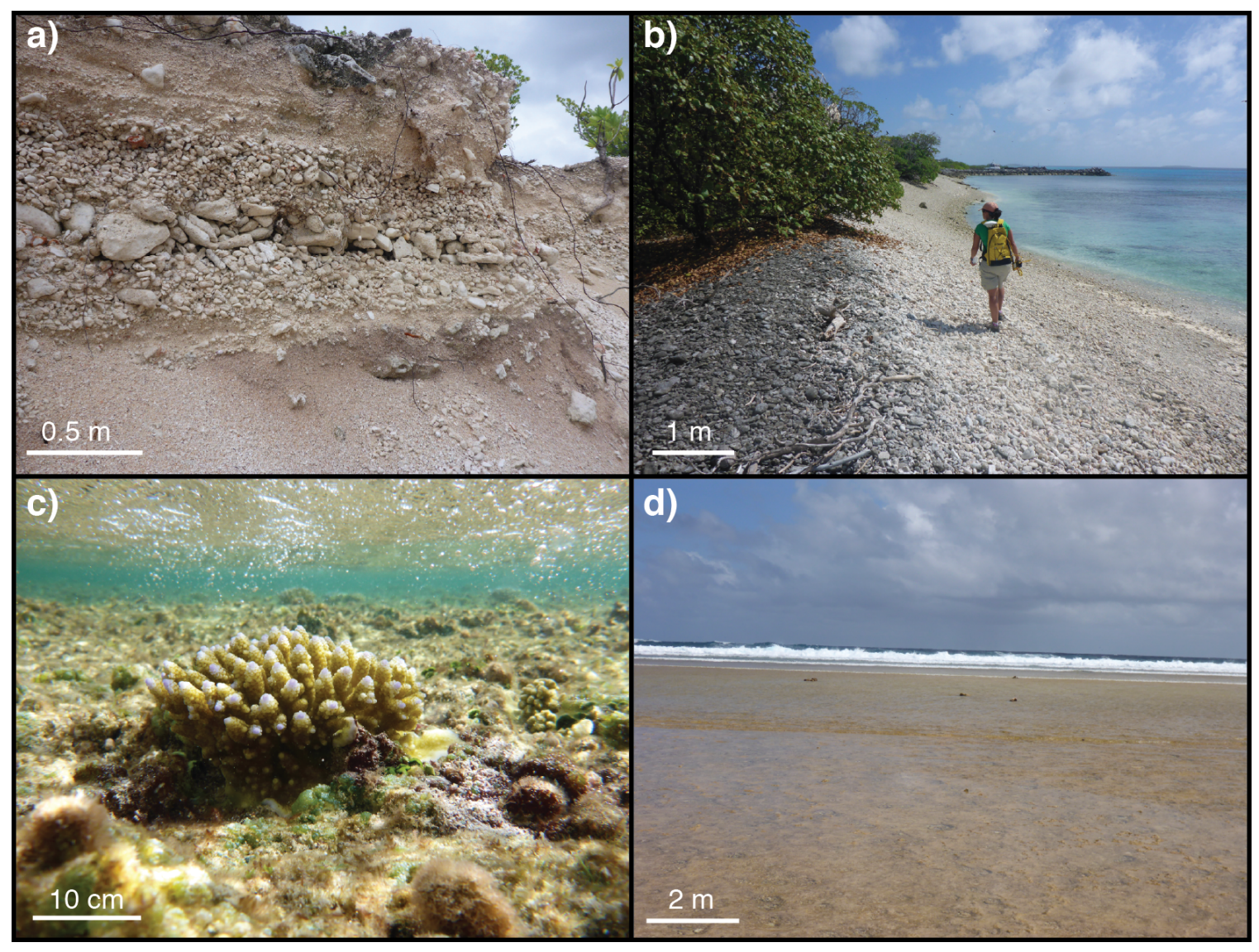

Figure 2. a) Exposed trench on Rotoava Motu, Fakarava Atoll, French Polynesia showing large variation in grain sizes of sediment composing the motu. b) Beach of motu on ocean-side in Kwajalein Atoll, c) small acropora coral on a reef flat at low tide on ocean-side, and d) reef flat at low tide on ocean-side at Ebeye Motu, Kwajalein Atoll, in the Marshall Islands. 


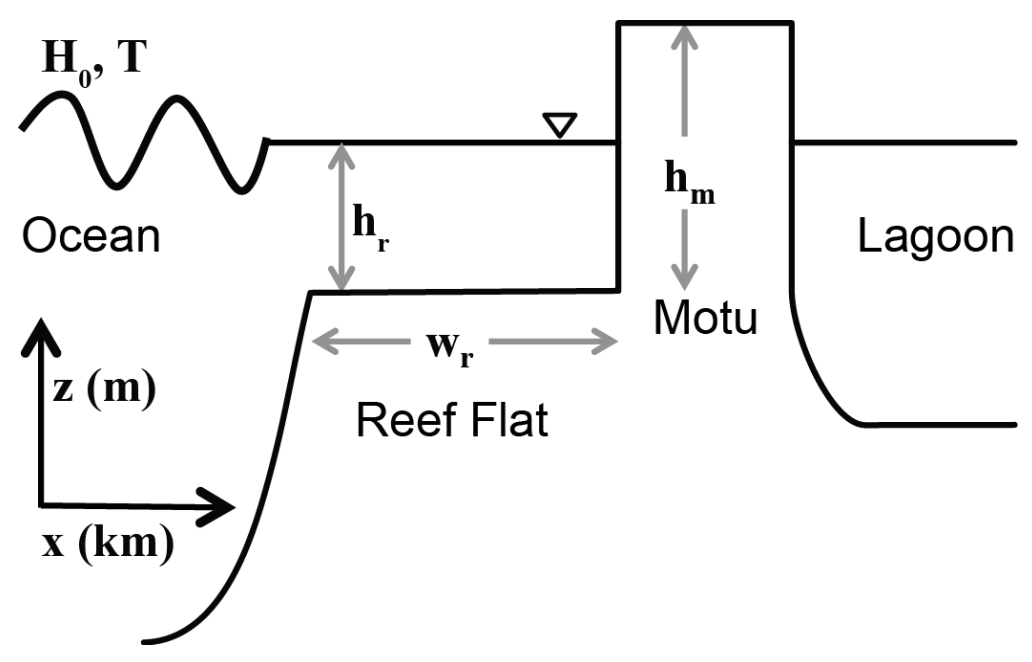

Figure 3. Example diagram of model setup for XBeach simulations with differing reef flat and motu geometries: reef-flat width $\left(w_{r}\right)$, reef-flat depth $\left(h_{r}\right)$, and motu height $\left(h_{m}\right)$. 
a)

c)
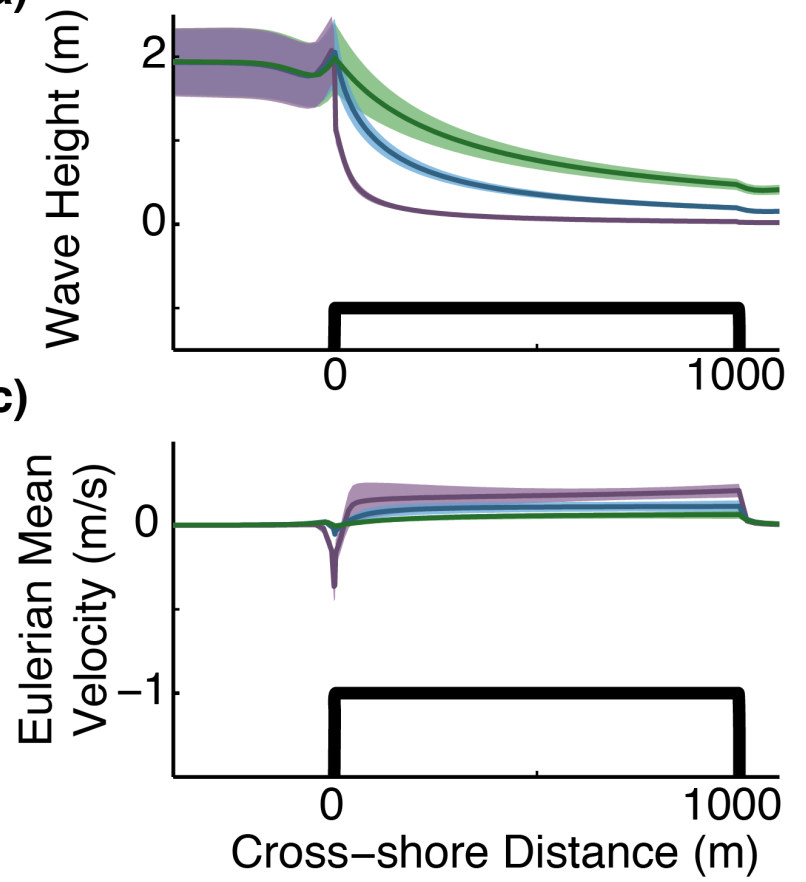

- Bathymetry

Water Depth $\left(h_{r}\right)=1.0 \mathrm{~m}$ b)

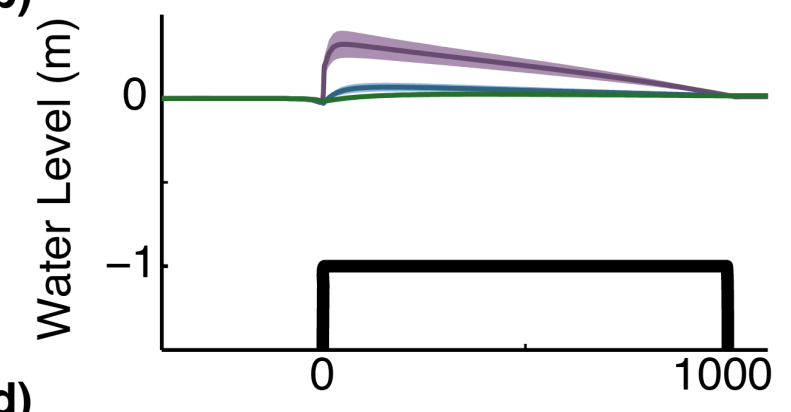

d)

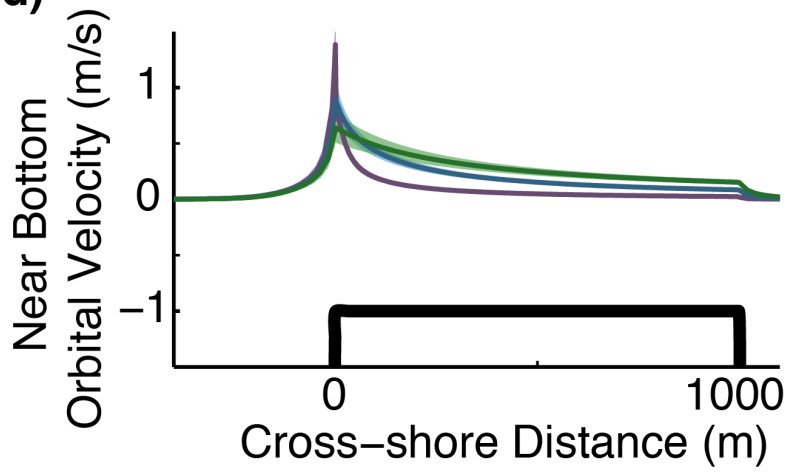

Water Depth $\left(h_{\mathrm{r}}\right)=3.0 \mathrm{~m}$

Water Depth $\left(h_{r}\right)=5.0 \mathrm{~m}$

Figure 4. Effect of varying water depth over reef flat of $1 \mathrm{~km}$ width on a) wave height, b) water level, c) mean Eulerian velocity, and d) the near-bottom orbital velocity for an offshore wave height of $2 \mathrm{~m}$ and a wave period of $10 \mathrm{~s}$. 


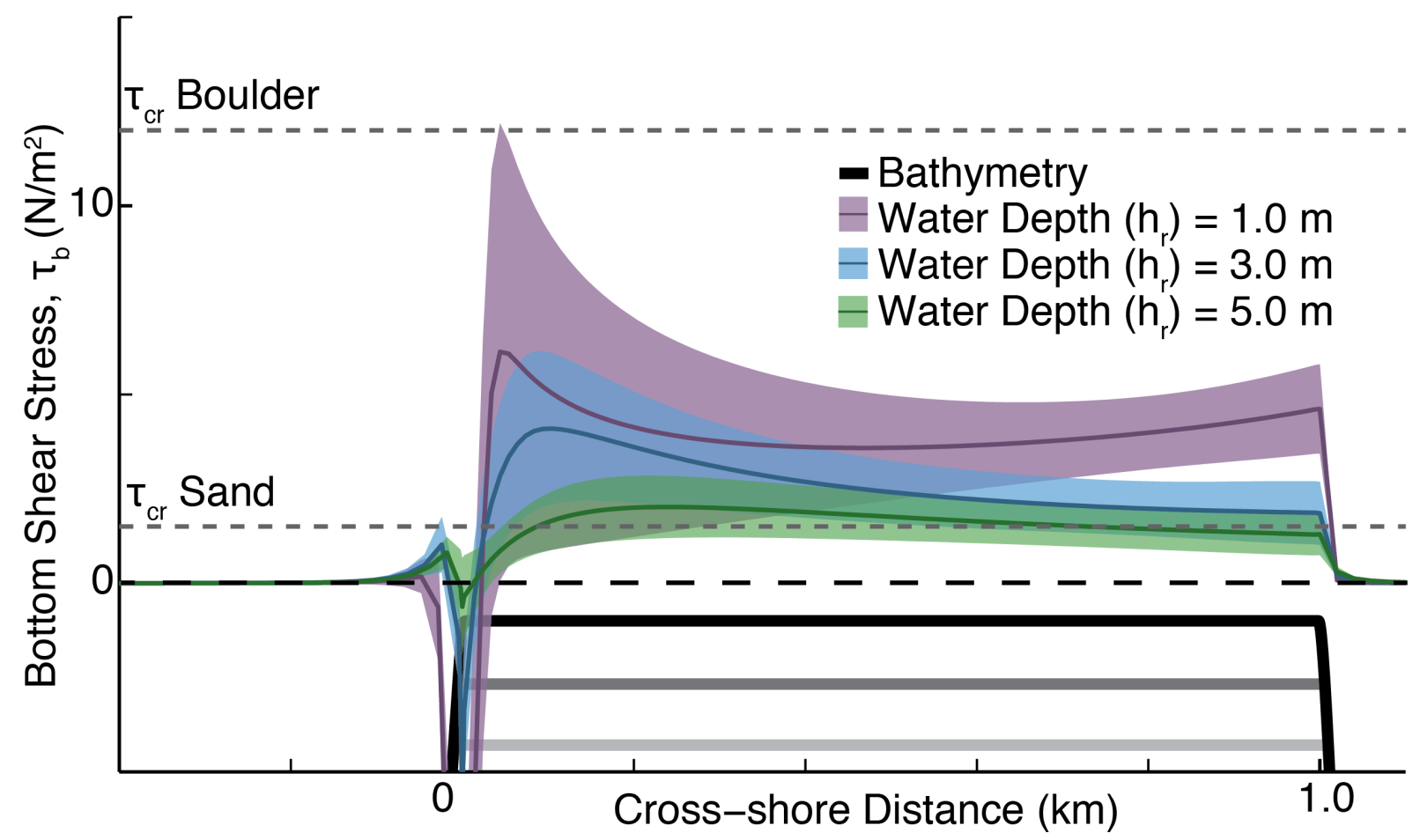

Figure 5. Effect of varying water depth over the reef flat of $1 \mathrm{~km}$ width on bottom shear stress with plotted critical shear stress for very coarse sand and a coral class for an offshore wave height of $2 \mathrm{~m}$ with a zero line plotted (dashed black line) and the varying reef-flat depths (gray solid lines). 


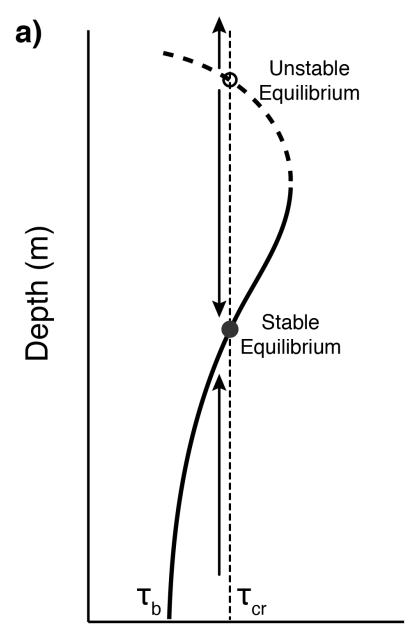

Bottom Shear Stress, $\tau_{b}\left(N / m^{2}\right)$
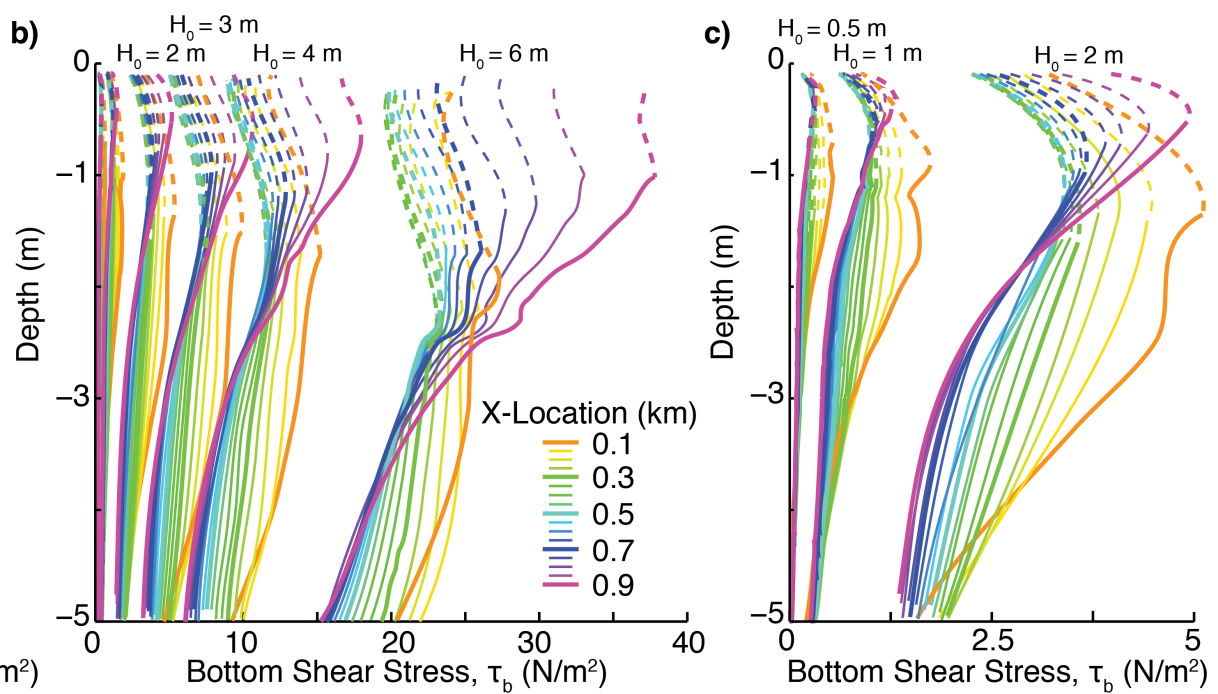

Figure 6. a) Example bottom shear stress, $\tau_{b}$, variation with depth subsequent stable and unstable equilibria for a given critical bottom shear stress, $\tau_{\mathrm{cr}}$. b) Bottom shear stress variation with depth at locations every $50 \mathrm{~m}$ across a $1 \mathrm{~km}$ wide reef flat for six different offshore wave heights $\left(H_{0}=\right.$ $0.5,1.0,2.0,3.0,4.0$, and $6.0 \mathrm{~m}$ ) where the solid line indicates potentially stable equilibria and the dashed lines indicate potentially unstable equilibria. c) Close up of bottom shear stress variation with depth at locations every $50 \mathrm{~m}$ across a $1 \mathrm{~km}$ wide reef flat for three different offshore wave heights $\left(H_{0}=0.5,1.0\right.$, and $\left.2.0 \mathrm{~m}\right)$. 


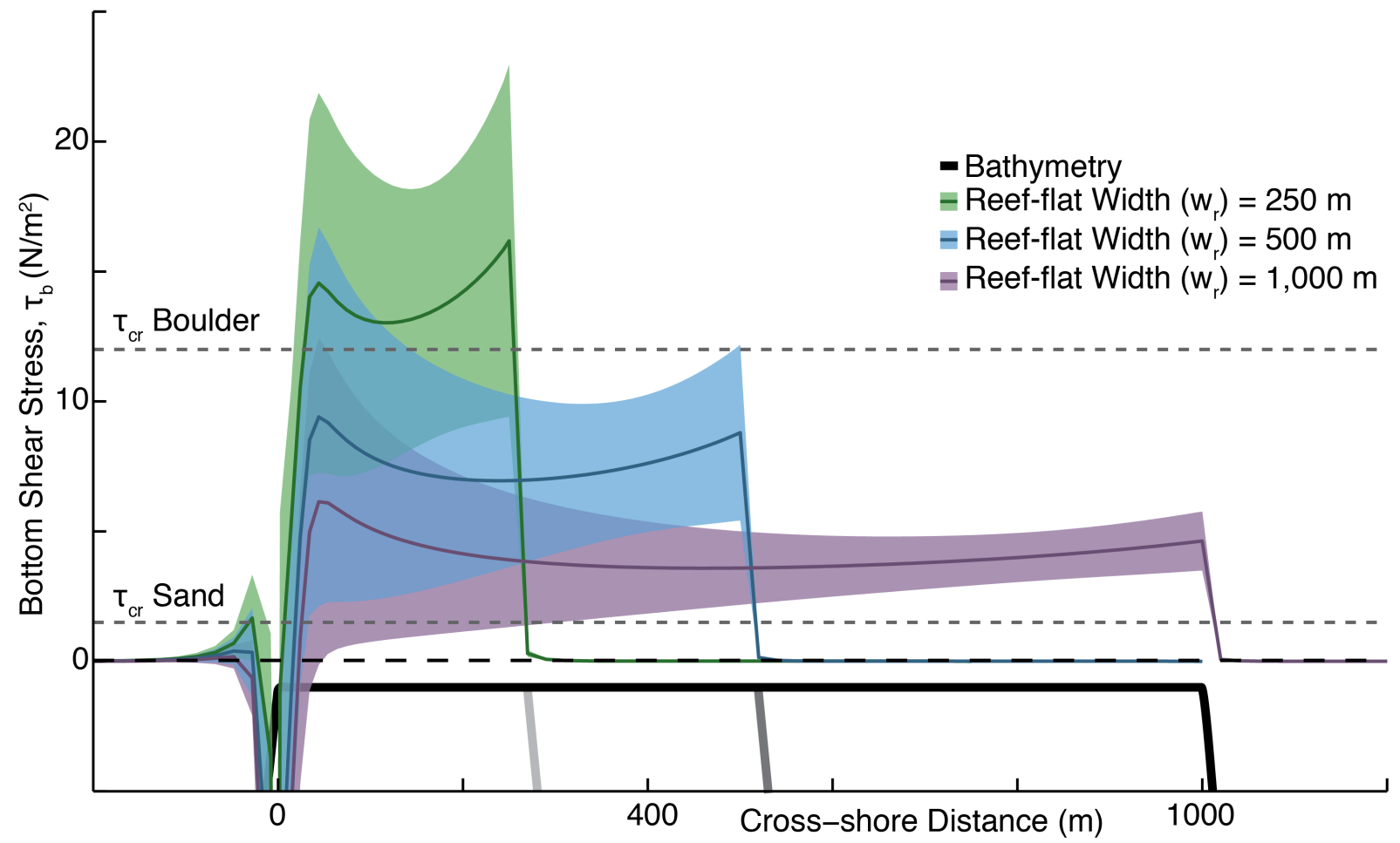

Figure 7. Effect of varying reef-flat width on bottom shear stress, $\tau_{\mathrm{b}}$, with plotted critical shear stress for a very coarse, dense sand and a coral boulder-sized clast with an offshore wave height of $2 \mathrm{~m}$ and a reef-flat water depth of $1 \mathrm{~m}$. 


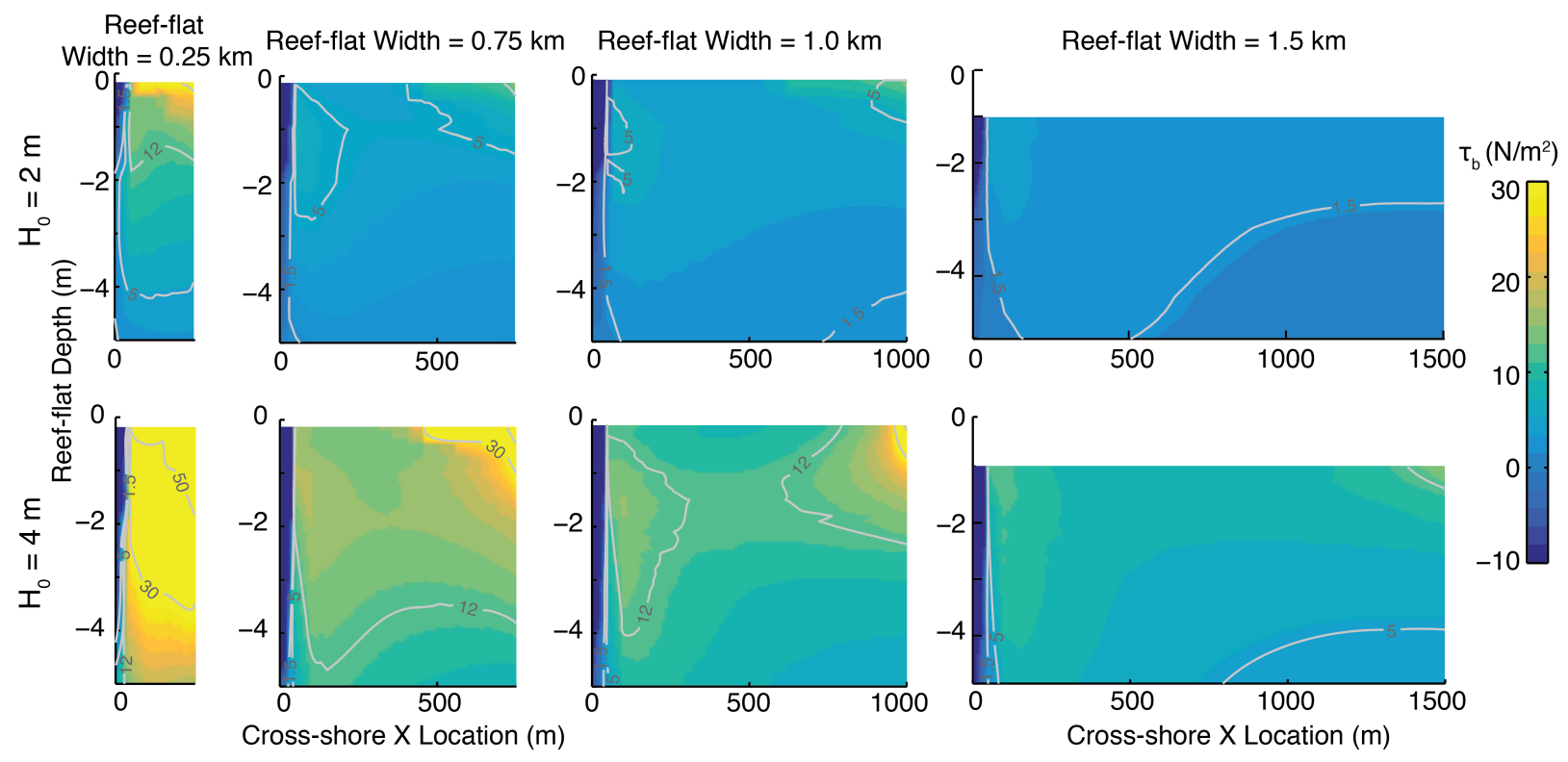

Figure 8 . Phase space plot of bottom shear stress, $\tau_{\mathrm{b}}$, across the reef flat (x-axis) for varying water depth (y-axis) for different total reef-flat widths for an offshore wave height of $2 \mathrm{~m}$ (top row) and $4 \mathrm{~m}$ (bottom row). 

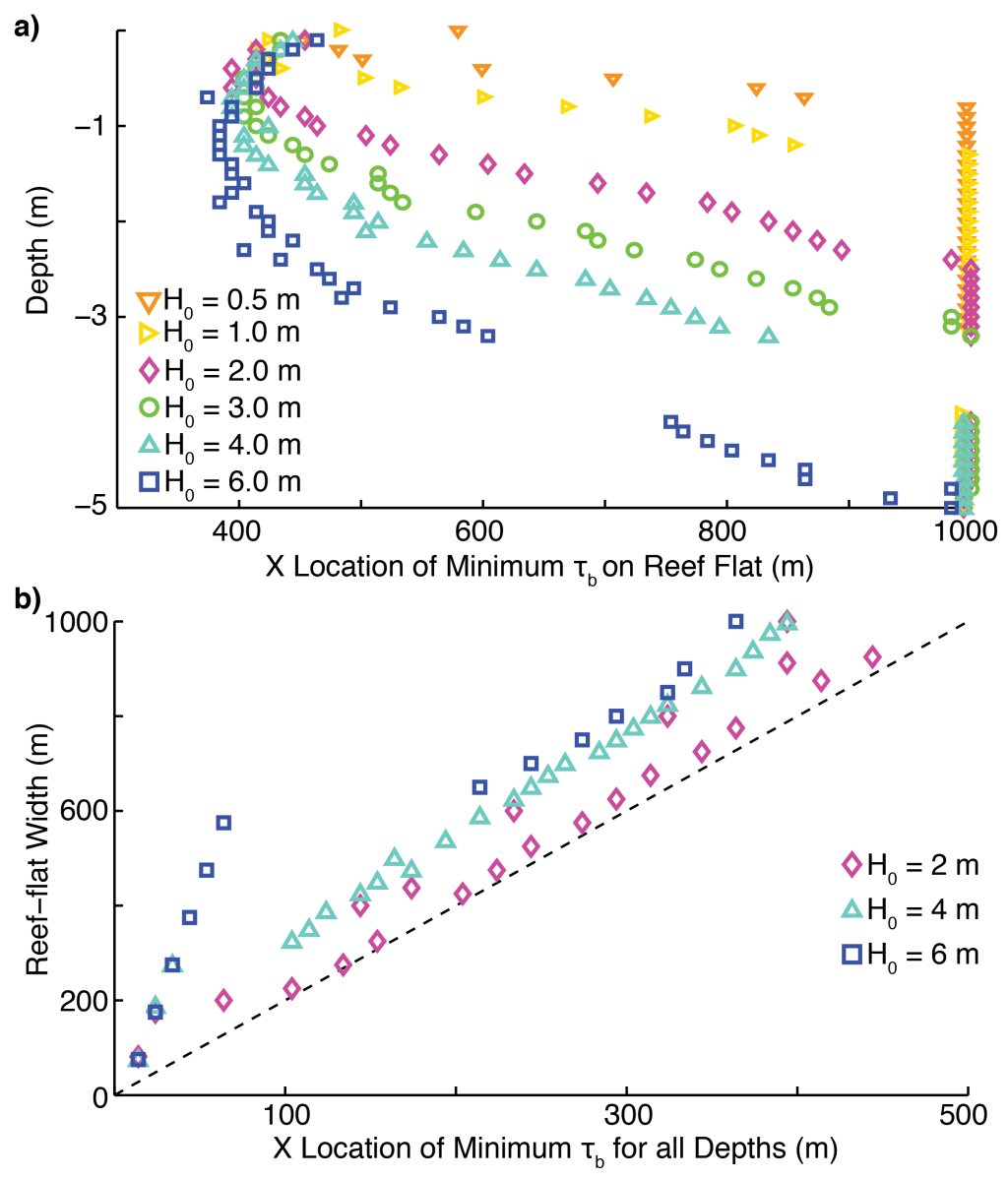

Figure 9. a) Variation of location on the reef flat of the minimum in bottom shear stress, $\tau_{b}$, with depth for six different offshore wave heights for a total reef-flat width of $1 \mathrm{~km}$. b) Variation of location of minimum bottom shear stress, $\tau_{b}$, with total reef-flat width for three different offshore wave heights. 
a)

c)
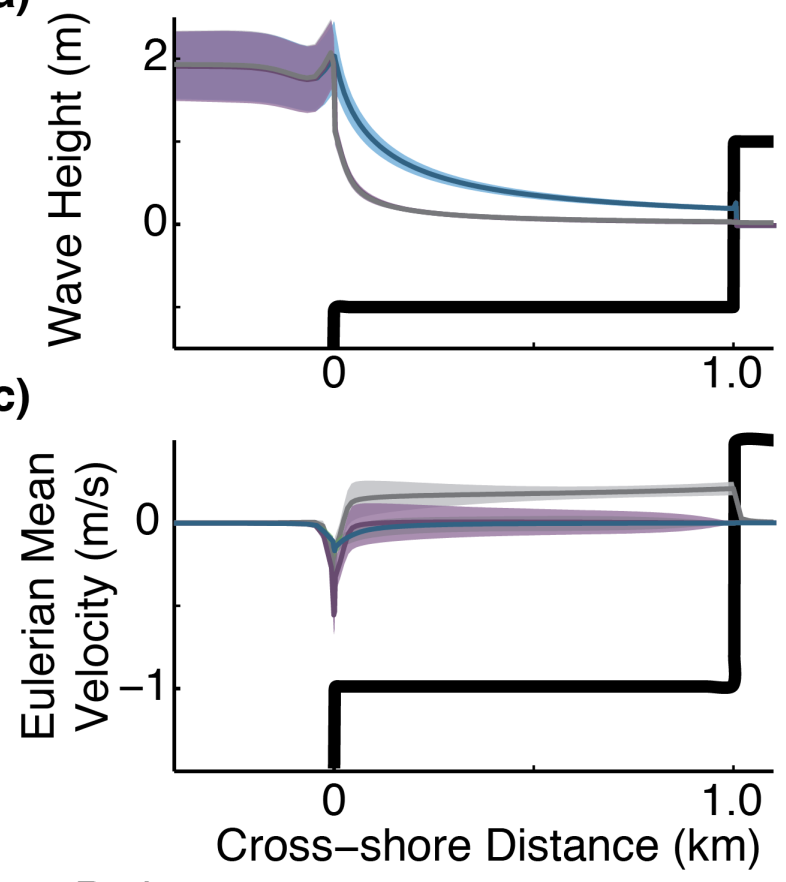

- Bathymetry

- Water Depth $\left(\mathrm{h}_{\mathrm{r}}\right)=1.0 \mathrm{~m}$, No Motu b)

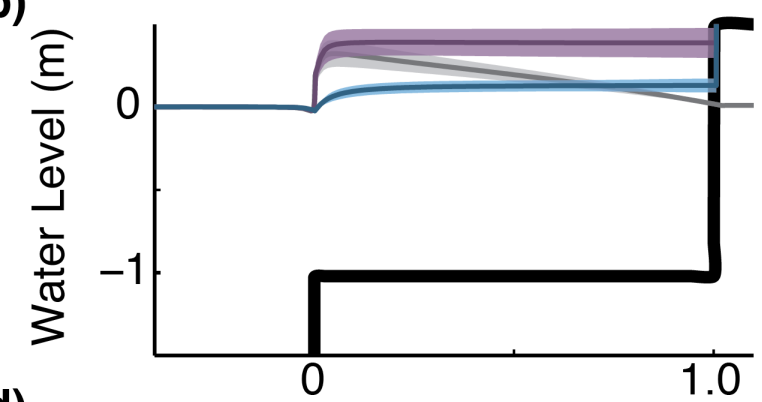

d)

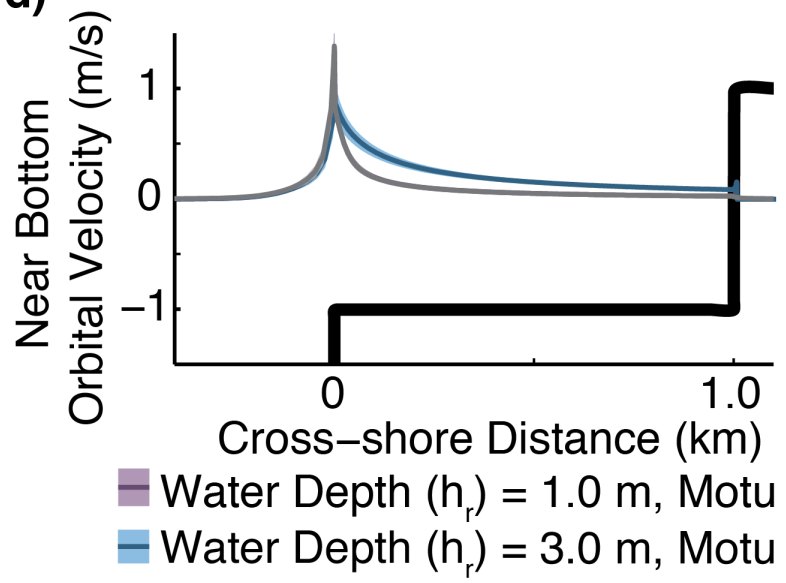

Figure 10. Effect of varying water depth over reef flat of $1 \mathrm{~km}$ width with a motu and no motu on a) wave height, b) water level, c) mean Eulerian velocity, and d) the near-bottom orbital velocity for an offshore wave height of $2 \mathrm{~m}$ and a wave period of $10 \mathrm{~s}$. 


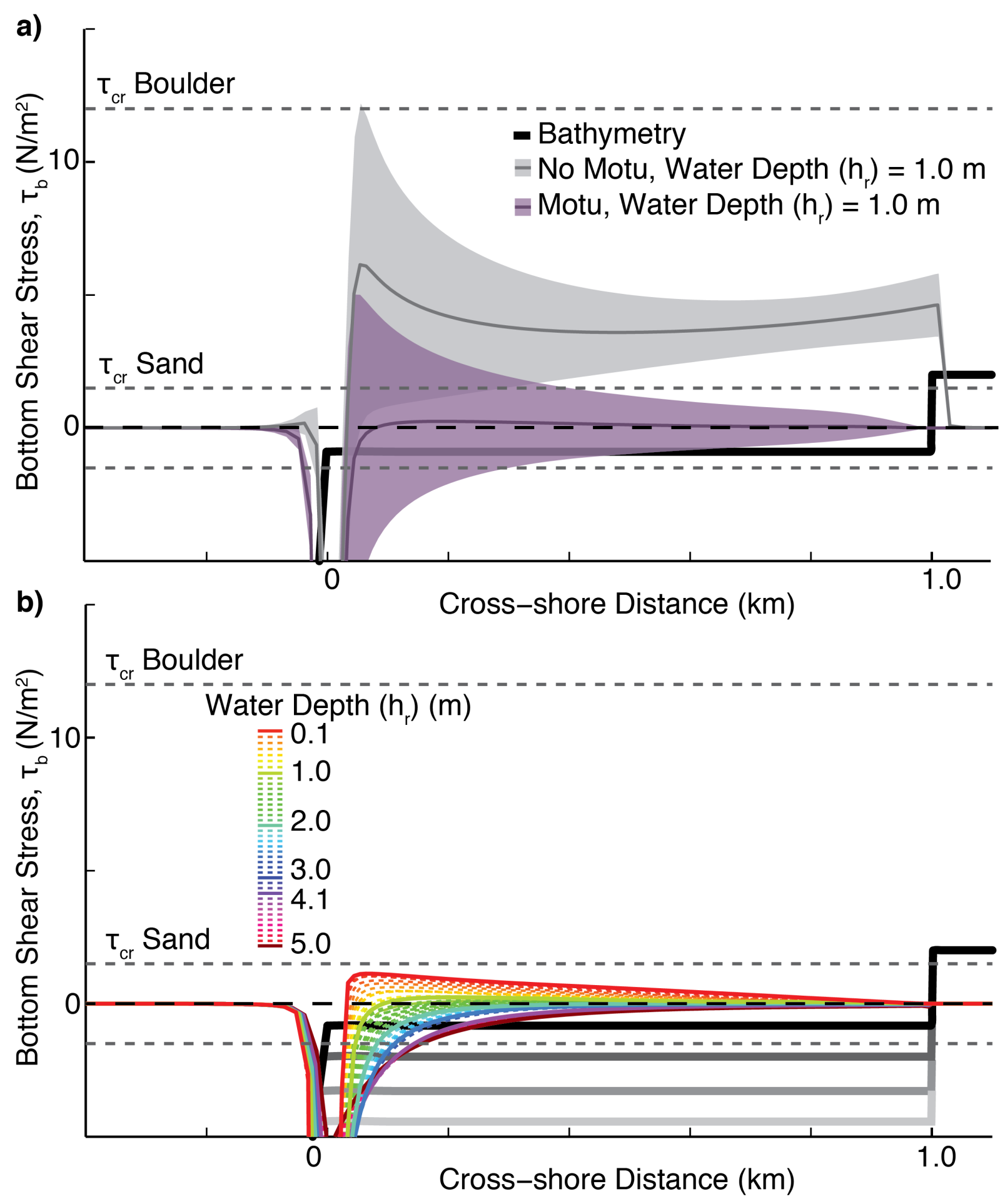

Figure 11. a) Bottom shear stress for $1 \mathrm{~m}$ deep reef flat with a reef-flat width of $1 \mathrm{~km}$ with a motu and no motu. b) Effect of varying water depth with a motu over reef flat of $1 \mathrm{~km}$ width at $0.1 \mathrm{~m}$ increments on bottom shear stress with critical shear stress for mobilizing sand and a coral boulder-sized clast plotted for an offshore wave height of $2 \mathrm{~m}$. 


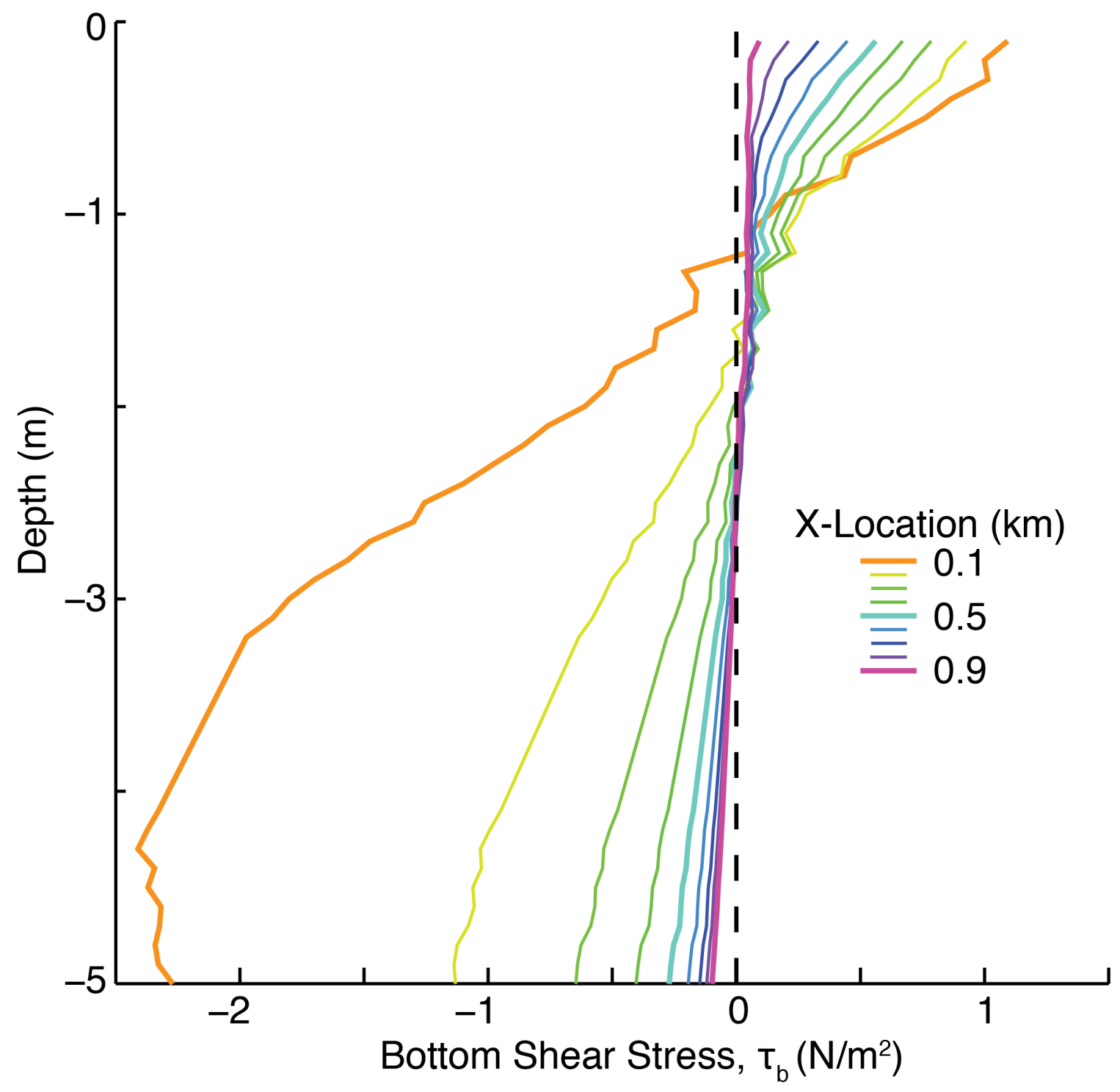

Figure 12. Variation in bottom shear stress as a function of depth for a reef flat of $1 \mathrm{~km}$ wide with a motu at locations every $100 \mathrm{~m}$ for an offshore wave height of $2 \mathrm{~m}$. 

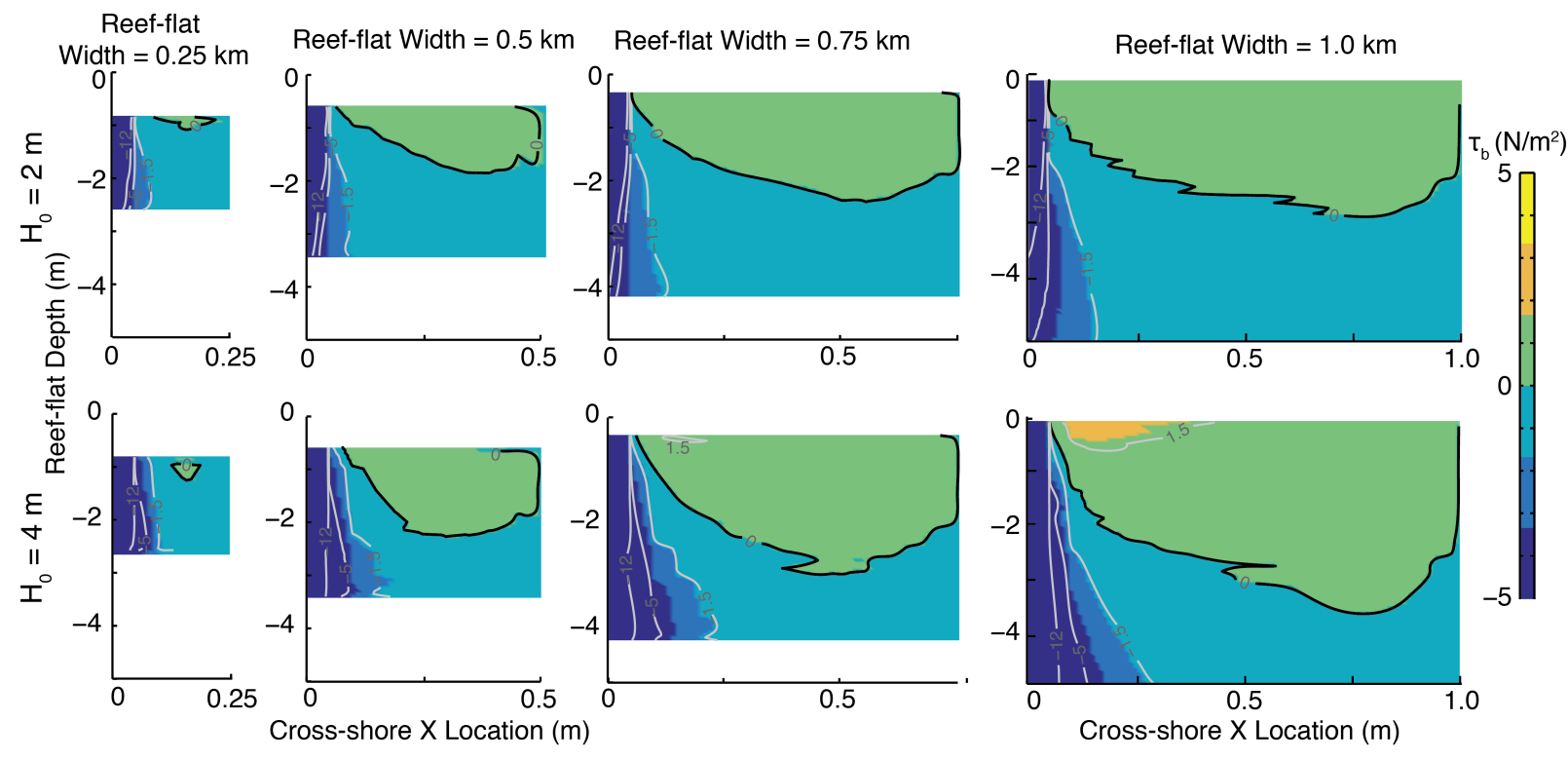

Figure 13. Varying water depth (y-axis) and $\mathrm{x}$-location over the reef flat (x-axis) with a motu for varying total reef-flat widths colored and contoured by bottom shear stress, $\tau_{\mathrm{b}}$, for an offshore wave height of $2 \mathrm{~m}$ (top row) and $4 \mathrm{~m}$ (bottom row), where the change from negative to positive shear stress is indicated by the black contour line. 

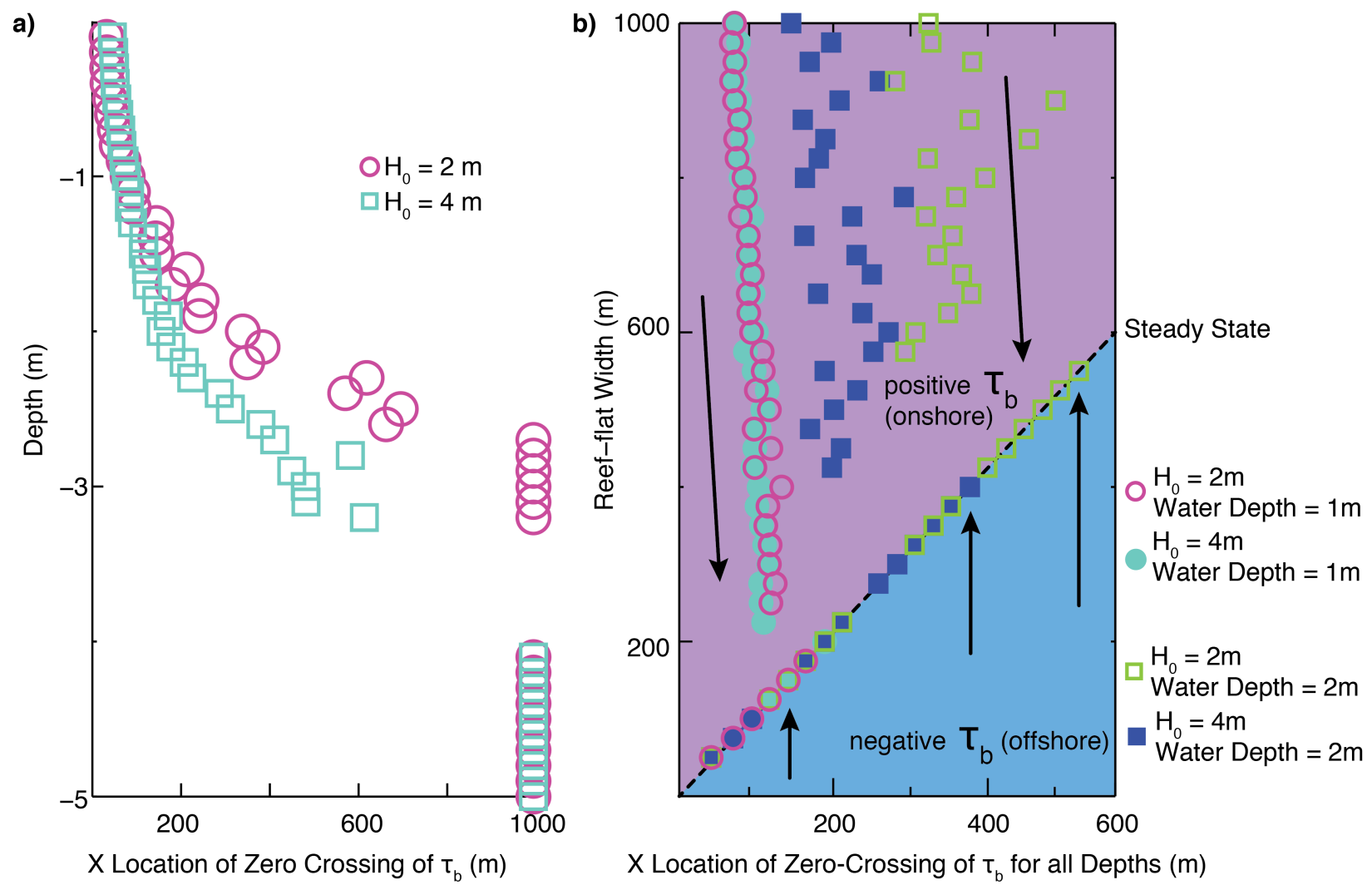

Figure 14. a) Variation of location on the reef flat with a motu of the zero crossing of bottom shear stress, $\tau_{\mathrm{b}}$, with depth for two different offshore wave heights for a total reef-flat width of 1 $\mathrm{km}$. b) Variation of location of zero crossing of bottom shear stress, $\tau_{\mathrm{b}}$, with total reef-flat width for two different offshore wave heights at two different reef-flat depths. 

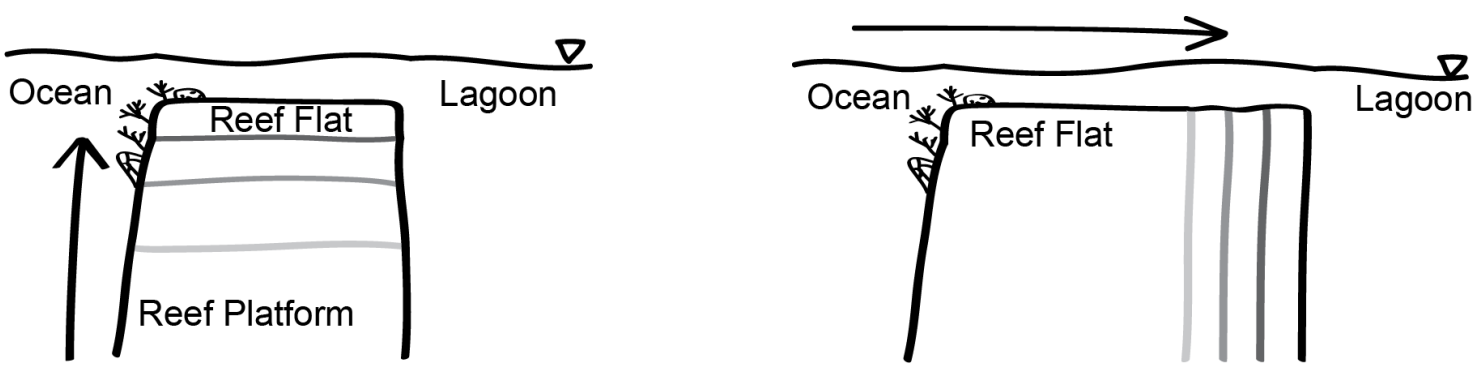

a) Vertical Growth of Reef Flat to Equilibrium Depth b) Lateral Growth of Reef Flat to Equilibrium Width

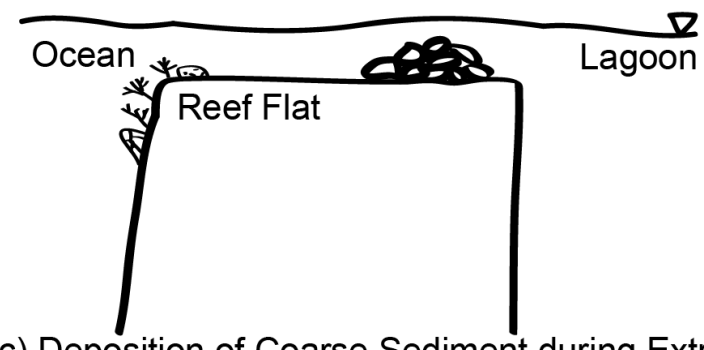

c) Deposition of Coarse Sediment during Extreme Event

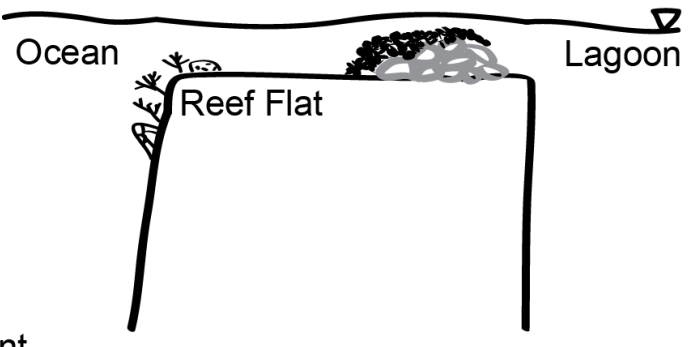

d) Deposition of Fine Sediment: Nucleation of "Proto-Motu"
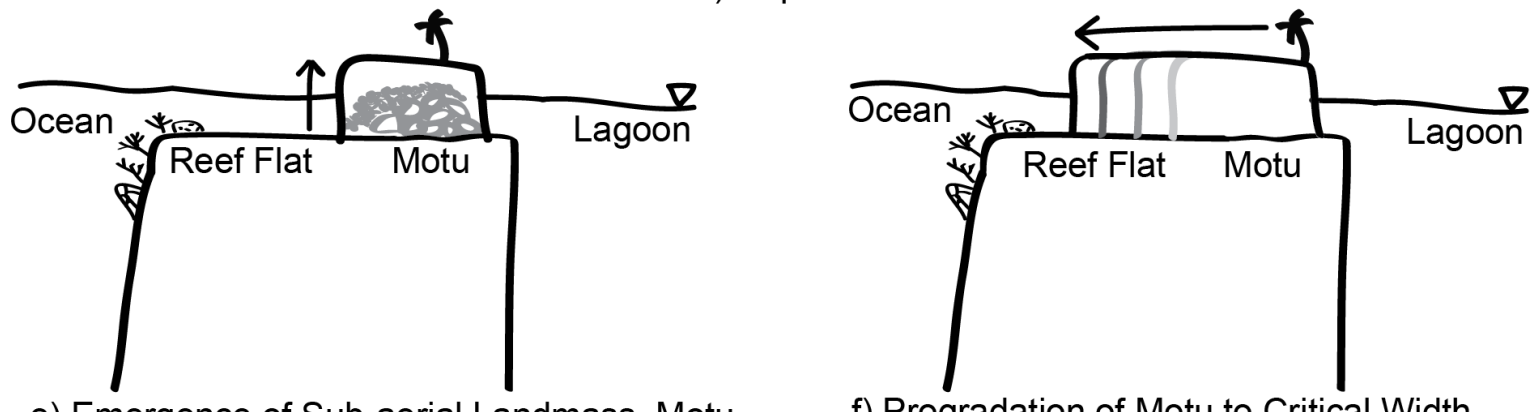

e) Emergence of Sub-aerial Landmass, Motu

f) Progradation of Motu to Critical Width

Figure 15. Conceptual diagram of possible motu formation and evolution on a reef flat. a) The reef platform accretes vertically until reaching an equilibrium depth, b) subsequent lateral growth as the reef flat depth is maintained. c) During an extreme event increased bottom shear stress leads to mobilization of coarser-grained sediment from the reef edge, which is subsequently deposited at the shear minimum approximately halfway across the reef flat. d) During subsequent fair-weather conditions, even if the coral rubble is below sea level it may be shallow enough that increased deposition of fine sediment over the pile of coarse sediment could lead to the shoaling of a "proto-motu," an incipient landmass on the reef flat. e) Continued deposition of sediment leads to the formation of a sub-aerial landmass, a motu, onshore of the reef edge. f) The motu progrades laterally over the reef flat until the reef flat reaches a critical width. 


\section{Supplemental Information}

As water depth increases over the reef flat, there is increased cross-shore radiation stress over the reef flat (Figure S1). Radiation stress is the depth-averaged momentum flux, and induces changes in mean surface elevation and mean flow. We tease out the non-linear components of bottom shear stress by investigating the effect of turning off the generation of infragravity waves in the model simulations (Figure S2). Mean wave height and near bottom orbital velocity over the reef-flat has little difference with the generation of IG waves (Figure S2a \& S2d). Water elevation is significantly increased over the reef flat with the generation of IG waves (Figure S2b). The mean Eulerian velocity is also decreased with no IG wave generated (Figure S2c). These results highlight the importance of IG waves in transformation over the reef fleet and the importance of penetration of waves over the reef flat.

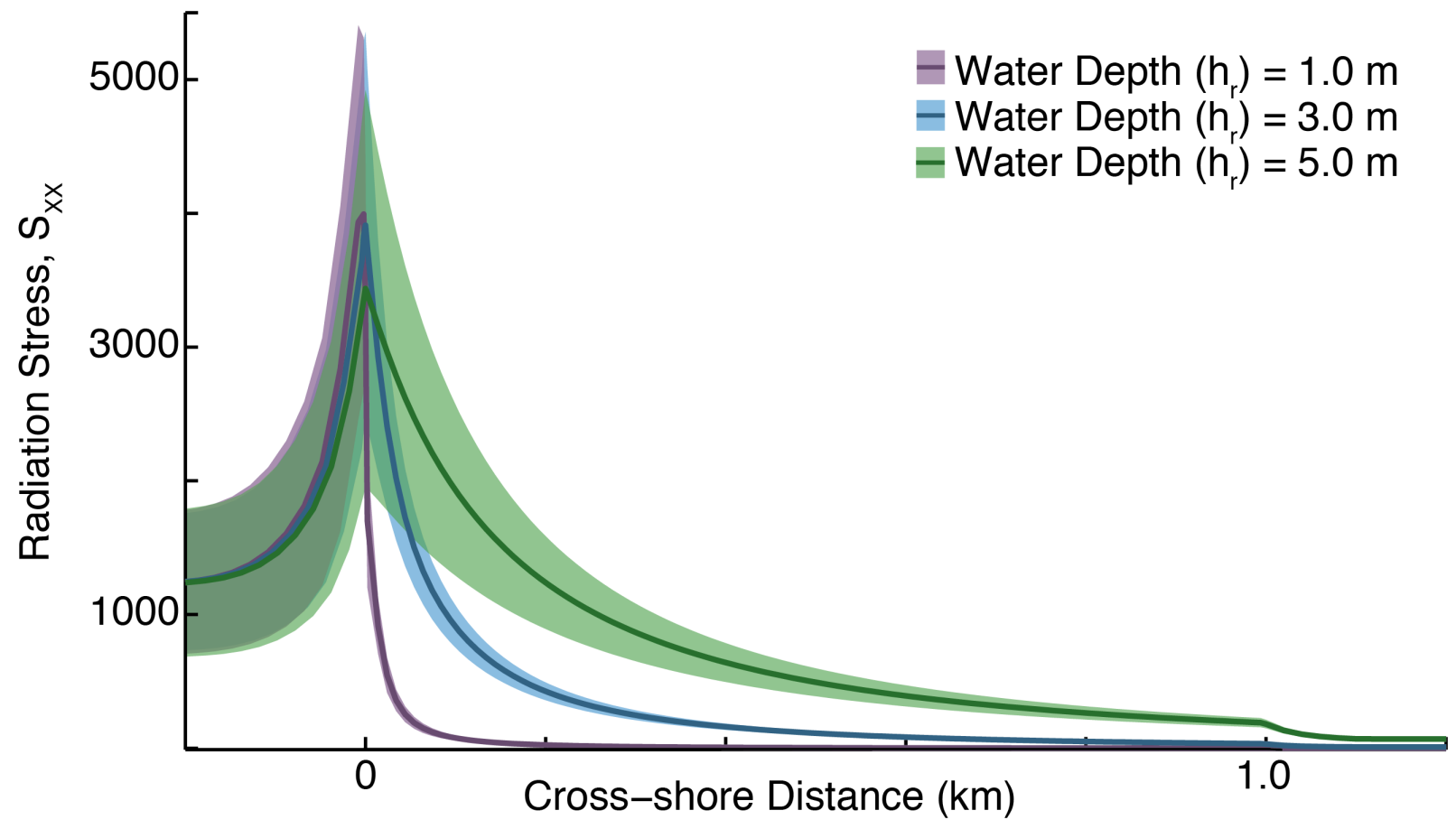

Figure $\mathrm{S} 1$. Variation in radiation stress, $\mathrm{S}_{\mathrm{XX}}$, as a function of depth for a reef flat of $1 \mathrm{~km}$ wide. 
a)

c)
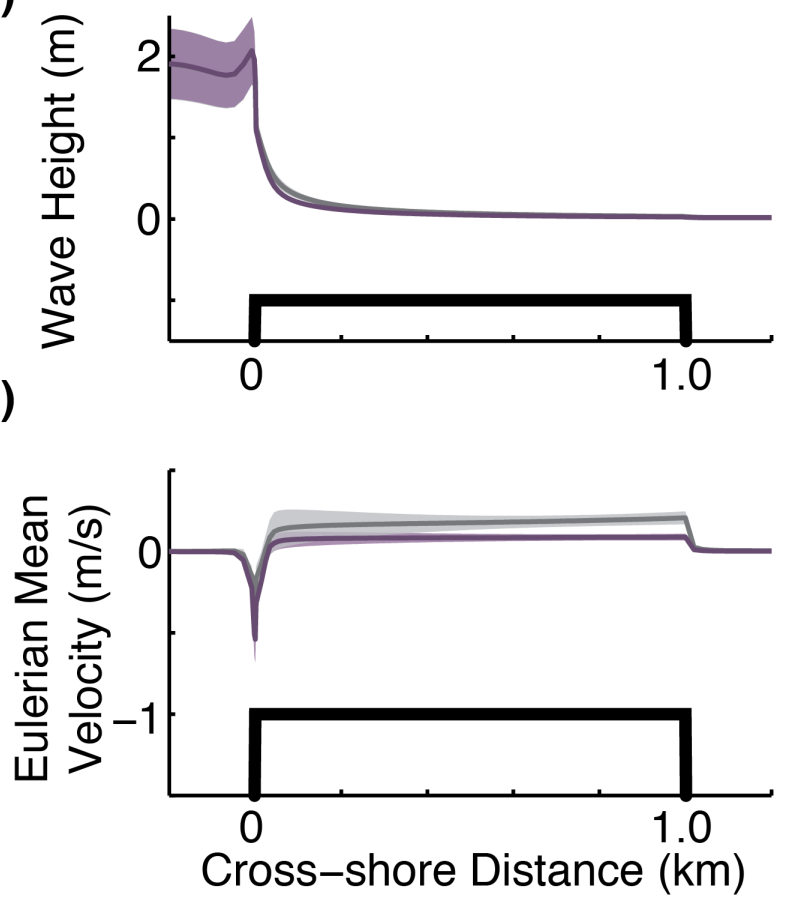

- Bathymetry b)

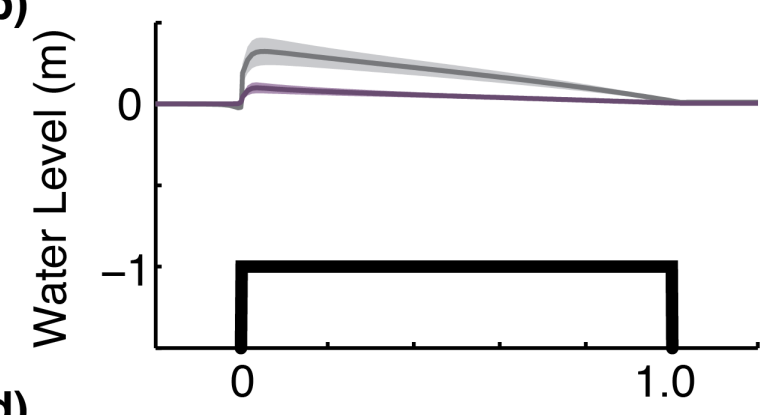

d)

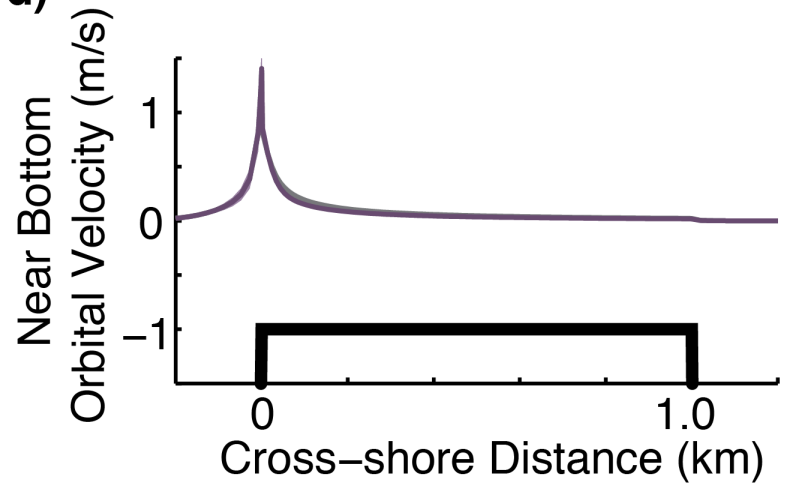

No IG Waves,

Water Depth $\left(h_{r}\right)=1.0 \mathrm{~m}$

Figure S2. Effect of generation of infragravity waves over reef flat of $1 \mathrm{~km}$ width on a) wave height, b) water level, c) mean Eulerian velocity, and d) the near-bottom orbital velocity for an offshore wave height of $2 \mathrm{~m}$ and a wave period of $10 \mathrm{~s}$.

Infragravity waves are important for the magnitude of bottom shear stress over the entire width of the reef flat, contributing up to $50 \%$ of the bottom shear stress (Figure S3). The generation of IG waves also increases the temporal variability of the bottom shear stress increasing the potential of sediment transport of coarse sediment over the reef flat. Without infragravity waves, onshore sediment transport is damped and for deep reef flats, there can even be significant offshore sediment transport. When a motu is present on the reef flat, the generation of IG waves merely dampens the bottom shear stress temporal variability, while having very little effect on the mean bottom shear stress (Figure S4). 


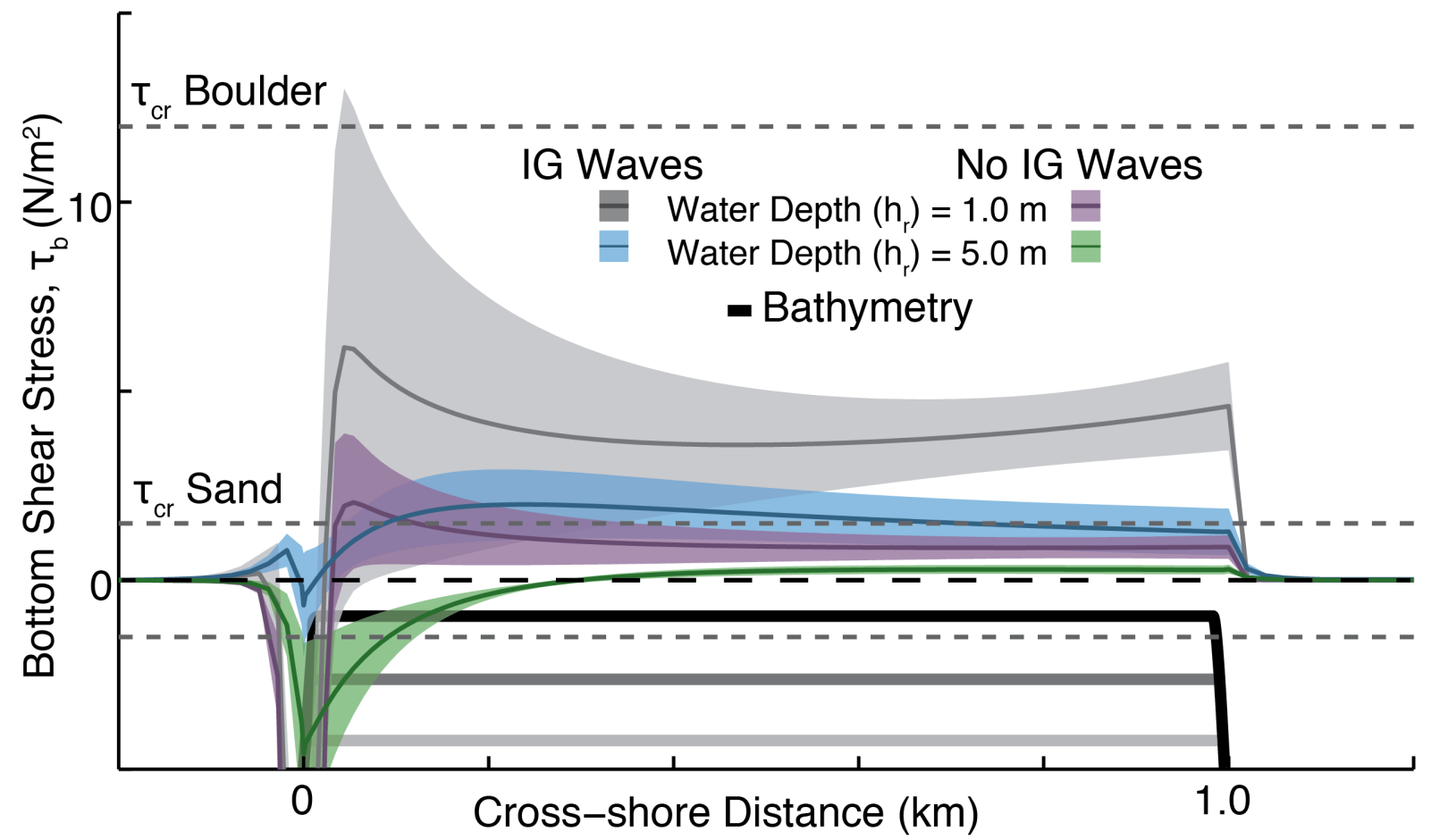

Figure S3. Effect of varying IG generation and water depth over the reef flat of $1 \mathrm{~km}$ width on bottom shear stress with plotted critical shear stress for very coarse sand and a coral class for an offshore wave height of $2 \mathrm{~m}$ with a zero line plotted (dashed black line) and the varying reef-flat depths (gray solid lines). 


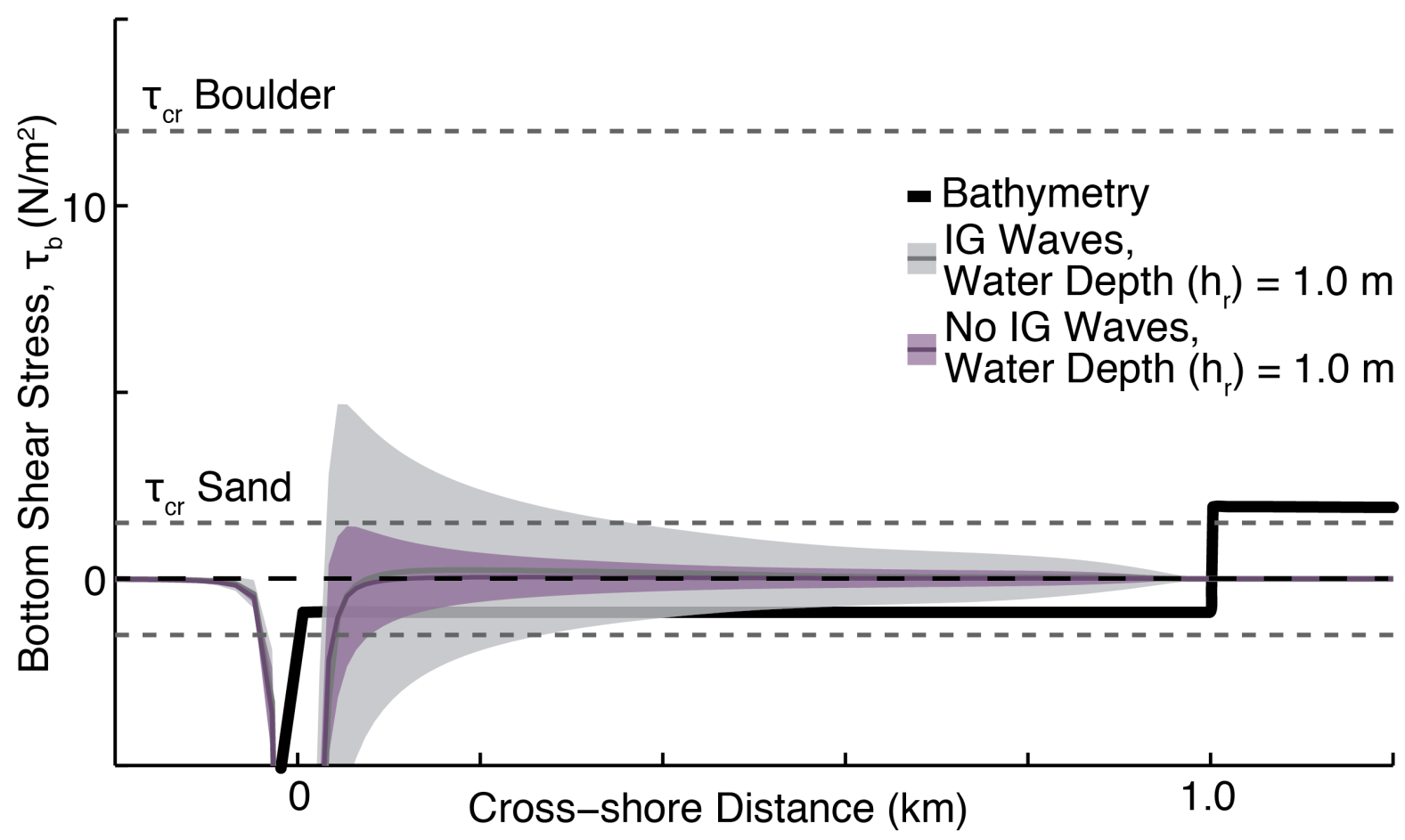

Figure S4. Bottom shear stress for $1 \mathrm{~m}$ deep reef flat with a reef-flat width of $1 \mathrm{~km}$ with a motu with generation of IG waves or no IG waves.

\section{References}

Barnett, J., and Adger, W.N., 2003, Climate Dangers and Atoll Countries: Climatic Change, v. 61, no. 3, p. 321-337, doi: 10.1023/B:CLIM.0000004559.08755.88.

Barry, S.J., Cowell, P.J., and Woodroffe, C.D., 2008, Growth-limiting size of atoll-islets: Morphodynamics in nature: Marine Geology, v. 247, no. 3-4, p. 159-177, doi: 10.1016/j.margeo.2007.09.004.

Bayliss-Smith, T.P., 1988, The Role of Hurricanes in the Development of Reef Islands, Ontong Java Atoll, Solomon Islands: The Geographical Journal, v. 154, no. 3, p. 377-391, doi: $10.2307 / 634610$.

Becker, J.M., Merrifield, M.A., and Ford, M., 2014, Water level effects on breaking wave setup for Pacific Island fringing reefs: Journal of Geophysical Research: Oceans, v. 119, no. 2, p. 914-932, doi: 10.1002/2013JC009373.

Bourrouilh-Le Jan, F., and Talandier, J., 1985, Sedimentation et fracturation de haute energie en milieu recifal: tsunamis, ouragans et cyclones, leurs effets sur la sedimentation et la geometrie d'un atoll: Marine Geology, v. 67. 
Brander, R.W., Kench, P.S., and Hart, D., 2004, Spatial and temporal variations in wave characteristics across a reef platform, Warraber Island, Torres Strait, Australia: Marine Geology, v. 207, no. 1-4, p. 169-184, doi: http://dx.doi.org/10.1016/j.margeo.2004.03.014.

Carter, R.W.G., and Woodroffe, C.D., 1994, Coral atolls, in Carter, R.W.G. and Woodroffe, C.D. eds., Coastal evolution: Late Quaternary shoreline morphodynamics, Cambridge University Press, Cambridge, p. 267-302.

Church, J.A., White, N.J., and Hunter, J.R., 2006, Sea-level rise at tropical Pacific and Indian Ocean islands: Global and Planetary Change, v. 53.

Dickinson, W.R., 1998, Holocene Sea-Level Record on Funafuti and Potential Impact of Global Warming on Central Pacific Atolls: Quaternary Research, v. 51.

Dickinson, W.R., 2003, Impact of Mid-Holocene Hydro-Isostatic Highstand in Regional Sea Level on Habitability of Islands in Pacific Oceania: Journal of Coastal Research, v. 19, no. 3, p. 489-502.

Dickinson, W.R., 2009, Pacific atoll living: how long already and until when? GSA Today, v. 19, no. 3, p. 4-10, doi: 10.1130/GSATG35A.1.

Van Dongeren, A., Lowe, R., Pomeroy, A., Trang, D.M., Roelvink, D., Symonds, G., and Ranasinghe, R., 2013, Numerical modeling of low-frequency wave dynamics over a fringing coral reef: Coastal Engineering, v. 73, no. 0, p. 178-190, doi: http://dx.doi.org/10.1016/j.coastaleng.2012.11.004.

Fagherazzi, S., Carniello, L., D'Alpaos, L., and Defina, A., 2006, Critical bifurcation of shallow microtidal landforms in tidal flats and salt marshes: Proceedings of the National Academy of Sciences , v. 103 , no. 22 , p. 8337-8341, doi: 10.1073/pnas.0508379103.

Ford, M., 2013, Shoreline changes interpreted from multi-temporal aerial photographs and high resolution satellite images: Wotje Atoll, Marshall Islands: Remote Sensing of Environment, v. 135, p. 130-140, doi: 10.1016/j.rse.2013.03.027.

Ford, M.R., 2014, The application of PIT tags to measure transport of detrital coral fragments on a fringing reef: Majuro Atoll, Marshall Islands: Coral reefs, v. 33, no. 2, p. 375-379.

Ford, M.R., and Kench, P.S., 2014, Formation and adjustment of typhoon-impacted reef islands interpreted from remote imagery: Nadikdik Atoll, Marshall Islands: Geomorphology, v. 214, p. 216-222, doi: 10.1016/j.geomorph.2014.02.006.

Fredsoe, J., and Deigaard, R., 1992, Mechanics of Coastal Sediment Transport (P. L.-F. Liu, Ed.): World Scientific Publishing Co Pte Ltd.

Gelfenbaum, G., Apotsos, A., Stevens, A.W., and Jaffe, B., 2011, Effects of fringing reefs on tsunami inundation: American Samoa: Earth-Science Reviews, v. 107, no. 1, p. 12-22. 
Harmelin-Vivien, M.L., and Laboute, P., 1986, Catastrophic impact of hurricanes on atoll outer reef slopes in the Tuamotu (French Polynesia): Coral Reefs, v. 5.

Horton, B.P., Rahmstorf, S., Engelhart, S.E., and Kemp, A.C., 2014, Expert assessment of sealevel rise by AD 2100 and AD 2300: Quaternary Science Reviews, v. 84, p. 1-6, doi: 10.1016/j.quascirev.2013.11.002.

IPCC, 2013, IPCC, 2013: Summary for Policymakers. In: Climate Change 2013: The Physical Science Basis. Contribution of Working Group I to the Fifth Assessment Report of the Intergovernmental Panel on Climate Change: Cambridge University Press.

Kench, P.S., and Brander, R.W., 2006, Wave Processes on Coral Reef Flats: Implications for Reef Geomorphology Using Australian Case Studies: Journal of Coastal Research, v. 22.

Kench, P.S., Brander, R.W., Parnell, K.E., and McLean, R.F., 2006, Wave energy gradients across a Maldivian atoll: Implications for island geomorphology: Geomorphology, v. 81 .

Kench, P.S., Chan, J., Owen, S.D., and McLean, R.F., 2014a, The geomorphology, development and temporal dynamics of Tepuka Island, Funafuti atoll, Tuvalu: Geomorphology, v. 222, p. 46-58, doi: 10.1016/j.geomorph.2014.03.043.

Kench, P.S., and Cowell, P.J., 2001, The Morphological Response of Atoll Islands to Sea-Level Rise. Part 2: Application of the Modified Shoreface Translation Model (STM): Journal of Coastal Research, v. 34.

Kench, P.S., McLean, R.F., and Nichol, S.L., 2005, New model for reef-island evolution: Maldives, Indian Ocean: Geology, v. 33.

Kench, P.S., Owen, S.D., and Ford, M.R., 2014b, Evidence for coral island formation during rising sea level in the central Pacific Ocean: Geophysical Research Letters, v. 41, no. 3, p. 820-827, doi: 10.1002/2013GL059000.

Kopp, R.E., Horton, R.M., Little, C.M., Mitrovica, J.X., Oppenheimer, M., Rasmussen, D.J., Strauss, B.H., and Tebaldi, C., 2014, Probabilistic 21st and 22nd century sea-level projections at a global network of tide-gauge sites: Earth's Future, v. 2, no. 8, p. 383-406, doi: 10.1002/2014EF000239.

Kunkel, C.M., Hallberg, R.W., and Oppenheimer, M., 2006, Coral reefs reduce tsunami impact in model simulations: Geophysical Research Letters, v. 33, no. 23.

Lugo-Fernández, A., Roberts, H.H., and Suhayda, J.N., 1998, Wave transformations across a Caribbean fringing-barrier coral reef: Continental Shelf Research, v. 18, no. 10, p. 10991124.

Madsen, O.S., 1991, Mechanics of cohesionless sediment transport in coastal waters, in Coastal Sediments, ASCE, p. 15-27. 
Mandlier, P.G., and Kench, P.S., 2012, Analytical modelling of wave refraction and convergence on coral reef platforms: Implications for island formation and stability: Geomorphology, $\mathrm{v}$. 159 , p. 84-92.

McCall, R.T., Plant, N., and van Thiel de Vries, J., 2011, The effect of longshore topographic variation on overwash modelling:.

McLean, R.F., and Woodroffe, C.D., 1994, Coral Atolls, in Carter, R.W.G. and Woodroffe, C.D. eds., Coastal evolution: Late Quaternary shoreline morphodynamics, Cambridge University Press.

Miller, M.C., McCave, I.N., and Komar, P.D., 1977, Threshold of sediment motion under unidirectional currents: Sedimentology, v. 24, no. 4, p. 507-527.

Mimura, N., 1999, Vulnerability of island countries in the South Pacific to sea level rise and climate change: Climate research, v. 12, no. 2-3, p. 137-143.

Mitrovica, J.X., and Milne, G.A., 2002, On the origin of the late Holocene sea-level highstands within the equatorial basins: Quaternary Science Reviews, v. 21.

Monismith, S.G., Herdman, L.M.M., Ahmerkamp, S., and Hench, J.L., 2013, Wave Transformation and Wave-Driven Flow across a Steep Coral Reef: Journal of Physical Oceanography, v. 43, no. 7, p. 1356-1379, doi: 10.1175/JPO-D-12-0164.1.

Murphy, F.J., 2009, Motu, in Gillespie, R.G. and Clague, D.A. eds., Encyclopedia of islands, University of California Press, Berkeley.

Nunn, P.D., 1990, Coastal Processes and Landforms of Fiji: Their Bearing on Holocene SeaLevel Changes in the South and West Pacific: Journal of Coastal Research, v. 6, no. 2.

Nunn, P.D., 1998, Sea-Level Changes over the past 1,000 Years in the Pacific: Journal of Coastal Research, v. 14, no. 1.

Peltier, W.R., 2001, Global glacial isostatic adjustment and modern instrumental records of relative sea level history: International Geophysics, v. 75, p. 65-95.

Péquignet, A.-C., Becker, J.M., Merrifield, M.A., and Boc, S.J., 2011, The dissipation of wind wave energy across a fringing reef at Ipan, Guam: Coral Reefs, v. 30, no. 1, p. 71-82.

Perry, C.T., Kench, P.S., O’Leary, M.J., Morgan, K.M., and Januchowski-Hartley, F., 2015, Linking reef ecology to island building: Parrotfish identified as major producers of islandbuilding sediment in the Maldives: Geology , doi: 10.1130/G36623.1.

Perry, C.T., Kench, P.S., Smithers, S.G., Riegl, B., Yamano, H., and O’Leary, M.J., 2011, Implications of reef ecosystem change for the stability and maintenance of coral reef islands: Global Change Biology, v. 17, no. 12, p. 3679-3696. 
Pirazzoli, P.A., and Montaggioni, L.F., 1986, Late Holocene Sea-Level Changes in the Northwest Tuamotu Islands, French Polynesia: Quaternary Research, v. 25.

Pomeroy, A., Lowe, R., Symonds, G., Van Dongeren, A., and Moore, C., 2012, The dynamics of infragravity wave transformation over a fringing reef: Journal of Geophysical Research: Oceans, v. 117, no. C11, p. C11022, doi: 10.1029/2012JC008310.

Quataert, E., Storlazzi, C., van Rooijen, A., Cheriton, O., and van Dongeren, A., 2015, The influence of coral reefs and climate change on wave-driven flooding of tropical coastlines.: Geophysical Research Letters, p. n/a-n/a, doi: 10.1002/2015GL064861.

Rashid, R., Eisenhauer, A., Stocchi, P., Liebetrau, V., Fietzke, J., Rüggeberg, A., and Dullo, W.C., 2014, Constraining mid to late Holocene relative sea level change in the southern equatorial Pacific Ocean relative to the Society Islands, French Polynesia: Geochemistry, Geophysics, Geosystems, v. 15, no. 6, p. 2601-2615, doi: 10.1002/2014GC005272.

Roelvink, D., Reniers, A., van Dongeren, A., van Thiel de Vries, J., McCall, R., and Lescinski, J., 2009, Modelling storm impacts on beaches, dunes and barrier islands: Coastal Engineering, v. 56, no. 11, Äì12, p. 1133-1152, doi: http://dx.doi.org/10.1016/j.coastaleng.2009.08.006.

Stoddart, D.R., Taylor, J.D., Fosberg, F.R., and Farrow, G.E., 1971, Geomorphology of Aldabra Atoll: Philosophical Transactions of the Royal Society of London, , no. Series B, Biological Sciences.

Terry, J.P., and Chui, T.F.M., 2012, Evaluating the fate of freshwater lenses on atoll islands after eustatic sea-level rise and cyclone-driven inundation: A modelling approach: Global and Planetary Change, v. 88-89.

Toomey, M., Ashton, A.D., and Perron, J.T., 2013, Profiles of ocean island coral reefs controlled by sea-level history and carbonate accumulation rates: Geology,.

Webb, A.P., and Kench, P.S., 2010, The dynamic response of reef islands to sea-level rise: Evidence from multi-decadal analysis of island change in the Central Pacific: Global and Planetary Change, v. 72.

Woodroffe, C.D., 2008, Reef-island topography and vulnerability of atolls to sea-level rise: Global and Planetary Change, v. 62.

Woodroffe, C.D., and Morrison, R.J., 2001, Reef-island accretion and soil development on Makin, Kiribati, central Pacific: Catena, v. 44.

Woodroffe, C.D., Samosorn, B., Hua, Q., and Hart, D.E., 2007, Incremental accretion of a sandy reef island over the past 3000 years indicated by component-specific radiocarbon dating: Geophysical Research Letters, v. 34, no. 3, p. L03602, doi: 10.1029/2006GL028875. 
Yamano, H., Kayanne, H., Yamaguchi, T., Kuwahara, Y., Yokoki, H., Shimazaki, H., and Chikamori, M., 2007, Atoll island vulnerability to flooding and inundation revealed by historical reconstruction: Fongafale Islet, Funafuti Atoll, Tuvalu: Global and Planetary Change, v. 57, no. 3, p. 407-416.

Yasukochi, T., Kayanne, H., Yamaguchi, T., and Yamano, H., 2014, Sedimentary facies and Holocene depositional processes of Laura Island, Majuro Atoll: Geomorphology, v. 222, p. 59-67, doi: 10.1016/j.geomorph.2014.04.017. 


\section{Chapter 5: Conclusions and Future Work}

Understanding coastal evolution across different temporal and spatial scales is vital to predicting the response of the coast to climate change in the coming years and decades especially with predicted rates of rising sea level. To further our knowledge in coastal geomorphology, I have investigated long-term effects of sediment transport in two different environments: sandy, wave-dominated coasts and carbonate reef platforms with emergent landmasses. I used both computer modeling and field work to answer questions about the formative drivers of long-term sediment transport and coastal evolution and to try to understand the timescales over which these processes operate for both sandy and carbonate wave-dominated systems.

Utilizing a basic energetics-based sediment transport equation (Chapter 2), I derived a model for cross-shore shoreface evolution that is predicated upon an equilibrium shoreface profile based upon both offshore and onshore components. My model suggests that shorefaces evolve diffusively over time and predicts a timescale over which the shoreface evolves for a given location based upon the wave climate, this leads to an estimation of a morphodynamic depth of closure for a given time envelope. Comparison of my model to field analogues finds a best fit of profiles for active coasts, implying that for passive margins, inheritance may play a large role in shaping the shoreface.

Analyzing different sediment transport equations could be a straightforward extension of this research. For example, I used an energetics-based cross-shore sediment transport equation; alternative approaches to quantifying sediment transport exist, such as formulations based upon an exceedence of shear stress, like the Meyer-Peter-Mueller or the Madsen equation (Madsen, 1991). It would be interesting to see if, for these equations, equilibrium profiles are similarly independent of grain size. Another extension would be to apply my analysis beyond the 6 field sites highlighted here. This would require a wave record at least as long as the recurrence interval for the characteristic cross-shore wave parameter (ranges from 3-10 years depending on location) for the location and profile data that extends offshore to at least 30 meters depth. It would also be very interesting to look at long-term repeated profile measurements for a given location and how the profile has evolved and whether the temporal changes are linked to changes in offshore wave climate or some relation to my equilibrium profile. A difficulty with this suggested approach is that most beach profiles extend only 5-10 meters in depth making it difficult to discuss longer-term trends and behavior of the entire shoreface. 
In Chapter 3, I investigated the distinctions between the cross-shore and alongshore evolution timescales. In particular, I find that the alongshore coastline evolution is driven by the background wave climate and can be approximated by a linear relationship with the mean wave climate and recurs on monthly timescales. On the other hand, cross-shore evolution is dominated by infrequent extreme events that recur annually to decadally. As the weighting of the wave heights is increased from the mean to the alongshore to the cross-shore weighting, the distribution of the wave heights moves from a narrow unimodal peak that diffuses into a wider curve that maybe bimodal or unimodal. There is, moreover, a strong link between the distribution of weighted wave heights for a given location and the prevalence of tropical storms vs. extra-tropical storms affecting the site. For locations where tropical storms are prevalent, the cross-shore weighted wave height distribution is bimodal, and it would be interesting to investigate further the links between the bimodal distribution of cross-shore weighted wave heights and tropical storms by looking at non-hindcasted wave buoy data. It would also be interesting to apply this analysis to sites outside of the US.

I present a model for motu formation and evolution on a reef flat, motivated by XBeach hydrodynamic modeling, which suggests that larger offshore waves could drive deposition of coarse-grained sediment, creating a site for nucleation of a sub-aerial landmass. Currently, my modeling of motu formation and evolution was driven by a range of different offshore wave climates that was argued to be representative of a wave conditions that varying from background sea state to extreme events like tropical storms. However, it would be interesting to use hindcasted WaveWatchIII data to pull a long-term wave record for a specific atoll. These records could then be analyzed similar to the approach used in Chapter 3 and then an effective wave height could be used to drive the model for a field-specific location. It would of course also be useful to collect field data to test the general model behavior on a real atoll.

Another aspect that is particularly interesting is to investigate the actual widths of reefflats and motu around the world. My model predicts that reef flats without motu should reach an equilibrium depth and width that is dependent on the offshore wave climate and the sediment available in the system. I also found that, once a motu is established, the reef-flat width should decrease. To understand the processes shaping atoll morphometrics (like reef-flat width or motu width), I used ArcGIS to automate detection and measurements of morphometrics of atolls 
around the world using freely available satellite images. My developed methodology allows for relatively quick and easy scheme to calculate the reef-flat widths for a given atoll. These morphometrics can then be compared to the wave climate for the atoll (either gathered from local wave buoys or from hindcasted wave data like WaveWatchIII) and plotted on the equilibrium reef-flat width and motu width figure (Chapter 4, Figure 9b and 14b).

\section{References}

Madsen, O.S., 1991, Mechanics of cohesionless sediment transport in coastal waters, in Coastal Sediments, ASCE, p. 15-27. 